University of Rhode Island

DigitalCommons@URI

Open Access Master's Theses

2020

\title{
QUALITY CONTROL MEASURES FOR CYCLIC SIMPLE SHEAR TESTS ON SAND
}

Fenia Mika Miescke

University of Rhode Island, fenia_mi@my.uri.edu

Follow this and additional works at: https://digitalcommons.uri.edu/theses

\section{Recommended Citation}

Miescke, Fenia Mika, "QUALITY CONTROL MEASURES FOR CYCLIC SIMPLE SHEAR TESTS ON SAND" (2020). Open Access Master's Theses. Paper 1908.

https://digitalcommons.uri.edu/theses/1908

This Thesis is brought to you for free and open access by DigitalCommons@URI. It has been accepted for inclusion in Open Access Master's Theses by an authorized administrator of DigitalCommons@URI. For more information, please contact digitalcommons-group@uri.edu. 
QUALITY CONTROL MEASURES FOR CYCLIC SIMPLE SHEAR TESTS ON SAND

BY

FENIA MIKA MIESCKE

A THESIS SUBMITTED IN PARTIAL FULFILLMENT OF THE

REQUIREMENTS FOR THE DEGREE OF

MASTER OF SCIENCE

IN

OCEAN ENGINEERING 
MASTER OF SCIENCE THESIS

$\mathrm{OF}$

FENIA MIKA MIESCKE

\section{APPROVED:}

Thesis Committee:

$\begin{array}{ll}\text { Major Professor } & \text { Christopher Baxter } \\ & \text { Gopu Potty } \\ & \text { Aaron Bradshaw } \\ & \text { Brenton DeBoef } \\ & \text { DEAN OF THE GRADUATE SCHOOL }\end{array}$

UNIVERSITY OF RHODE ISLAND 


\begin{abstract}
One of the most common tests to evaluate the cyclic strength of soils are constant volume (undrained) cyclic direct simple shear tests. They are easy and fast to perform and best represent in-situ stress conditions during earthquakes. Over the past 15 years the interest in cyclic testing has increased and with this the number of companies developing and manufacturing cyclic direct simple shear devices has also increased. Despite this, the American Society of Testing Materials does not provide any guidelines for cyclic direct simple shear tests, which leads to the issue that testers are left on their own in terms of data quality evaluation. Several recent studies, such as Zehtab et al. (2019), Ulmer et al. (2019) and Konstadinou et al. (in press) have focused on identifying and evaluating factors that can be used to assess sample quality in cyclic direct simple shear test results.
\end{abstract}

The objective of this thesis was to apply published quality control measures for cyclic direct simple shear (CDSS) to tests performed on a commercially available CDSS apparatus manufactured by the Geocomp Corporation. Tests were performed on samples of Monterey and Ottawa sand, two commonly tested materials in the geotechnical literature. Samples were prepared to a relative density of $40 \%$ and samples were consolidated to $100 \mathrm{kPa}, 200 \mathrm{kPa}$, or $300 \mathrm{kPa}$ prior to stress-controlled cyclic shearing. No modifications were made to the CDSS apparatus for this study.

Three quality control measures were focused on: 1) axial strain during cyclic shear (i.e. constant volume conditions); 2) shear strain developed during consolidation; and 3) the effect of consolidation stress on cyclic strength (i.e. $K_{\sigma}$ ). 
For almost all the tests, the axial strain during cyclic shearing met the recommended limits of $<0,03 \%$. Furthermore, the behavior of each test appeared reasonable (e.g. stress-strain, stress path, etc.) and the relationships between the cyclic stress ratio (CSR) and the number of cycles to failure (N) were internally consistent for each sand.

There was good agreement between the cyclic stress ratio (CSR)/ number of cycles to failure $(\mathrm{N})$ relationship for Ottawa sand with comparable results from Zehtab et al. (2019). However, there was not good agreement between the test results on Monterey sand with the results published by Ulmer (2019).

The measured shear strain during consolidation exceeded recommended values for almost all the tests. This is due to the fact that vertical consolidation stresses apply some load to the horizontal load cell and the software moves the water bath to maintain zero horizontal load during consolidation. It is recommended that modifications to the water bath be made to isolate or detach the horizontal load cell during consolidation.

Finally, CDSS tests at increasing consolidation stresses yielded results that were contrary to established behavior of how the cyclic strength decreases with increasing stress (i.e. the $K_{\sigma}$ effect). At this time it is not clear how this effect can be corrected. It is hypothesized that the lack of horizontal stiffness is responsible for the increasing CRR with consolidation stress, and more research is needed to address this issue. It is recommended that the side support arm be replaced with a stiffer frame. 


\section{ACKNOWLEDGMENTS}

First and foremost I want to thank my Major Professor, Prof. Christopher Baxter, for always taking time out for me and my questions and helping me wherever he could. He is always enthusiastic and seems to never give up hope, even when nothing is working. I really enjoyed the days we spent in the lab trying to come up with new ideas to improve our testing and finally ended up asking Fred Pease for help before we break something. Special thanks goes to Fred Pease, who has saved my thesis many times by constructing unique components for the device I was working on and cheering me up with good stories and English expressions I hadn’t known before.

Special thanks also go to Artur Apostolov and Kaveh Zehtab from Geocomp Corporation who helped us tremendously with the software settings to finally obtain good data. They both devoted a lot of time in answering all our questions.

I would also thank all my professors for all their effort in teaching the great classes I took. I have learned a lot and had so much fun diving deep into the field of Geotechnics with Prof. Chris Baxter and Prof. Aaron Bradshaw and the field of Physical Oceanography with Prof. Jaime Palter and Prof. Melissa Omand. I am also very thankful to the many people at the TU Braunschweig and the University of Rhode Island that organize this Dual Degree Exchange Program every year and make this wonderful experience possible.

I want to acknowledge my incredible friends who, despite the COVID-19 pandemic,

filled my spring and summer in Rhode Island with amazing memories. Especially Jenny, thank you for not leaving the U.S. when the pandemic started. I feel like 
having a little Rhode Island family now and I never felt alone.

Finally, I want to thank my family for always supporting me in everything I do, especially my mom and godfather for always letting me go so far away on my own although they like having me home. I will come back now, I promise. I also want to thank all my cousins who are always excited about all what I am doing, in this case especially Philip Boll who had been an exchange student in the Dual Degree Program 20 years ago and told me that Chris Baxter is a good advisor since he has also written his thesis with him. 


\section{TABLE OF CONTENTS}

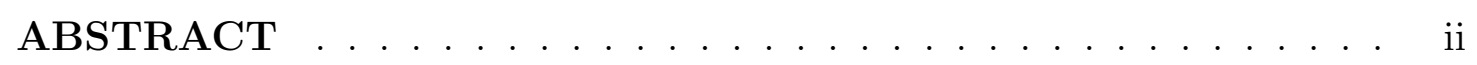

ACKNOWLEDGMENTS .................. iv

TABLE OF CONTENTS $\ldots \ldots \ldots \ldots \ldots \ldots \ldots$ vi

LIST OF FIGURES . . . . . . . . . . . . . . viii

LIST OF TABLES $\ldots \ldots \ldots \ldots \ldots \ldots \ldots \ldots \ldots$

\section{CHAPTER}

1 Introduction . . . . . . . . . . . . . . . 1

2 Literature Review . . . . . . . . . . . . . . . 4

2.1 Soil liquefaction and cyclic behavior of saturated sands under undrained loading . . . . . . . . . . . . . . . 4

2.2 Laboratory testing to obtain cyclic strength of sand . . . . . . 11

2.2.1 Cyclic Triaxial Test . . . . . . . . . . . . . . . . 12

2.2.2 Cyclic Torsional Shear Test . . . . . . . . . . . . 13

2.2 .3 Cyclic Direct Simple Shear . . . . . . . . . . . . . 15

2.3 Quality control measures for CDSS tests . . . . . . . . . 25

2.4 Examples of high quality CDSS test results from the literature . 31

List of References . . . . . . . . . . . . . . . . . . . . . 42

3 CDSS Testing Methodology . . . . . . . . . . . . . . . . 44

3.1 Testing Equipment . . . . . . . . . . . . . . . . . 44

3.2 Properties of Soil Tested . . . . . . . . . . . . . . 48

3.3 Sample Preparation and Testing Procedure . . . . . . . . . 50 


\section{Page}

4 CDSS Testing Results and Discussion . . . . . . . . . . . . 54

4.1 Test Results on Ottawa Sand . . . . . . . . . . . . . . . . . 56

4.2 Test Results on Monterey Sand . . . . . . . . . . . . . . 65

4.3 Discussion of Quality Control Measures that Affected CDSS Results .................... . . 75

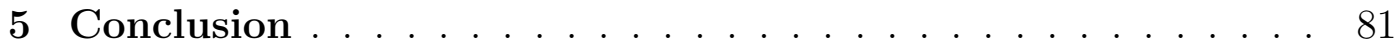
APPENDIX

BIBLIOGRAPHY . . . . . . . . . . . . . . . . . . 123 


\section{LIST OF FIGURES}

Figure

Page

1 Cyclic direct simple shear apparatus designed and manufactured by Geocomp Corporation . . . . . . . . . . . . . . . . . 3

2 CSR versus number of cycles to reach initial liquefaction $r_{u}=$ 1,0 from shaking table tests by De Alba et al. (1976) . . . . . 7

$3 \quad$ Illustration of the graph curvature and the $K_{\sigma}$ factor for triaxial tests on Fraser River Sand at $D_{r}=72 \%$ and varying confining stresses $($ Idriss, 2008) . . . . . . . . . . . . . . . 9

4 Values of overburden correction factor, $K_{\sigma}$, as a function of vertical effective stress from the literature (Youd et al. 2001). . 9

5 Example of a traditional triaxial test on sand performed in the Marine Geotechnic Laboratory at URI Narragansett Bay Campus $(2019) \ldots \ldots \ldots \ldots \ldots \ldots \ldots$

$6 \quad$ Hollow cylinder torsional shear procedure (Kramer, 1996) . . . . 14

$7 \quad$ Shematic drawing of a direct simple shear test apparatus . . . . 15

8 Cyclic direct simple shear apparatus at the Marine Geotechnics Laboratory at the URI Narragansett Bay Campus, manufactured by Geocomp Corporation . . . . . . . . . . . . . 17

$9 \quad$ Example of a stress-strain curve for a stress-controlled test consolidated to $100 \mathrm{kPa}($ Ulmer, 2020) . . . . . . . . . . . . 18

10 Example of a stress-strain curve for a strain-controlled test consolidated to $100 \mathrm{kPa}($ Ulmer, 2020) . . . . . . . . . . . 18

11 Shear stress (a), shear strain (b), excess pore pressure (c) versus number of cycles to failure from tests run on Monterey sand with $\sigma_{v 0}^{\prime}=100 \mathrm{kPa}$ and a relative sample density of $74 \%$ taken from this study .................... . . 20

12 Stress-strain relationship from tests run on Monterey sand with $\sigma_{v 0}^{\prime}=100 \mathrm{kPa}$ and relative sample density of $74 \%$ taken from this study . . . . . . . . . . . . . . . 21 
13 Vertical effective stress vs. shear stress (i.e. stress path) for test on Monterey sand with $\sigma_{v 0}^{\prime}=100 k P a$ and relative sample density of $74 \%$ taken from this study . . . . . . . . . . . . 22

14 Grading Criteria for passive controlled constant volume CDSS tests after Ulmer et al. (2019) . . . . . . . . . . . . . 30

15 Grading Criteria for active controlled constant volume CDSS tests after Ulmer et al. (2019) . . . . . . . . . . . . . 30

16 Liquefaction resistance curves after Ulmer et al (2020). Liquefaction is defined as the single strain-amplitude of $\gamma=3.5 \%$ at a consolidation stress of $\sigma_{v}=100 \mathrm{kPa}$. All tests with passive control: a) all tests and b) all tests that passed the acceptance criteria . . . . . . . . . . . . . . . 33

17 Liquefaction triggering curves for an effective consolidation

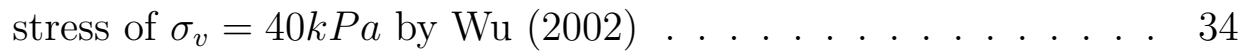

18 Liquefaction triggering curves for an effective consolidation

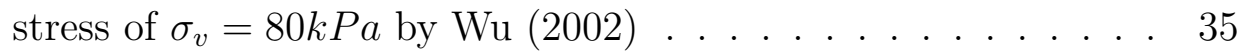

19 Liquefaction triggering curves for an effective consolidation

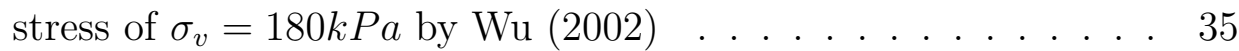

20 Comparison between liquefaction resistance curves after $\mathrm{Wu}$ (2002) . . . . . . . . . . . . . . . 36

21 Comparison of CSR versus $\mathrm{N}$ data from Konstadinou et al. (2020), Tatsuoka et al. (1982) and Tokimatsu et al. (1986) . . . 37

22 Comparison between cyclic strength resistance curves of samples laterally confined with a wire-reinforced membrane versus confined by stacked Teflon coated rings by Konstadinou et al. (2020) . . . . . . . . . . . . . . . . 38

23 Unidirectional CDSS tests by Gokyer et al. (2019) . . . . . . . 39

24 Comparison of Unidirectional and Multidirectional CDSS tests by Gokyer et al. (2019) . . . . . . . . . . . . . . . . . 40

25 CSR or Ottawa sand for $r_{u}=1.0$ per $\mathrm{N}$ for different consolidation stresses under constant volume conditions (CV) and inadequate volume control (IVC) by Zehtab et al. (2019) . . . . . . 
26 Comparison of cyclic behavior of Ottawa sand with results of Ishihara and Yamazaki (1980), Bhatia (1982) and Zekkos et al. (2018) by Zehtab et al. (2019) . . . . . . . . . . . . . . . . 42

27 Test setup in the Shear Trac II with labeled components . . . . 44

28 Sample in Shear Trac II with labeled components . . . . . . . . 45

29 Tested sand types. Left: Monterey sand, Right: Ottawa sand . 49

$30 \quad$ Grain size distributions Ottawa sand . . . . . . . . . . . . . . 49

$31 \quad$ Grain size distributions Monterey sand . . . . . . . . . . . 50

32 Gain settings in the DIAGS software . . . . . . . . . . 52

33 Example of gain saturation extracted from the CDSS software

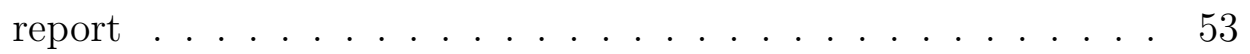

34 Shear stress, shear strain and excess pore pressure ratio versus number of cycles $(\mathrm{N})$ for tests on Ottawa sand at $\sigma_{v 0}^{\prime}=100 \mathrm{kPa}$, $D_{r}=39-41 \%$ and CSR $=0.075$. The red dashed line indicates the used failure criteria (Testnumber: Ott_100_5) . . . . . . . 57

35 Shear strain and axial strain versus number of cycles (N) for tests on Ottawa sand at $\sigma_{v 0}^{\prime}=100 \mathrm{kPa}, D_{r}=39-41 \%$ and $\mathrm{CSR}=0.075$. Note that the third plot of axial strain vs $\mathrm{N}$ shows a zoom in of the second axial strain vs $\mathrm{N}$ plot. The red dashed line indicates the axial strain limit of $\pm 0.03 \%$ (recommended by Zehtab et al. 2019), the grey dashed line the limit of $\pm 0.05 \%$ (recommended by ASTM for monotonic DSS tests),(Testnumber: Ott_100_5) . . . . . . . . . . . . 59

36 Stress-strain hysteresis loops and stress path for tests on Ottawa sand at $\sigma_{v 0}^{\prime}=100 \mathrm{kPa}, D_{r}=39-41 \%$ and $\mathrm{CSR}=0.075$ (Testnumber: Ott_100_5) .............. 60 
Shear stress and shear strain development during consolidation phase versus time for tests on Ottawa sand at $\sigma_{v 0}^{\prime}=100 \mathrm{kPa}$, $D_{r}=39-41 \%$ and CSR $=0.075$. Red dashed lines indicate the shear strain limits for consolidation phase of $\pm 0.05 \%$ (recommended by Ulmer et al. 2019). Note that the consolidation settings were set to "stress control" meaning that the Shear Trac keeps zero shear stress during consolidation phase by moving the water bath (Testnumber: Ott_100_5) . . . . . . . . . .

38 Comparison of CSR versus number of cycles to failure for CDSS tests on Ottawa sand. Data with good and with bad height control from this study and from Zehtab et al. (2019) are included. 64

39 Shear stress, shear strain and excess pore pressure ratio versus number of cycles $(\mathrm{N})$ for tests on Monterey sand at $\sigma_{v 0}^{\prime}=100$ $\mathrm{kPa}, D_{r}=39-41 \%$ and $\mathrm{CSR}=0.1$. The red dashed line indicates the used failure criteria (Mon_100_1) . . . . . . . 66

40 Shear strain and axial strain versus number of cycles $(\mathrm{N})$ for tests on Monterey sand at $\sigma_{v 0}^{\prime}=100 \mathrm{kPa}, D_{r}=39-41 \%$ and $\mathrm{CSR}=0.1$. Note that the third plot of axial strain vs $\mathrm{N}$ shows a zoom in of the second axial strain vs $\mathrm{N}$ plot. The red dashed line indicates the axial strain limit of $\pm 0.03 \%$ (recommended by Zehtab et al. 2019), the grey dashed line the limit of $\pm 0.05 \%$ (recommended by ASTM for monotonic DSS tests), (Mon_100_1) 67

41 Stress-strain hysteresis loops and stress path for tests on Monterey sand at $\sigma_{v 0}^{\prime}=100 \mathrm{kPa}, D_{r}=39-41 \%$ and $\mathrm{CSR}=0.1$ $($ Mon_100_1) . . . . . . . . . . . . . . .

42 Shear stress and shear strain development during consolidation phase versus time for tests on Monterey sand at $\sigma_{v 0}^{\prime}=100 \mathrm{kPa}$, $D_{r}=39-41 \%$ and CSR $=0.1$. Red dashed lines indicate the shear strain limits for consolidation phase of $\pm 0.05 \%$ (recommended by Ulmer et al. 2019). Note that the consolidation settings were set to "stress control" meaning that the Shear Trac keeps zero shear stress during consolidation phase by moving the water bath $($ Mon_100_1) . . . . . . . . . . . .

43 All data for Monterey sand at $D_{r}=40 \%$ and effective consolidation stresses of $\sigma_{v 0}^{\prime}=100,200$ and $300 \mathrm{kPa} \ldots \ldots 71$ 
44 Stress-strain hysteresis loops and stress path for tests on Monterey sand at $\sigma_{v 0}^{\prime}=100 \mathrm{kPa}$ and $\left.D_{r}=39-41 \%\right) \ldots . . .71$

45 CSR versus $N_{f}$ plot for CDSS tests performed by Zehtab et al. (2019) on Ottawa sand at different consolidation stresses . . . . 72

46 CDSS data of Wu 2002 for effective consolidation stresses of 40 $\mathrm{kPa}, 80 \mathrm{kPa}$ and $180 \mathrm{kPa}$ of saturated samples of Monterey sand 73

47 Data comparison of Ulmer et al. (2019) and data of this study at $D_{r}=40 \%$ and $\sigma_{v 0}^{\prime}=100 \mathrm{kPa} \ldots \ldots \ldots 74$

48 Example of exceeding axial strain during shear phase on Monterey sand at $\sigma_{v 0}^{\prime}=200 \mathrm{kPa}, D_{r}=40 \%$ and $\mathrm{CSR}=0.14 \ldots 77$

49 Example a non exceeding axial strain during shear phase on Monterey sand at $\sigma_{v 0}^{\prime}=100 \mathrm{kPa}, D_{r}=40 \%$ and $\mathrm{CSR}=0.1 \quad . \quad 77$

50 Example of shear strain development during consolidation that exceeded recommended values for good quality tests at $\sigma_{v 0}^{\prime}=$ $100 \mathrm{kPa}, D_{r}=40 \%$ and $\mathrm{CSR}=0.1 \ldots \ldots . \ldots 78$

51 Example of shear strain development during consolidation that only slightly exceeded recommended values for good quality tests at $\sigma_{v 0}^{\prime}=100 \mathrm{kPa}, D_{r}=40 \%$ and $\mathrm{CSR}=0.1 \ldots . . . \quad 79$

.52 Tools used for Sample preparation . . . . . . . . . . . . . 85

.53 Finished test setup . . . . . . . . . . . . . . . . . . . 90

.54 Screenshot of DIAGS - vertical controller - file - settings - A/D

- Channel 1 (force) . . . . . . . . . . . . . . . . 91

.55 Screenshot of DIAGS - vertical controller - file - settings - Motor 93

.56 Screenshot of DIAGS - vertical controller - file - settings - PID . 94

.57 Vertical DIAGS settings overview . . . . . . . . . . . . 96

$.58 \quad$ Vertical DIAGS settings overview . . . . . . . . . . . . . 96

$.59 \quad$ Ottawa sand, $\sigma_{v 0}^{\prime}=100 \mathrm{kPa}, \mathrm{Dr}=40 \%, \mathrm{CSR}=0.1 \ldots 97$

$.60 \quad$ Ottawa sand, $\sigma_{v 0}^{\prime}=100 \mathrm{kPa}, \mathrm{Dr}=40 \%, \mathrm{CSR}=0.1 \ldots . . .98$ 
$.61 \quad$ Ottawa sand, $\sigma_{v 0}^{\prime}=100 \mathrm{kPa}, \mathrm{Dr}=40 \%, \mathrm{CSR}=0.15 \ldots . . .99$

.62 Ottawa sand, $\sigma_{v 0}^{\prime}=100 \mathrm{kPa}, \mathrm{Dr}=39 \%, \mathrm{CSR}=0.13 \ldots 100$

$.63 \quad$ Ottawa sand, $\sigma_{v 0}^{\prime}=100 \mathrm{kPa}, \mathrm{Dr}=40 \%, \mathrm{CSR}=0.075 \ldots . . .101$

$.64 \quad$ Ottawa sand, $\sigma_{v 0}^{\prime}=100 \mathrm{kPa}, \mathrm{Dr}=39 \%, \mathrm{CSR}=0.12 \ldots . . .102$

.65 Monterey sand, $\sigma_{v 0}^{\prime}=100 \mathrm{kPa}, \mathrm{Dr}=39 \%, \mathrm{CSR}=0.1 \ldots 103$

.66 Monterey sand, $\sigma_{v 0}^{\prime}=100 \mathrm{kPa}, \mathrm{Dr}=39 \%, \mathrm{CSR}=0.15 \ldots . .104$

$.67 \quad$ Monterey sand, $\sigma_{v 0}^{\prime}=100 \mathrm{kPa}, \mathrm{Dr}=40 \%, \mathrm{CSR}=0.1 \ldots . . .105$

$.68 \quad$ Monterey sand, $\sigma_{v 0}^{\prime}=100 \mathrm{kPa}, \mathrm{Dr}=40 \%, \mathrm{CSR}=0.15 \ldots 106$

.69 Monterey sand, $\sigma_{v 0}^{\prime}=100 \mathrm{kPa}, \mathrm{Dr}=40 \%, \mathrm{CSR}=0.13 \ldots 107$

$.70 \quad$ Monterey sand, $\sigma_{v 0}^{\prime}=100 \mathrm{kPa}, \mathrm{Dr}=41 \%, \mathrm{CSR}=0.14 \ldots 108$

$.71 \quad$ Monterey sand, $\sigma_{v 0}^{\prime}=100 \mathrm{kPa}, \mathrm{Dr}=40 \%, \mathrm{CSR}=0.075 \ldots . .109$

$.72 \quad$ Monterey sand, $\sigma_{v 0}^{\prime}=100 \mathrm{kPa}, \mathrm{Dr}=41 \%, \mathrm{CSR}=0.12 \ldots 110$

$.73 \quad$ Monterey sand, $\sigma_{v 0}^{\prime}=200 \mathrm{kPa}, \mathrm{Dr}=40 \%, \mathrm{CSR}=0.1 \ldots 111$

$.74 \quad$ Monterey sand, $\sigma_{v 0}^{\prime}=200 \mathrm{kPa}, \mathrm{Dr}=39 \%, \mathrm{CSR}=0.15 \ldots 112$

$.75 \quad$ Monterey sand, $\sigma_{v 0}^{\prime}=200 \mathrm{kPa}, \mathrm{Dr}=40 \%, \mathrm{CSR}=0.14 \ldots . .113$

$.76 \quad$ Monterey sand, $\sigma_{v 0}^{\prime}=200 \mathrm{kPa}, \mathrm{Dr}=40 \%, \mathrm{CSR}=0.13 \ldots 114$

$.77 \quad$ Monterey sand, $\sigma_{v 0}^{\prime}=200 \mathrm{kPa}, \mathrm{Dr}=41 \%, \mathrm{CSR}=0.075 \ldots . .115$

$.78 \quad$ Monterey sand, $\sigma_{v 0}^{\prime}=200 \mathrm{kPa}, \mathrm{Dr}=39 \%, \mathrm{CSR}=0.12 \ldots 116$

$.79 \quad$ Monterey sand, $\sigma_{v 0}^{\prime}=200 \mathrm{kPa}, \mathrm{Dr}=39 \%, \mathrm{CSR}=0.15 \ldots 117$

$.80 \quad$ Monterey sand, $\sigma_{v 0}^{\prime}=300 \mathrm{kPa}, \mathrm{Dr}=41 \%, \mathrm{CSR}=0.1 \ldots 118$

.81 Monterey sand, $\sigma_{v 0}^{\prime}=300 \mathrm{kPa}, \mathrm{Dr}=41 \%, \mathrm{CSR}=0.12 \ldots 119$

$.82 \quad$ Monterey sand, $\sigma_{v 0}^{\prime}=300 \mathrm{kPa}, \mathrm{Dr}=41 \%, \mathrm{CSR}=0.15 \ldots . .120$

$.83 \quad$ Monterey sand, $\sigma_{v 0}^{\prime}=300 \mathrm{kPa}, \mathrm{Dr}=41 \%, \mathrm{CSR}=0.14 \ldots . .121$ 
$.84 \quad$ Monterey sand, $\sigma_{v 0}^{\prime}=300 \mathrm{kPa}, \mathrm{Dr}=39 \%, \mathrm{CSR}=0.13 \ldots 122$ 


\section{LIST OF TABLES}

Table

Page

1 Comparison of literature experimental investigations on CDSS

testing with testing characteristics of this study . . . . . . 32

2 Index properties of Ottawa and Monterey sand . . . . . . . . . 48

3 Results of all CDSS tests on Ottawa and Monterey sand . . . . 55

$4 \quad$ Test parameters for tests conducted on Ottawa sand . . . . . . 56

$5 \quad$ Test parameters for tests conducted on Monterey sand . . . . . 65 


\section{CHAPTER 1}

\section{Introduction}

Soil liquefaction is a phenomenon that can occur in saturated soils under dynamic loading, such as during earthquakes. It describes the transformation of the soil to a substance that exhibits fluid-like behavior in terms of shear strength and deformation. This is particularly important for loose, saturated sand deposits that tend to contract and are unable to drain due to rapid cyclic loading. Once liquefaction is triggered it can cause severe damage to buildings and other structures.

To mitigate damage from liquefaction it is essential to be able to predict liquefaction as reliably as possible. There are many different in-situ and laboratory tests to evaluate the liquefaction of soils, however in-situ tests are currently considered to be more reliable due to the inability to obtain undisturbed samples for laboratory testing (?). Field-based methods include Standard Penetration Tests (SPT), Cone Penetration Tests (CPT) and shear wave velocity measurements (Vs) (?). Laboratory tests also exist to assess liquefaction, such as cyclic triaxial (CTRX), cyclic torsional simple shear (CTS) and cyclic direct simple shear (CDSS) tests (?).

To evaluate the shear strength of soils under cyclic loading in the laboratory, soil specimens are commonly tested under undrained or constant volume conditions. This condition corresponds to the case where either the loading is too fast (e.g. earthquakes) or the hydraulic conductivity of the soil is too low (e.g. silts and clays) and water is not able to exit or enter the soil during shear. In a triaxial test, the undrained condition is relatively easy to maintain for saturated samples 
by simply restricting flow to and from the sample. In a cyclic direct simple shear test, undrained conditions are almost always maintained by restricting volume change during shear. In many ways, the cyclic direct simple shear tests is more representative of in situ conditions than cyclic triaxial tests. Samples are consolidated under Ko conditions and shearing is induced on a horizontal plane (much like earthquake loading). As a result, with advances in data acquisition and control systems, over the past 15 years the interest in those cyclic direct simple shear tests has increased and there are now several companies selling these systems. Previously there were only a few cyclic direct simple shear devices developed by universities and research institutions, with the increasing number of available commercial systems the question of data reliability has come up. The American Society of Testing Materials has not developed any standards for cyclic direct simple shear testing, and investigators are left on their own how to judge the quality of their own tests.

The objective of this thesis is to assess quality control measures in cyclic direct simple shear testing. A commercial system manufactured by the Geocomp Corporation (Figure 1) was used to perform cyclic direct shear tests on dry samples of Monterey and Ottawa sand. The results were compared to the results of similar tests performed on other devices from the literature. Influencing factors such as constant volume control, shear strain during consolidation, internal consistency, and consolidation stress effects were evaluated. The understanding of such factors and their influence on test results is essential to evaluating sample and testing quality and producing reliable and reproducible data. 


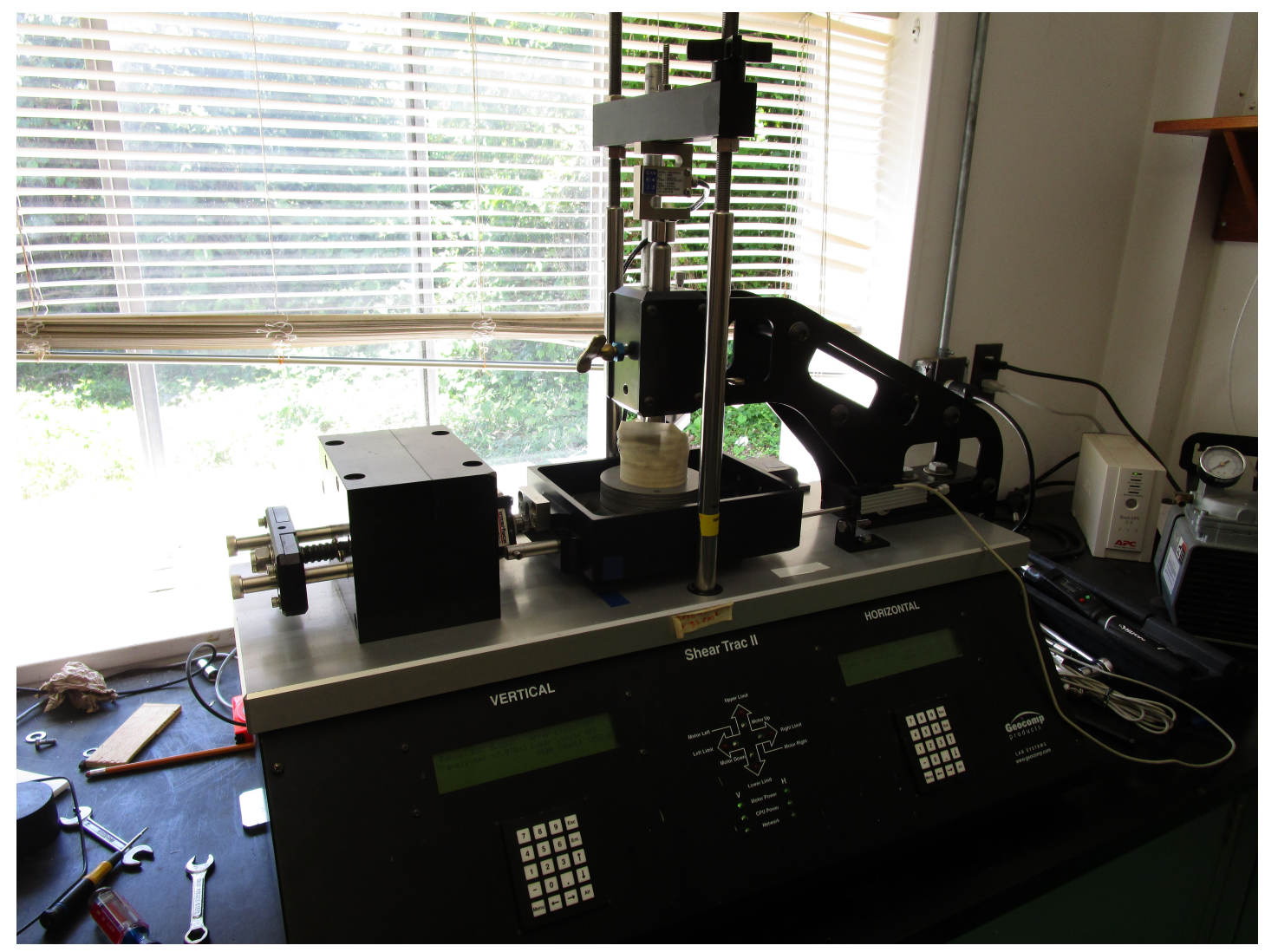

Figure 1. Cyclic direct simple shear apparatus designed and manufactured by Geocomp Corporation 


\section{CHAPTER 2}

\section{Literature Review}

Although earthquakes and their hazard and damage potential have been recognized for millenia, investigation of the geotechnical aspects did not really begin until 1964 (Kramer, 1996), when two large earthquakes struck Niigata, Japan and south-central Alaska. Since then there has been an explosion of research in geotechnical earthquake engineering, including seismology, ground motions, site response analyses, dynamic soil-structure interaction, numerical modeling, liquefaction triggering, dynamic properties of soils, and others.

This chapter presents a review of the literature relevant to the laboratory determination of the dynamic properties of sand and liquefaction. This includes an overview of the phenomenon of liquefaction and relevant parameters and the laboratory tests that have been developed to measure the cyclic strength of sand. Special emphasis is on quality control measures for cyclic direct simple shear tests and examples from the literature of high quality cyclic direct simple shear test results.

\subsection{Soil liquefaction and cyclic behavior of saturated sands under undrained loading}

Soil liquefaction is a significant phenomenon that occurs in-situ in contractive, saturated sand deposits under cyclic, undrained loading conditions. However, with increasing laboratory studies on soil liquefaction, Casagrande (1976), Kramer (1996) and Idriss and Boulanger (2008) drew attention to the misuse of the word liq- 
uefaction as it has been used in literature to collectively describe two different phenomena.

Kramer (1996) as well as Idriss and Boulanger (2008) distinguish between the terms flow liquefaction and cyclic mobility, describing the liquefaction of sands under different states of shear stress relative to the soil's shear strength as well as differences in deformation caused by them.

Flow liquefaction occurs when contractive, saturated sand deposits with low residual strengths fail due to cyclic or static loading. It is characterized by very low strength after liquefaction and large displacements. During loading, loose sand deposits tend to contract. Because the loading is too rapid to allow for drainage (i.e. volume change) and water is incompressible compared to the soil skeleton, the additional stresses acting on the sand particle skeleton are transferred to the pore water (Idriss, 2008). As pore water pressures continue to increase the effective stresses acting on the soil matrix decrease, and can approach zero effective stress. Liquefaction failure is often defined as when the effective stresses in the soil become zero. The significant criterion for flow liquefaction is that the static shear stresses are higher than the soils' shear strength in a state of liquefaction (Kramer, 1996). This means that when the strength is exceeded, there is almost no resistance to the static shear stresses and the resulting deformations are large. Flow liquefaction can often be observed on slopes where there are static shear stresses acting on the soil.

In contrast to flow liquefaction, cyclic mobility describes the phenomenon in which static shear stresses are less than the soils' shear strength in a liquefied state. Cyclic mobility can occur in contractive as well as dilative soils and the 
deformations caused by it are driven by both cyclic and static shear stresses (Kramer, 1996). Deformations occur incrementally (instead of flowing) and can be large or small. Cyclic mobility can be observed in undrained sand deposits exposed to cyclic loading that are still confined by lateral earth pressures, so there is little or no potential for flow. However, when cyclic stresses are large and/or the deposit is near the surface, surface manifestation can occur in the form of sand boils and post-cyclic volume change. While cyclic mobility occurs more frequently in nature with the effects ranging from insignificant to damaging, flow liquefaction occurs much less frequently, but with more damaging effects (Kramer, 1996). In the laboratory, testing conditions usually recreate the phenomenon of cyclic mobility. A soils resistance to liquefaction (i.e. its cyclic strength) depends on many factors including relative density, consolidation stress, soil type, aging, and others. The following is a review of the relevant parameters that are used to describe liquefaction behavior in the laboratory.

Cyclic Stress Ratio vs. Number of Cycles to Failure

The Cyclic Stress Ratio (CSR) is defined as:

$$
C S R=\frac{\tau_{c y c}}{\sigma_{v_{c o n}}^{\prime}}
$$

where $\tau_{c y c}$ is the applied cyclic shear stress and $\sigma_{v_{c o n}}^{\prime}$ is the initial effective consolidation stress. In a stress-controlled cyclic direct simple shear test, a sample is consolidated to some vertical effective stress and then subjected to uniform shear stress cycles of a certain amplitude until failure. Samples loaded to higher values of CSR fail (i.e. liquefy) in fewer loading cycles than samples loaded 
to lower values of CSR, and it is common practice to characterize the cyclic strength of soil as a plot of CSR vs. number of cycles $(\mathrm{N})$ to liquefaction (Figure 2)(Idriss, 2008).

Plotting the number of cycles to failure as a function of cyclic stress ratio is based on metal fatigue theory, and according to Green et al. (2005), was first proposed by Palmgren in 1924 and was further developed by Miner in 1945. Later this theory was adapted by Seed, Lee and Idriss for evaluation of soil liquefaction potential. The y-axis in Figure 2 is often called the cyclic resistance ratio (CRR) because the values plotted represent the CSR required to cause liquefaction in a given number of cycles (i.e. the cyclic resistance or the cyclic strength of the soil).

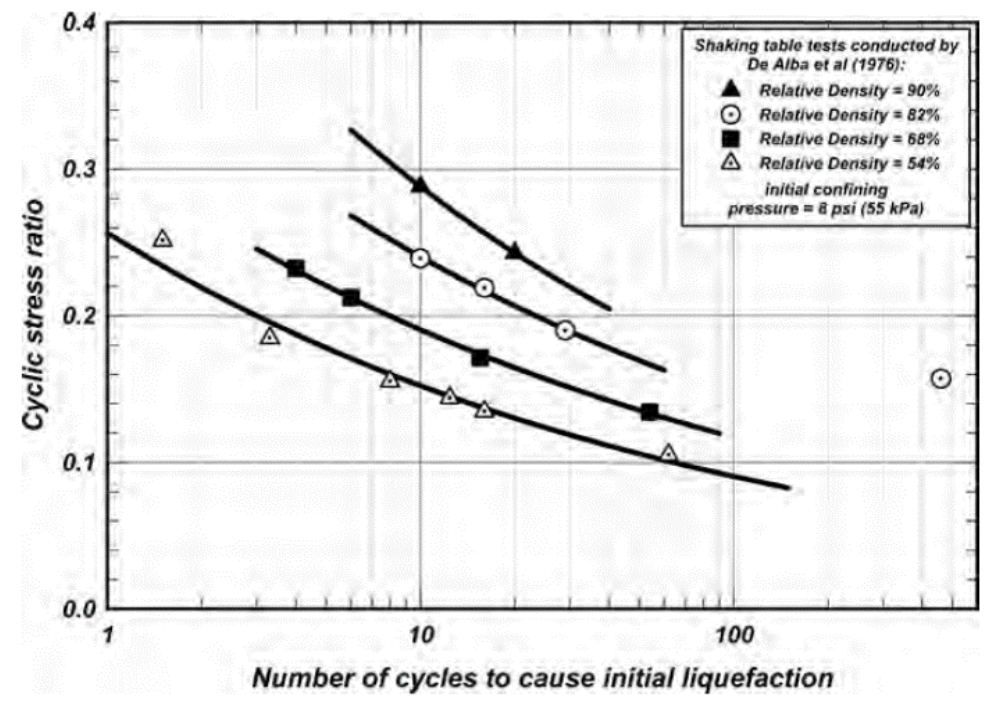

Figure 2. CSR versus number of cycles to reach initial liquefaction $r_{u}=1,0$ from shaking table tests by De Alba et al. (1976) 
Effect of Overburden Stress on Cyclic Resistance $\left(K_{\sigma}\right)$

Dividing the cyclic stress by the effective confining stress (CSR), as shown in Equation 1, implies that the cyclic resistance is a unique function of stress for a given relative density. This is not correct; the cyclic resistance decreases with increasing stress because, for a given relative density, the sand becomes more contractive. Likewise, the cyclic resistance increases with decreasing stress for a given relative density because the sand becomes more dilative. An overburden correction factor $\left(K_{\sigma}\right)$ was first introduced by Seed in 1983 to account for this dependency of the cyclic resistance ratio $(\mathrm{CRR})$ on consolidation stress and is expressed as:

$$
K_{\sigma}=\frac{C R R_{\sigma^{\prime} c}}{C R R_{\sigma^{\prime} c=1}}
$$

where $C R R_{\sigma c}=1$ is the cyclic resistance ratio a $100 \mathrm{kPa}$ and $C R R_{\sigma c}$ is the cyclic resistance ratio at a different confining stress. Figure 3 illustrates how $K_{\sigma}$ is estimated for a given sand and confining stress, and Figure 4 shows a typical range of Ks values from the literature. 


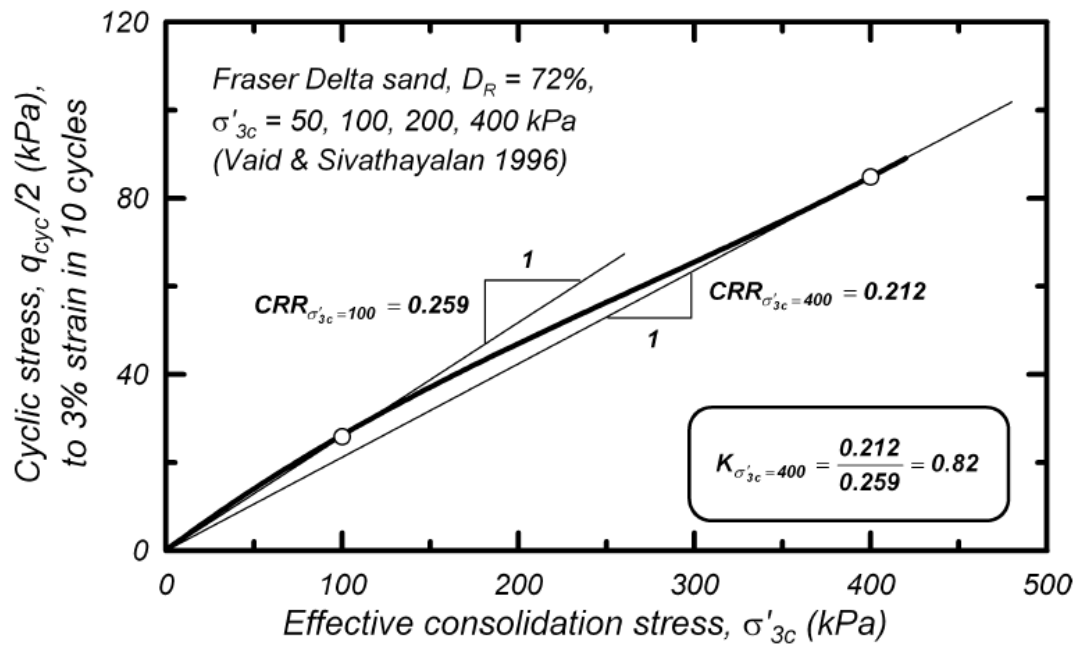

Figure 3. Illustration of the graph curvature and the $K_{\sigma}$ factor for triaxial tests on Fraser River Sand at $D_{r}=72 \%$ and varying confining stresses (Idriss, 2008)

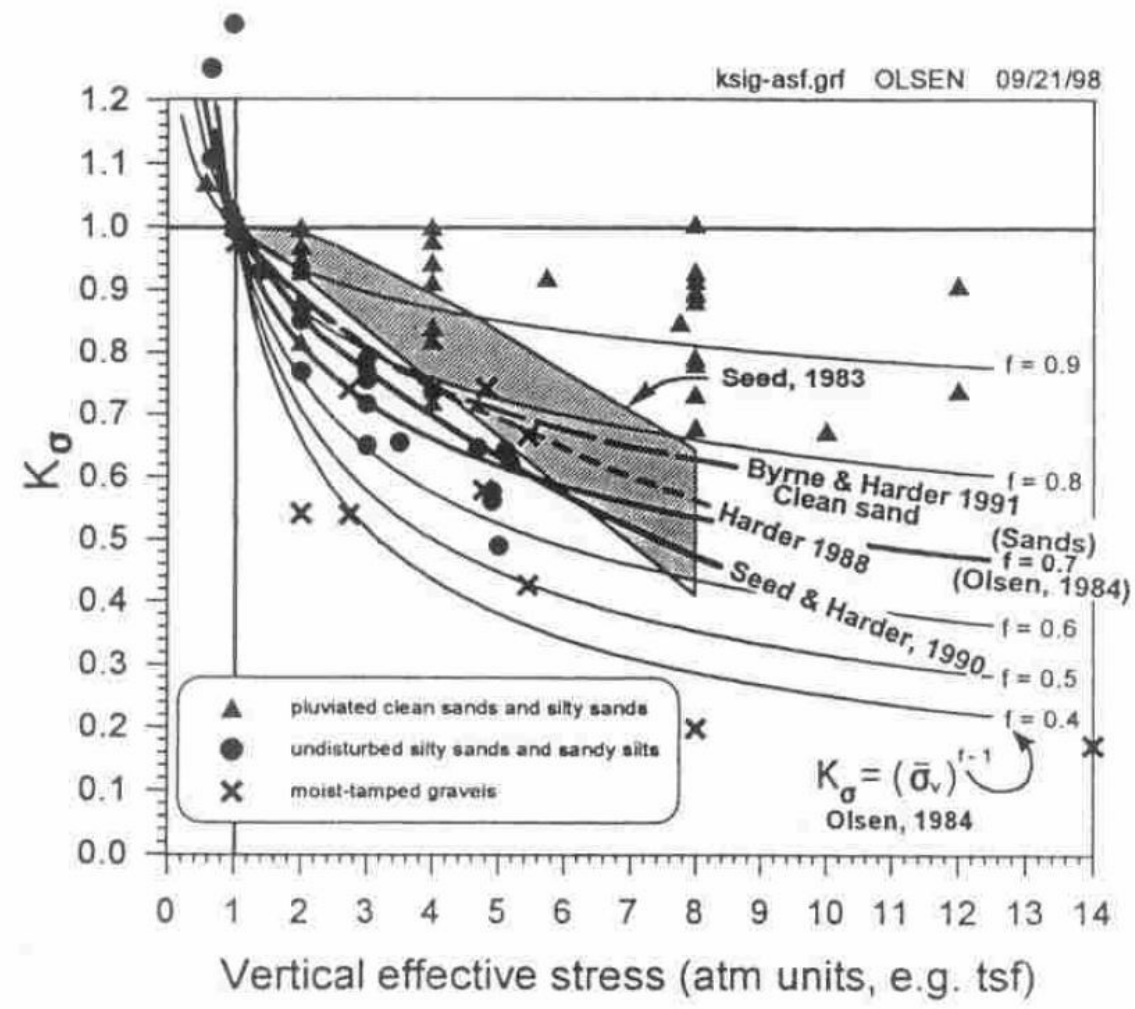

Figure 4. Values of overburden correction factor, $K_{\sigma}$, as a function of vertical effective stress from the literature (Youd et al. 2001). 
Note that, in Figure 4, the value of $K_{\sigma}$ is equal to 1 at $100 \mathrm{kPa}$ (i.e. 1 atm) and decreases with increasing confining stress, meaning that the CRR of a soil consolidated at high stresses is lower than the CRR of the same soil at lower stresses. The value of $K_{\sigma}$ is further affected by sample preparation technique. $K_{\sigma}$ shows an increased scatter of values for air-pluviated samples ranging between 0.7 to 1.0 .

Failure Criteria for Liquefaction

When assessing the strength of soil in the laboratory, it is always important to clearly define failure. It could be the maximum load carried by the soil, or a limiting strain, or one of several other criteria. In liquefaction studies, the two most commonly used failure criteria for cyclic direct simple shear tests are: i) an excess pore pressure ratio of 1.0 or ii) a defined value of shear strain.

The excess pore pressure ratio $\left(r_{u}\right)$ is defined as:

$$
r_{u}=\frac{\Delta u}{\sigma_{c o n}^{\prime}}
$$

where $\Delta u$ is the excess pore water pressure built up during cyclic undrained loading and $\sigma_{\text {con. }}^{\prime}$ is the initial effective consolidation stress. When excess pore water pressures build up during undrained cyclic loading the pore water pressure ratio increases and may eventually reach a value of 1.0. This means that the excess pore pressure is equal to the initial effective consolidation stress and the actual effective stress during shear is zero if the total vertical stress is kept constant $\left(\sigma^{\prime}=\sigma-\Delta u\right)$. An excess pore water pressure ratio of 1.0 is often used as a failure criterion as it indicates the "initial liquefaction" of the soil. Further, 
$r_{u}$ can not only be reached in contractive soils but also in dilative soils.

Another definition of soil failure in cyclic direct simple shear tests involves soil deformation (i.e. shear strain). However, this failure criterion is also affected by pore water pressure development. Ishihara (1985) determined shear strain value of $2.5-3.5 \%$ at the state of initial liquefaction when $r u=1,0$ and therefore recommended a single shear strain amplitude of $3 \%$ as a deformation failure criterion (Kammerer, 2002). In further investigations a double shear strain amplitude of $7.5 \%$ was used by Seed and $5 \%$ single shear strain amplitude was used by De Alba. However, Kammerer (2002) argued that a single shear strain amplitude of $3 \%$ corresponds well to the point of initial liquefaction at $\mathrm{ru}=$ 1.0. Although it was also noted that with the presence of initial shear stresses prior to the shear phase and a possible shift in the strain curve it is more suitable to use a double amplitude shear strain of $6 \%$ as a strain-based failure criterion.

\subsection{Laboratory testing to obtain cyclic strength of sand}

There are several laboratory tests used to obtain the cyclic strength of soils. In general, laboratory evaluations of liquefaction are used less in the U.S. than fieldbased approaches, mainly because of the difficulty in getting high quality samples for testing. However, they are used more in Japanese practice, and are particularly good for understanding the fundamental behavior of soils. These tests include the cyclic triaxial (CTRX), cyclic torsional simple shear (CTS) and cyclic direct simple shear (CDSS) tests. Each of these are described in more detail below. 


\subsubsection{Cyclic Triaxial Test}

The cyclic triaxial test is the most commonly used test to obtain dynamic soil properties at high strain levels in the laboratory (Kramer, 1996). This test is an extension of traditional triaxial testing (Figure 5), and much of the equipment is broadly available (Kammerer, 2002). This has led to the development of a large database to compare test results with. The test setup of a cyclic triaxial test is comparable to the monotonic triaxial tests with a cylindrical sample in a non-reinforced rubber membrane, with an applied confining stress and an applied axial stress. The deviator stress, the difference between confining and axial stress, is applied cyclically in either stress or strain controlled conditions (Kramer, 1996). The confining stress is held constant while the axial stress will cycle at a frequency of usually $1 \mathrm{~Hz}$ (Kramer, 1996). The frequency of loading roughly corresponds to the frequency of earthquakes, however cyclic triaxial tests are considered to be less representative for in-situ level ground loading conditions than cyclic direct simple shear tests (Gokyer et al. 2019). For this reason results of cyclic triaxial tests are normally corrected to be comparable to resuls of cyclic direct simple shear tests. Several correction factors ranging between 0.55 to 0.72 are suggested by Castro (1975), De Alba et al. (1976), Seed (1979), and Idriss and Boulanger (2008) with respect to different effective consolidation stresses (Gokyer et al. 2019). 


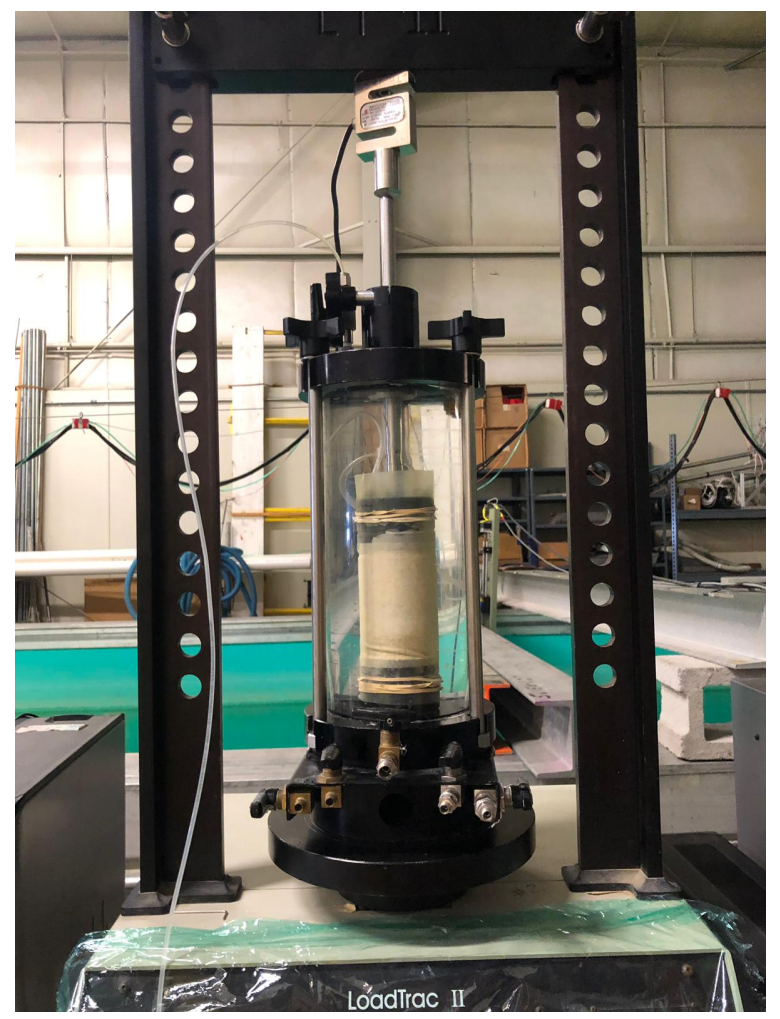

Figure 5. Example of a traditional triaxial test on sand performed in the Marine Geotechnic Laboratory at URI Narragansett Bay Campus (2019)

\subsubsection{Cyclic Torsional Shear Test}

Cyclic Torsional Shear Tests are performed on cylindrical specimens that can be either hollow or solid cylinders (Kammerer, 2002). Samples are placed in non-reinforced membranes and confined by a cell pressure and an inside confining stress for the hollow specimens (Figure 6). A cyclic torque is applied to the top of the sample to generate a rotational cyclic shear force in the sample which allows the principle stresses to rotate smoothly and without abrupt movements (Kramer, 1996); (Kammerer, 2002). Cyclic Torsional Shear tests can be performed under isotropic or anisotropic conditions and show a good representation of in-situ loading conditions (Kramer, 1996); (Kammerer, 2002). However, the geometry of the samples and the test procedure also exhibit disadvantages in terms uniformity 
of stress distribution (Kammerer, 2002). Due to a relatively tall sample in comparison to its diameter, there can be non-uniform void redistribution as well as a non-uniform applied lateral confining pressures on the sample. This non-uniform confining pressures and differences in the cross sectional area from top to bottom of the sample results in a non-uniform applied shear stress. Shear stresses at the top of the sample are higher than at the bottom due to a reduced cross-sectional area (Kammerer, 2002). Although test conditions are undrained pore water pressure redistribution can lead to local volume changes and local changes in density. With potential higher shear stresses at the top of the sample there will likely be a lower density in the top area. Further, as the torsional shear is only applied at the top of the sample the maximum strain will occur at the sample edges while the strain in the sample's center is zero. With these locally changing conditions and inhomogeneous sample properties samples tested in torsional shear show a lower resistance to liquefaction than samples tested on the same soil in a direct simple shear test (Kammerer, 2002).

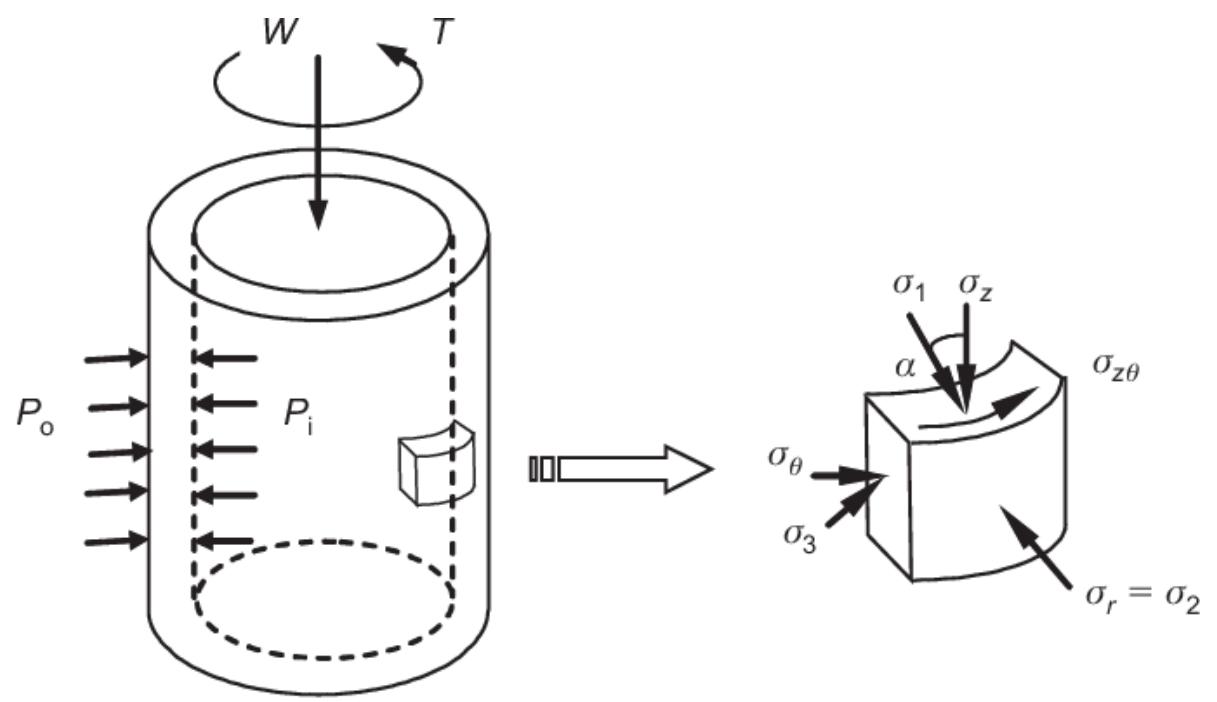

Figure 6. Hollow cylinder torsional shear procedure (Kramer, 1996) 


\subsubsection{Cyclic Direct Simple Shear}

Cyclic direct simple shear tests are performed on cylindrical samples laterally confined by either stacked Teflon-coated rings or wire-reinforced membranes (Figure 7). This confinement system is used to maintain $K_{0}$ conditions during the consolidation phase and then to allow simple shear conditions during the shear phase of the test. A comparison of both lateral confinement methods was made by Baxter et al. (2010) which showed that both methods produce comparable results when appropriate system corrections are applied. Cyclic DSS tests represent a similar loading condition as in situ-loading with $K_{0}$-consolidation and the ability to shear the soil in two horizontal directions independently. The large diameter to height ratio of the soil sample enables a uniform stress field and pore pressure redistribution can be minimized (Kammerer, 2002).

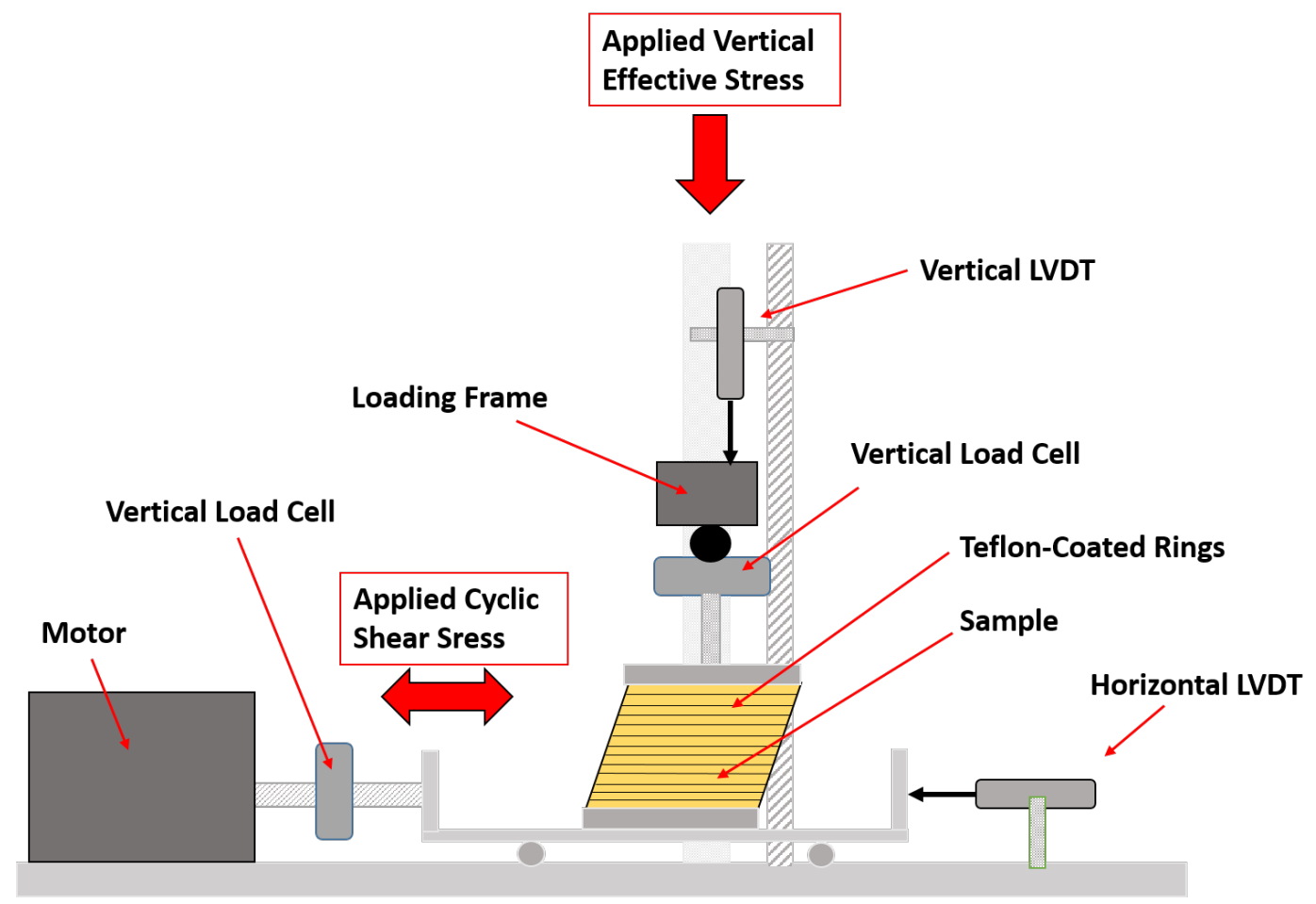

Figure 7. Shematic drawing of a direct simple shear test apparatus 
The direct simple shear test is considered to be the most representative test to replicate both in situ soil conditions $\left(K_{0}\right.$ conditions) and earthquake ground motions (i.e. cyclic motions in the horizontal direction). However, most laboratory studies of cyclic behavior have been performed using cyclic triaxial tests because of the wider availability of that equipment. Cyclic direct simple shear tests have historically been performed by only a few research and commercial labs on 'homemade' devices. With improvements in data acquisition and control systems, however, there has been an increase in the number of commercially available CDSS systems in the past 15 years, and this increase has raised questions about the reliability of the newer systems. In offshore practice cyclic direct simple shear testing is routinely used for testing clays for their undrained cyclic response. However, for sands there is a much greater concern about reliability of test data. This comes from the fact that sand is a much stiffer material than clay and sample stiffness highly affects liquefaction test results. It is not yet known if the commercial systems are capable of producing reliable data for cyclic direct simple shear tests on stiffer materials as sands. One such system is manufactured by the Geocomp Corp. and used in the Marine Geotechnics Laboratory at the URI Narragansett Bay Campus (Figure 8). This particular system was acquired in 2012, and the control systems (hardware and software) were updated in 2018 and 2020. The American Society for Testing of Materials (ASTM) has provided a broad collection of laboratory test standards including a standard for monotonic direct simple shear (DSS) tests. Monotonic shear does not represent the boundary conditions for earthquake loading conditions, but at this time (2020) there is no testing standard for cyclic simple shear testing. Therefore, researchers have to rely on judgment and published data to evaluate the quality of their results. Some authors (Ulmer et al. 2019, Zehtab et al. 2019, Gokyer et al. 2019, Konstadinou 
et al. (2020)) have focused specifically on the evaluation of cyclic direct simple shear data and factors influencing their quality.

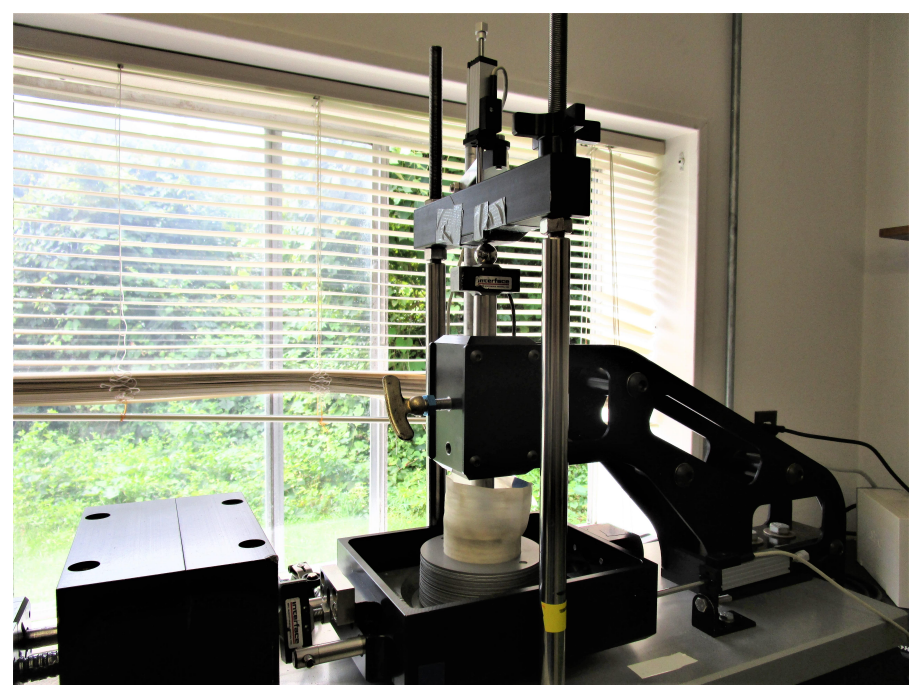

Figure 8. Cyclic direct simple shear apparatus at the Marine Geotechnics Laboratory at the URI Narragansett Bay Campus, manufactured by Geocomp Corporation

Stress-Controlled versus Strain-Controlled testing

Cyclic direct simple shear tests can either be performed under stress-controlled or strain-controlled conditions. For stress-controlled tests, a target cyclic shear stress is applied to the sample using a horizontal piston or linear actuator and controlled using a load cell. Figure 9 shows the shear stress-shear strain relationship for a sand in a stress-controlled CDSS test. In this case the sample was sheared to \pm 15 $\mathrm{kPa}$ and the resulting shear strain was measured. This test was consolidated to a vertical effective stress of $100 \mathrm{kPa}$ prior to shearing, so the CSR for this test is 0.15 .

On the other hand, for strain-controlled tests, a target cyclic shear strain is applied to the sample which is controlled over the horizontal displacement sensor. Figure 


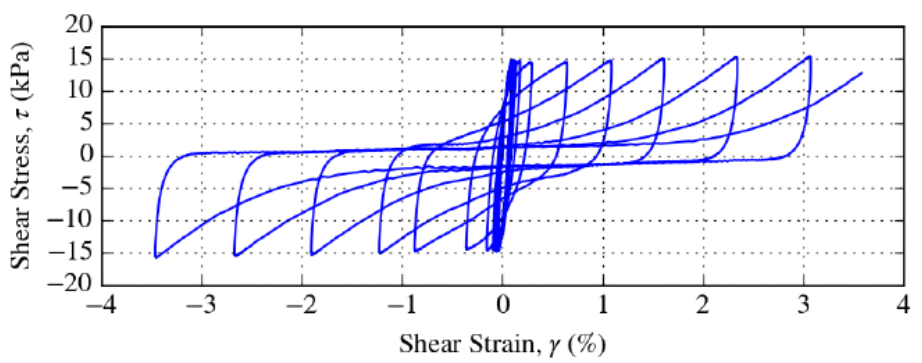

Figure 9. Example of a stress-strain curve for a stress-controlled test consolidated to $100 \mathrm{kPa}$ (Ulmer, 2020)

10 shows the shear stress-shear strain relationship for a sand in a strain-controlled CDSS test. This test was performed at a strain rate of $0.2 \%$.

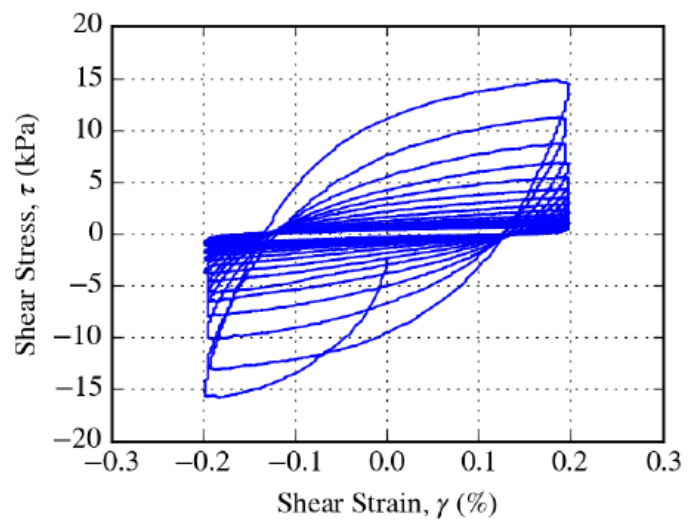

Figure 10. Example of a stress-strain curve for a strain-controlled test consolidated to $100 \mathrm{kPa}$ (Ulmer, 2020)

Cyclic shear strength is influenced by factors such as relative density, sample fabric (preparation technique), prior straining, effective stress and aging. With the strain approach developed by Dobry et al. (1982) it was stated that the pore water pressure buildup in stress-controlled tests are more affected by those factors than strain-controlled tests. This approach includes investigation by Silver and Seed (1971) showing that shear strains are more likely to control the 
densification of dry sands rather than shear stresses. Further, that the sample fabric has a higher effect on cyclic shear strength in stress-controlled tests than in strain-controlled tests. An important aspect in the stress approach is that the pore pressure buildup in sands is related to a threshold shear strain. Only if that shear strain is exceeded, densification and pore water pressure buildup will occur. The reason to assume that cyclic shear strength is controlled by shear strains rather than shear stresses is based on the shear modulus $(G)$ and the cyclic shear stress $(\tau)$ which are both affected by the above mentioned factors. With the ratio of $\gamma=\frac{\tau}{G}$ the shear strain will be less affected by the above mentioned factors. Thus, the pore water pressure buildup is less sensitive to those factors in strain-controlled tests than stress-controlled tests (Dobry et al., 1982).

\section{CDSS data presentation and interpretation}

The most common way to present cyclic shear data is by plotting shear stress, shear strain and pore pressure ratio against the number of loading cycles. This makes it easy to visualize at what cycle of loading the soil specimen fails.

Figure 11 shows an example of a shear stress, shear strain, and excess pore pressure versus number of cycles to failure plot from a CDSS test performed on Monterey sand at a consolidation stress of $100 \mathrm{kPa}$ and a relative sample density of $74 \%$. In Figure 11a, the target shear stress is $\pm 15 \mathrm{kPa}$, and the resulting CSR is 0.15 .

Figure 11b shows the shear strain that develops with numbers of cycles of loading. The double amplitude strain at the end of this particular test is $4 \%$. The strains are symmetrical in both directions, but in many tests a bias in one direction develops. Figure 11c shows the development of excess pore pressures with cycles of loading. The pore pressure ratio $(\mathrm{ru})$ is the ratio between the excess pore water pressures 
and the effective consolidation stress. A pore pressure ratio of 1.0 indicates zero effective stress (i.e. liquefaction) and this test reaches initial liquefaction in 23 cycles.

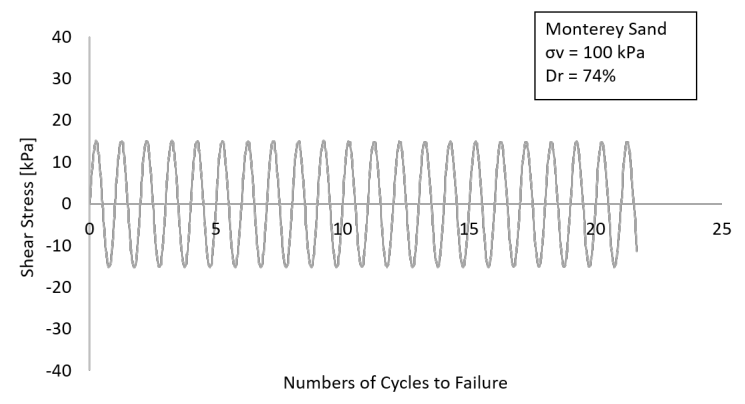

(a)

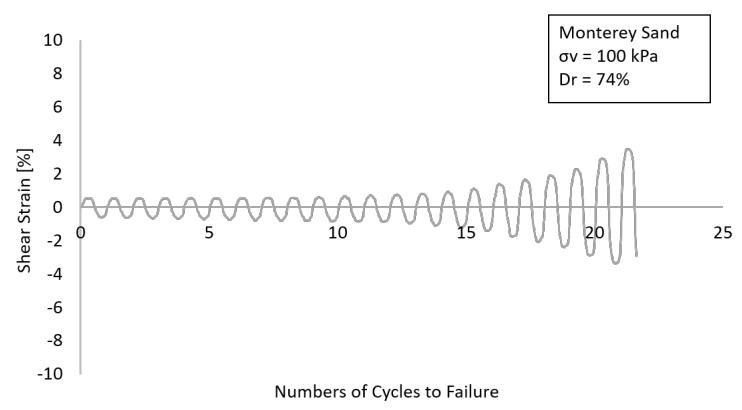

(b)

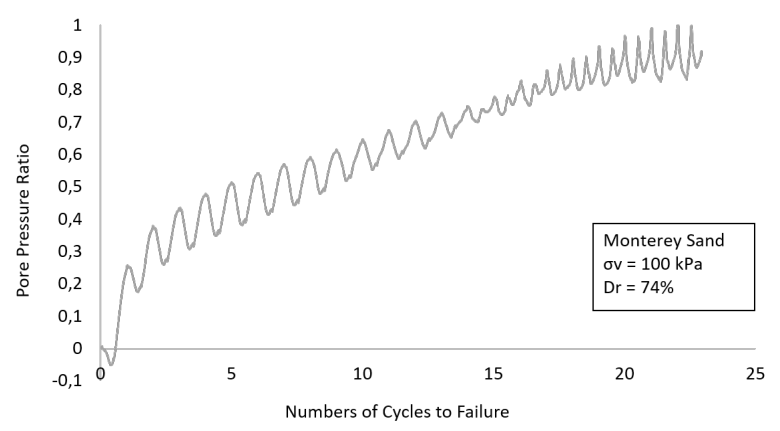

(c)

Figure 11. Shear stress (a), shear strain (b), excess pore pressure (c) versus number of cycles to failure from tests run on Monterey sand with $\sigma_{v 0}^{\prime}=100 \mathrm{kPa}$ and a relative sample density of $74 \%$ taken from this study 
Figure 12 shows a typical stress-strain plot of a stress-controlled CDSS test. As shear strains increase the loops stretch between larger positive and larger negative shear strain values. As the shear strain values increase, the hysteresis loops become more oblong and widen indicating a rapid increase in shear strain.

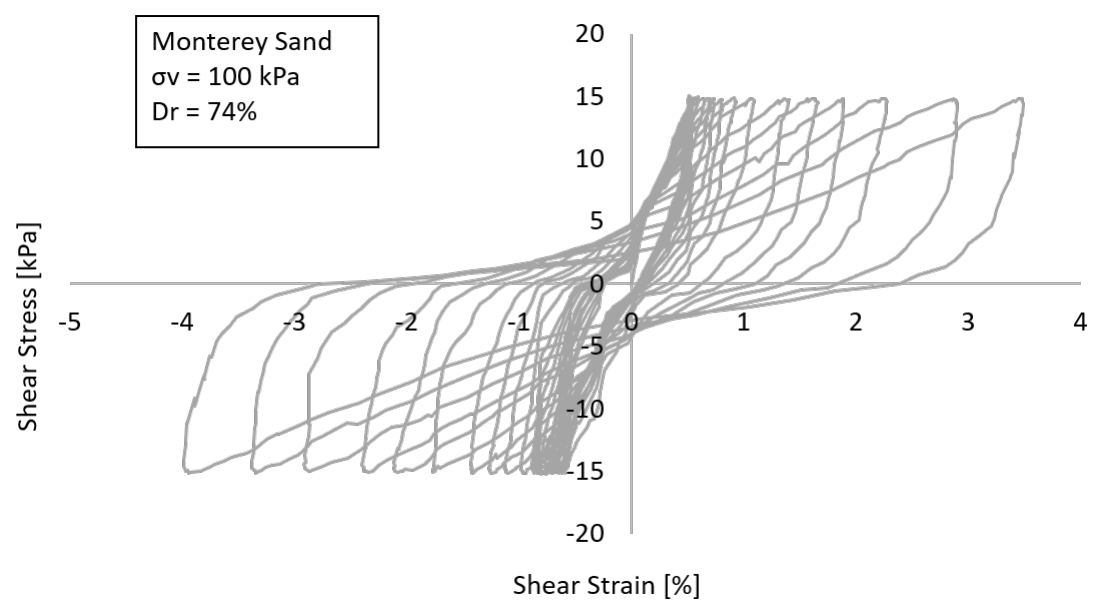

Figure 12. Stress-strain relationship from tests run on Monterey sand with $\sigma_{v 0}^{\prime}=$ $100 \mathrm{kPa}$ and relative sample density of $74 \%$ taken from this study

Figure 13 shows a plot of vertical effective stress vs. shear stress (i.e. stress path) for the test on Monterey sand. Mohr-Coulomb-Failure envelopes are suggested by the green lines. Loading occurs from right to left starting at the effective consolidation stress and zero shear stress. With ongoing cyclic loading, the shear stress is oscillates around zero while the vertical effective stress constantly decreases as the sample contracts. Eventually, as the vertical effective stress decreases every cycle, the curve hits the peak failure and the cycles bow backward yielding the failure envelope (green lines). At the point of initial liquefaction (which is one of the defined failure criteria) the effective vertical stress becomes zero and the soil has failed by definition. 


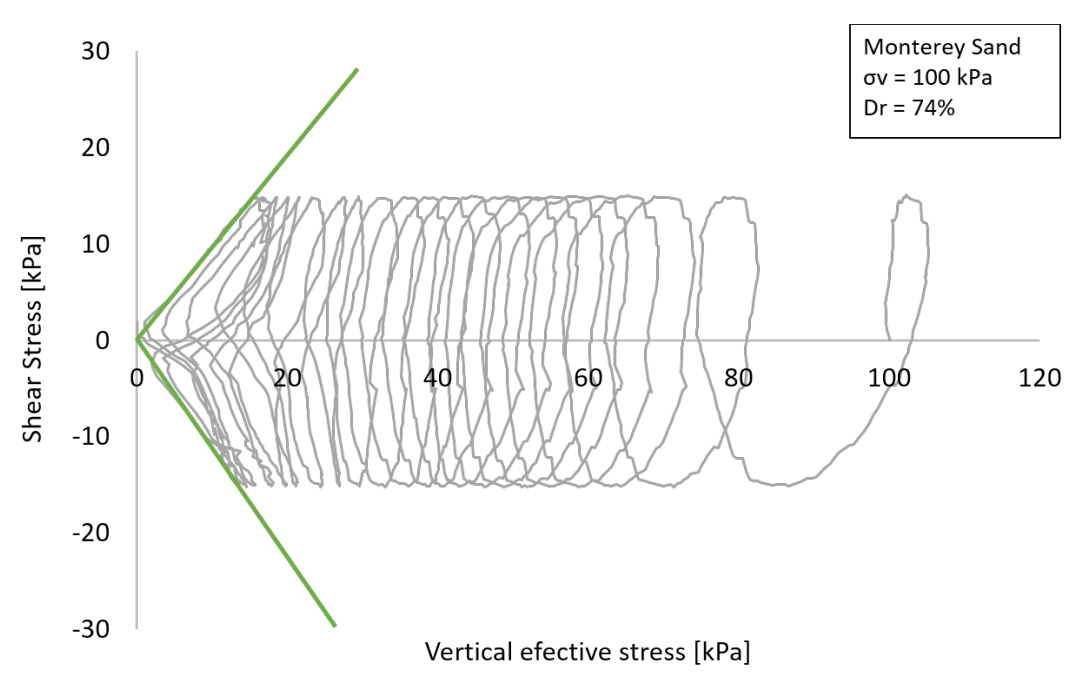

Figure 13. Vertical effective stress vs. shear stress (i.e. stress path) for test on Monterey sand with $\sigma_{v 0}^{\prime}=100 \mathrm{kPa}$ and relative sample density of $74 \%$ taken from this study

Constant Volume vs. Truly Undrained Loading Conditions

An undrained direct simple shear test can either be performed as a constant volume test or a truly undrained shear test. For a truly undrained shear test, the specimen is placed in a pressure chamber that enables confinement of the sample with a cell pressure and simultaneous application of a back pressure to guarantee that the sample is fully saturated. Specimens can be laterally confined using a wire-reinforced membrane or stacked Teflon coated rings. During shear the specimen can not change in volume, and excess pore water pressures are measured.

A constant volume CDSS test is performed without any external cell pressure or back pressure saturation (Dyvik et al., 1987). The sample is still laterally confined with either a wire-reinforced membrane or stacked rings. To ensure constant volume conditions, the sample height is kept constant during shear either with an active control system or by passive control with fixed vertical device hardware. 
It is important to note that the test results shown in Figure 11 was actually performed on a dry sample (as are all the tests performed in this thesis). The excess pore pressure in Figure 11c is actually the change in vertical stress required to maintain constant height conditions (i.e. undrained). It has been shown by Dyvik et al. (1987) that the amount of load change required to keep constant height, i.e. constant volume in a constant volume shear test on saturated, normally consolidated clay, is equal to the amount in pore water pressure developed on samples in a truly undrained shear test on the same saturated, normally consolidated clay. Further experimental investigations conducted by Finn (1985) on sands indicate that the behavior of cohesionless soils in direct simple shear tests are not affected by whether the soil is saturated or dry (Finn, 1985). Further, various authors state that since constant volume is enforced there is no need to

perform tests on saturated samples or measure pore pressures (Ulmer et al., 2019); (Zehtab et al., 2019); (Dyvik, 2019).

\section{Passive versus Active Height-Control}

In a passive height-control system the vertical loading frame of the shear device is locked preventing the sample from changing height during shear. With lateral confinement and prevention in vertical movement, the sample maintains a constant volume (Zehtab et al., 2019). The volume change tendencies of the soil (i.e. contraction or dilation) measured as a change in vertical load as the soil acts against the rigid crossbar with the load cell. However, a significant disadvantage of passive height control is that its accuracy highly depends on the rigidity of the vertical frame and other system components located between specimen and load cell (Zehtab et al., 2019). 
An active control system on the other hand maintains constant specimen height using a feedback loop that actively measures vertical displacement and almost simultaneously reacts with corrective adjustment (Zehtab et al., 2019). However, for an active control system it is also important to place the vertical displacement sensor as close to the sample as possible to avoid inaccuracy in measurement due to the influence of rigidity of the loading piston and cross arm.

Konstadinou et al. (2020) investigated apparatus stiffness influence on cyclic direct simple shear data by using an active and a passive height-control system. The authors recommend to design the apparatus components between the sample and the height measurement to reduce stiffness influence (i.e. stiffen or reduce the components in the height measurement area). The active height-control system is recommended over the passive height-control system because it shows a better ability to minimize system compliance. 


\subsection{Quality control measures for CDSS tests}

$\underline{\text { Factors affecting liquefaction test results }}$

Various factors affecting the reproducibility of cyclic direct shear test data have been identified by several authors, such as Ulmer et al. (2019), Dyvik and Suzuki (2019), Zehtab et al. (2019), Gokyer et al. (2019) and Konstadinou et al. (2020). In these studies, constant volume cyclic direct simple shear tests were performed with active and/or passive control with a focus on possible influencing factors on test quality in test setup and procedure. Because all the testing done as part of this thesis involved active control, only those aspects will be discussed below.

\section{- Stiffness of Shear Device and Equipment Components} Investigations made by Konstadinou et al. (2020) show that apparatus stiffness significantly affects the results of cyclic direct simple shear tests. Accordingly, resistance to liquefaction increases with decreasing apparatus stiffness. It is recommended to minimize the number of equipment components (loading piston, sample top cap, horizontal crossbar) between sample and active height control measurements (i.e. the vertical LVDT) to reduce the influence of system stiffness. Displacement should be measured as close to the sample as possible. Furthermore, the remaining device components that cannot be avoided in between the vertical LVDT and the sample should be designed to be as stiff as possible to maintain constant volume within the axial strain limits.

\section{- Stiffness of Soil Sample}

Dyvik and Suzuki (2019) performed monotonic constant volume DSS tests 
on different soil materials using active height control. Investigating the effect of varying specimen heights on measured shear stress and vertical effective stress they observed that sample stiffness plays an important role in the ability of active height control systems to work well. Changes in height during shear clearly affected test results, and those effects were more significant in stiff or dense samples. Thus, the effect of sample stiffness, especially for denser samples, needs to be considered as an influencing factor using active height control. Konstadinou et al. (2020) further recommended the implementation of a maximum sample stiffness to apparatus stiffness ratio rather than a sample height change limit in order to consider sample and apparatus stiffness. This ratio can be helpful for keeping system compliance in a certain tolerance and reduce the effect of equipment stiffness when kept at low values. The authors further considered active height control to be more suitable for keeping the ratio at a low value while passive control on the other hand failed to ful fill the criterion.

\section{- Sample fabric and preparation technique}

Various sample preparation techniques have been developed to obtain reproducible samples of sand in the laboratory. The techniques result in different fabrics, or particle arrangements, even for samples prepared to the same density. To examine the effect of sample fabric on liquefaction potential Mulilis et al. (1977) performed undrained stress-controlled cyclic triaxial tests on Monterey 0/30 saturated sand samples prepared to the same density using 11 different sample preparation techniques. Results show that sample preparation techniques strongly affect liquefaction potential. Therefore it is important to consider sample preparation technique when 
comparing cyclic shear data from different studies.

\section{- Axial Strain during Shear}

The ASTM has developed a standard for monotonic direct simple shear testing, which specifies that the axial strain of a specimen during monotonic, undrained simple shear tests must not exceed $0.05 \%$. However, several studies have shown that this value is not appropriate for cyclic direct simple shear tests because it is too high.

Dyvik and Suzuki (2019) performed monotonic constant volume tests on sand and clay with an active control system and varied the percentage of allowable deviation in sample height to evaluate its effect on shear stresses. It was shown that the number of cycles to failure increased with increasing allowable sample height deviation (Dyvik, 2019). The authors recommended to not exceed sample height deviations greater than $0.05 \%$, and that this value should actually be decreased to obtain reliable test results.

Zehtab et al. (2019) also examined the effect of inadequate height control in constant volume cyclic DSS tests and observed an increase in measured shear strength and limiting pore water pressure generation. The authors showed that an axial strain exceeding a value of $0.03 \%$ will lead to undesirable partial drainage and volume change of the sample. As a result, the measured shear strength increases which leads to an overestimation of soil strength properties. Pore water pressures increase more slowly causing the soil to fail at a higher number of cycles than it would have failed under constant volume

conditions. This leads to an overestimation of the cyclic soil resistance. 
Therefore it is recommended by Zehtab et al. (2019) to keep the axial strain as low as possible and at a minimum below $0.03 \%$.

Ulmer et al. (2019) further states that the effects of high axial strain might only be an issue if high strains occur before the soil specimen has liquefied. After liquefaction there is little to no influence on the number of cycles required to reach liquefaction.

\section{- Induced Shear Strain and Shear Stress during Consolidation}

If the vertical components of the test setup don't align properly or if the test equipment is angled or tilted in some way, application of the vertical consolidation stress can lead to either induced horizontal loads or shear strain on the sample. Induced shear stress and shear strain prior to cyclic loading may influence the soil's resistance to liquefaction (Ulmer et al., 2019). It is recommended to plot the data of the consolidation phase in order to keep track of possible changes in horizontal load and displacement (Ulmer et al., 2019). The shear strains induced during consolidation is recommended to be kept lower than $0,05 \%$ strain to prevent the soil from pre-shearing (Ulmer et al., 2019).

\section{- Biased Stress Path and Rocking}

Stress paths may either not oscillate around zero, show higher stresses in one direction or be more rounded in one and more pointed in the other direction. It is not known where these biases arise from, but one possibility is that they may be related to rocking of the loading piston. This pulling and pushing could also be caused in part by the cyclic movement of the 
water bath (Ulmer et al., 2019). It is not clear how these effects alter test results.

\section{- Potential for Distorted Stress - Strain Hysteresis Loops}

The final issue reported by Ulmer et al. (2019) is a distortion of the stress-strain hysteresis loops. The cause of that issue could not be examined but the authors hypothesize that it could be caused by the piston rocking while actively maintaining a constant sample height. It is not believed that this has an effect on the numbers of cycles needed to cause liquefaction (Ulmer et al., 2019).

Ulmer et al. (2019) developed a grading system for cyclic direct simple shear tests using passive height control (Table 14) and active height control (Table 15). The system is based on the observed factors affecting CDSS data using a passive and an active height-control system to maintain constant volume conditions in cyclic direct simple shear tests.

In each grading category a test is given a score between 0 and 3 points, with the scores summed to get a final quality score. The maximum possible score is 10 and the poorest score is -1 . The results of this study showed that samples prepared to lower relative densities $\left(D_{r}=25 \%\right)$ mostly achieved higher scores than samples prepared to higher densities $\left(D_{r}=60-80 \%\right)$. Tests with irregular spacing between cycles and/or a bias in the shear stress graph (towards $+\tau$ or $-\tau$ ) were eliminated due to uncertainties in evaluating those phenomena (Ulmer et al., 2019). 


\begin{tabular}{|c|c|c|c|}
\hline Criterion & & A-D & Score \\
\hline \multicolumn{4}{|c|}{$y$ during ramp-up. consolidation } \\
\hline & $\gamma \leq 0.05 \%$ & $A$ & +3 \\
\hline & $\gamma \leq 0.10 \%$ & $B$ & +2 \\
\hline & $\gamma \leq 0.20 \%$ & C & +1 \\
\hline & $\gamma>0.20 \%$ & $D$ & - \\
\hline \multicolumn{4}{|c|}{$\tau$ during ramp-up, consolidation } \\
\hline & $\tau \leq 1.0 \mathrm{kPa}$ & $A$ & +3 \\
\hline & $\tau \leq 2.0 \mathrm{kPa}$ & $B$ & +2 \\
\hline & $\tau \leq 3.0 \mathrm{kPa}$ & $C$ & +1 \\
\hline & $\tau>3.0 \mathrm{kPa}$ & $D$ & - \\
\hline \multicolumn{4}{|c|}{$\varepsilon$ during cyclic phase (c.p.) } \\
\hline \multicolumn{2}{|c|}{$\varepsilon \leq 0.05 \%$ for $80 \%$ of the c.p. or until $r_{u}=0.75$} & $A$ & +3 \\
\hline \multicolumn{2}{|c|}{$\varepsilon \leq 0.05 \%$ for $60 \%$ of the c.p. } & $A-$ & +2.5 \\
\hline \multicolumn{2}{|c|}{$\varepsilon \leq 0.05 \%$ for $40 \%$ of the c.p. } & $B^{+}$ & +2 \\
\hline \multicolumn{2}{|c|}{$\varepsilon \leq 0.10 \%$ for $100 \%$ of the c.p. or until $r_{u}=0.75$} & $B$ & +1.5 \\
\hline \multicolumn{2}{|c|}{$\varepsilon \leq 0.10 \%$ for $75 \%$ of the c.p. } & $B-$ & +1 \\
\hline \multicolumn{2}{|c|}{$\varepsilon \leq 0.10 \%$ for $50 \%$ of the c.p. } & $C$ & +0.5 \\
\hline \multicolumn{2}{|c|}{$\varepsilon>0.10 \%$ within $50 \%$ of the c.p. } & $D$ & - \\
\hline \multicolumn{4}{|c|}{ SP1 (vertical line in stress path) } \\
\hline \multirow{2}{*}{\multicolumn{2}{|c|}{ There is a vertical line }} & True & -1 \\
\hline & & False & +1 \\
\hline \multicolumn{4}{|c|}{ Stress path convergence } \\
\hline \multirow{2}{*}{\multicolumn{2}{|c|}{ Converges to $\sigma_{v}^{\prime}=\sigma_{\min }^{\prime}>0$}} & True & $\stackrel{-10 \times}{\left(\sigma_{\min }^{\prime} / \sigma_{\text {vo }}^{\prime}\right)}$ \\
\hline & & False & 0 \\
\hline
\end{tabular}

Figure 14. Grading Criteria for passive controlled constant volume CDSS tests after Ulmer et al. (2019)

\begin{tabular}{|c|c|c|}
\hline Criterion & A-D & Score \\
\hline \multicolumn{3}{|l|}{$y$ during ramp-up, consolidation } \\
\hline$\gamma \leq 0.05 \%$ & A & +3 \\
\hline$\gamma \leq 0.10 \%$ & B & +2 \\
\hline$\gamma \leq 0.20 \%$ & $\mathrm{C}$ & +1 \\
\hline$\gamma>0.20 \%$ & $\mathrm{D}$ & - \\
\hline \multicolumn{3}{|l|}{$\tau$ during ramp-up, consolidation } \\
\hline$\tau \leq 1.0 \mathrm{kPa}$ & A & +3 \\
\hline$\tau \leq 2.0 \mathrm{kPa}$ & B & +2 \\
\hline$\tau \leq 3.0 \mathrm{kPa}$ & $\mathrm{C}$ & +1 \\
\hline$\tau>3.0 \mathrm{kPa}$ & $\mathrm{D}$ & - \\
\hline \multicolumn{3}{|l|}{$\underline{\varepsilon \text { during cyclic phase (c.p.) }}$} \\
\hline$\varepsilon \leq 0.05 \%$ for $80 \%$ of the c.p. or until $r_{u}=0.75$ & A & +3 \\
\hline$\varepsilon \leq 0.05 \%$ for $60 \%$ of the c.p. & A- & +2.5 \\
\hline & $\mathrm{B}^{+}$ & +2 \\
\hline$\varepsilon \leq 0.10 \%$ for $100 \%$ of the c.p. or until $\mathrm{r}_{\mathrm{u}}=0.75$ & B & +1.5 \\
\hline$\varepsilon \leq 0.10 \%$ for $75 \%$ of the c.p. & B- & +1 \\
\hline$\varepsilon \leq 0.10 \%$ for $50 \%$ of the c.p. & $\mathrm{C}$ & +0.5 \\
\hline$\varepsilon>0.10 \%$ within $50 \%$ of the c.p. & D & - \\
\hline \multicolumn{3}{|l|}{ Vertical line in $\tau$ vs. $\sigma{ }_{v}^{\prime}$ path } \\
\hline \multirow[t]{2}{*}{ There is a vertical line } & True & -1 \\
\hline & False & +1 \\
\hline \multicolumn{3}{|l|}{ Biased $\tau$ vs. $\sigma_{v}^{\prime}$ path } \\
\hline \multirow{2}{*}{ There is a bias } & True & -1 \\
\hline & False & +1 \\
\hline \multicolumn{3}{|l|}{ Stress path convergence } \\
\hline \multirow{3}{*}{ Converges to $\sigma^{\prime}{ }_{v}=\sigma^{\prime} \min >0$} & True & $-10 \times$ \\
\hline & & $\begin{array}{c}\left(\sigma_{\min }^{\prime} /\right. \\
\left.\sigma_{\mathrm{v} 0}^{\prime}\right)\end{array}$ \\
\hline & False & 0 \\
\hline
\end{tabular}

Figure 15. Grading Criteria for active controlled constant volume CDSS tests after Ulmer et al. (2019) 


\subsection{Examples of high quality CDSS test results from the literature}

The objective of this thesis is to evaluate quality control measures for cyclic direct simple shear tests and to apply those measures to test results obtained with a CDSS apparatus manufactured by the Geocomp Corp. Part of the challenge with a project like this is identifying studies from the literature that have produced high quality CDSS data for comparison with the results of this study. The following figures show test results from reputable labs on samples of the same sands used in this study. Table 2.4 summarizes the relevant details of the 4 studies chosen. 


\begin{tabular}{|c|c|c|c|c|c|c|c|c|c|c|c|c|c|c|c|c|}
\hline 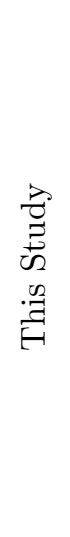 & 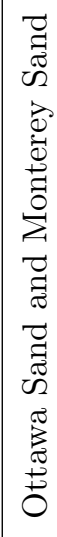 & 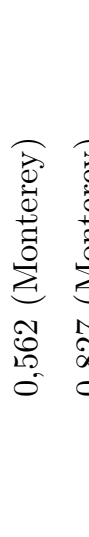 & 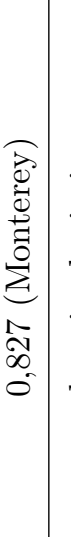 & 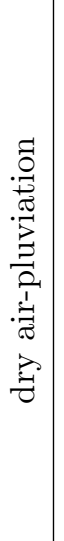 & $\vec{\theta}$ & 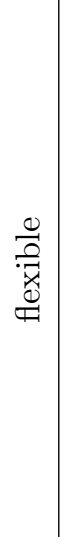 & $\begin{array}{l}\boldsymbol{2} \\
\tilde{\theta} \\
\hat{\theta}\end{array}$ & 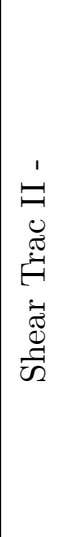 & 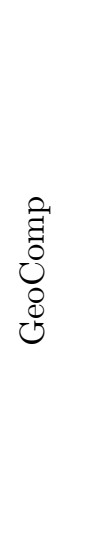 & 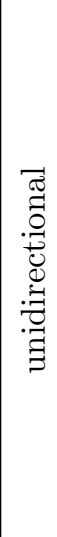 & 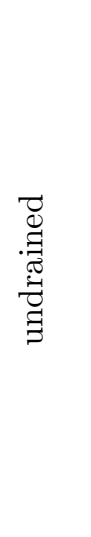 & 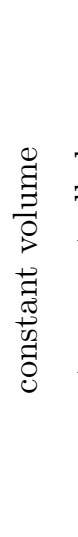 & 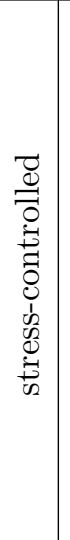 & 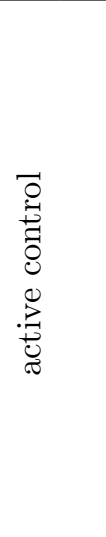 & $\begin{array}{l}\frac{0}{0} \\
0 \\
0 \\
0 \\
0 \\
0 \\
0\end{array}$ & 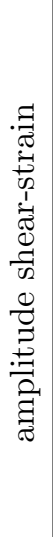 \\
\hline 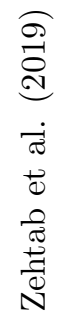 & 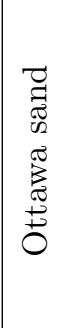 & & & 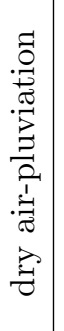 & $\vec{\theta}$ & 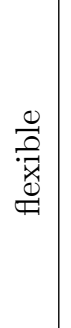 & $\begin{array}{l}\tilde{D} \\
\tilde{D} \\
\mathcal{\theta}\end{array}$ & 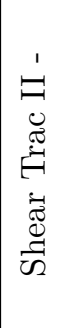 & 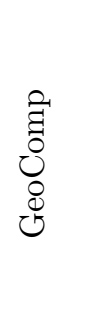 & 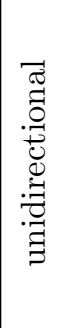 & 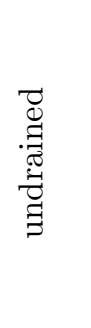 & 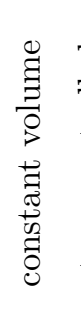 & 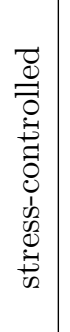 & 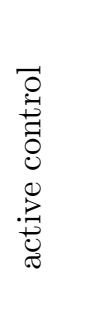 & $\begin{array}{l}0 \\
i \\
i \\
\approx\end{array}$ & \\
\hline 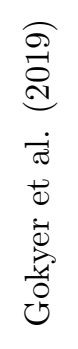 & 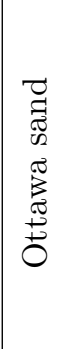 & $\begin{array}{c}\text { î } \\
\text { is } \\
0\end{array}$ & $\begin{array}{l}\overrightarrow{1} \\
D_{0} \\
0\end{array}$ & 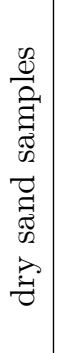 & $\vec{E}$ & $\begin{array}{l}\frac{0}{0} \\
\stackrel{\vec{\pi}}{\overrightarrow{0}} \\
\underline{\underline{e}}\end{array}$ & $\begin{array}{l}\boldsymbol{D} \\
\tilde{R} \\
\mathcal{O}\end{array}$ & 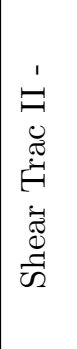 & 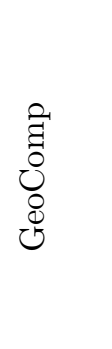 & 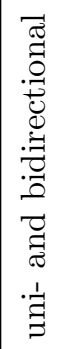 & 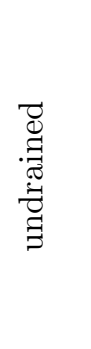 & 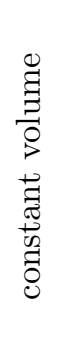 & 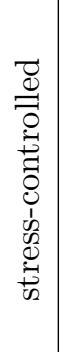 & ' & ' & \\
\hline 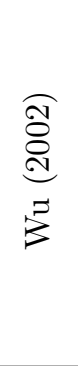 & 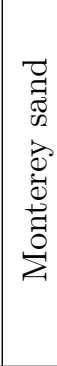 & $\begin{array}{l}\vec{F} \\
\overrightarrow{10} \\
0 \\
0\end{array}$ & & 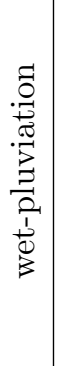 & 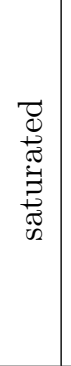 & 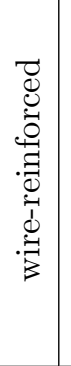 & $\begin{array}{l}\boldsymbol{D} \\
\tilde{D} \\
\mathcal{O} \\
\mathcal{O}\end{array}$ & 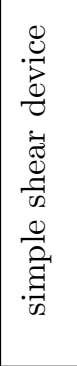 & 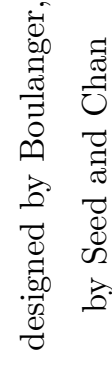 & 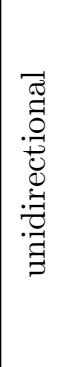 & 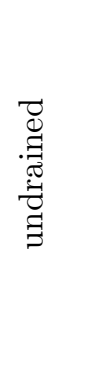 & 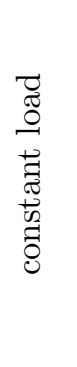 & 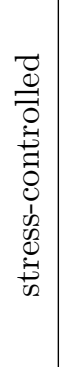 & ' & I & \\
\hline 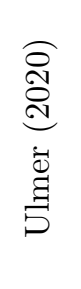 & 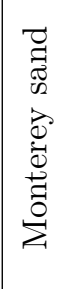 & $\begin{array}{l}0 \\
0 \\
0 \\
10 \\
0\end{array}$ & $\begin{array}{l}\hat{N} \\
\text { on } \\
0 \\
0\end{array}$ & 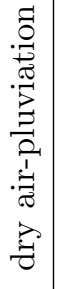 & $\vec{\theta}$ & 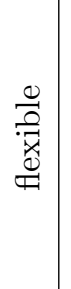 & $\begin{array}{l}\boldsymbol{D} \\
\tilde{D} \\
\mathcal{O}\end{array}$ & $\begin{array}{l}8 \\
0 \\
1 \\
1 \\
1 \\
02 \\
02 \\
02 \\
1 \\
0 \\
0 \\
0\end{array}$ & 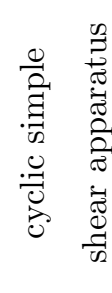 & 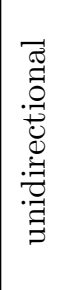 & 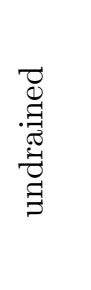 & 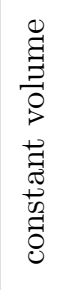 & 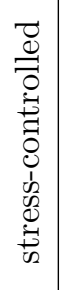 & 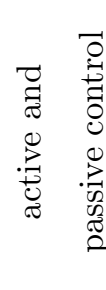 & & \\
\hline 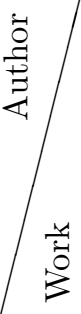 & 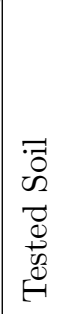 & हَّ & . & 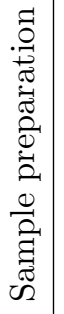 & 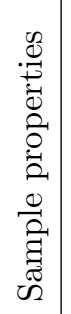 & 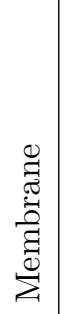 & 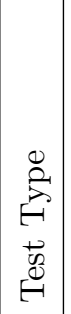 & 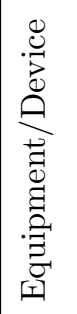 & & 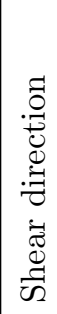 & 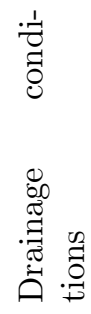 & 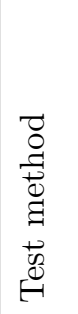 & & 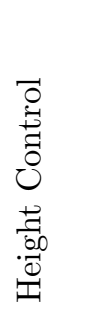 & 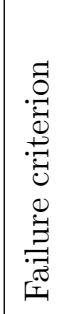 & \\
\hline
\end{tabular}


Ulmer et al. 2019

\begin{tabular}{c|c} 
Sand Type & Monterey sand \\
\hline Sample preparation technique & Dry air-pluviation \\
\hline Relative Densities & $25 ; 60$ and $80 \%$ \\
\hline Height control & passive and active \\
\hline Failure criterion & different pore pressure ratios and different shear strains \\
\hline
\end{tabular}
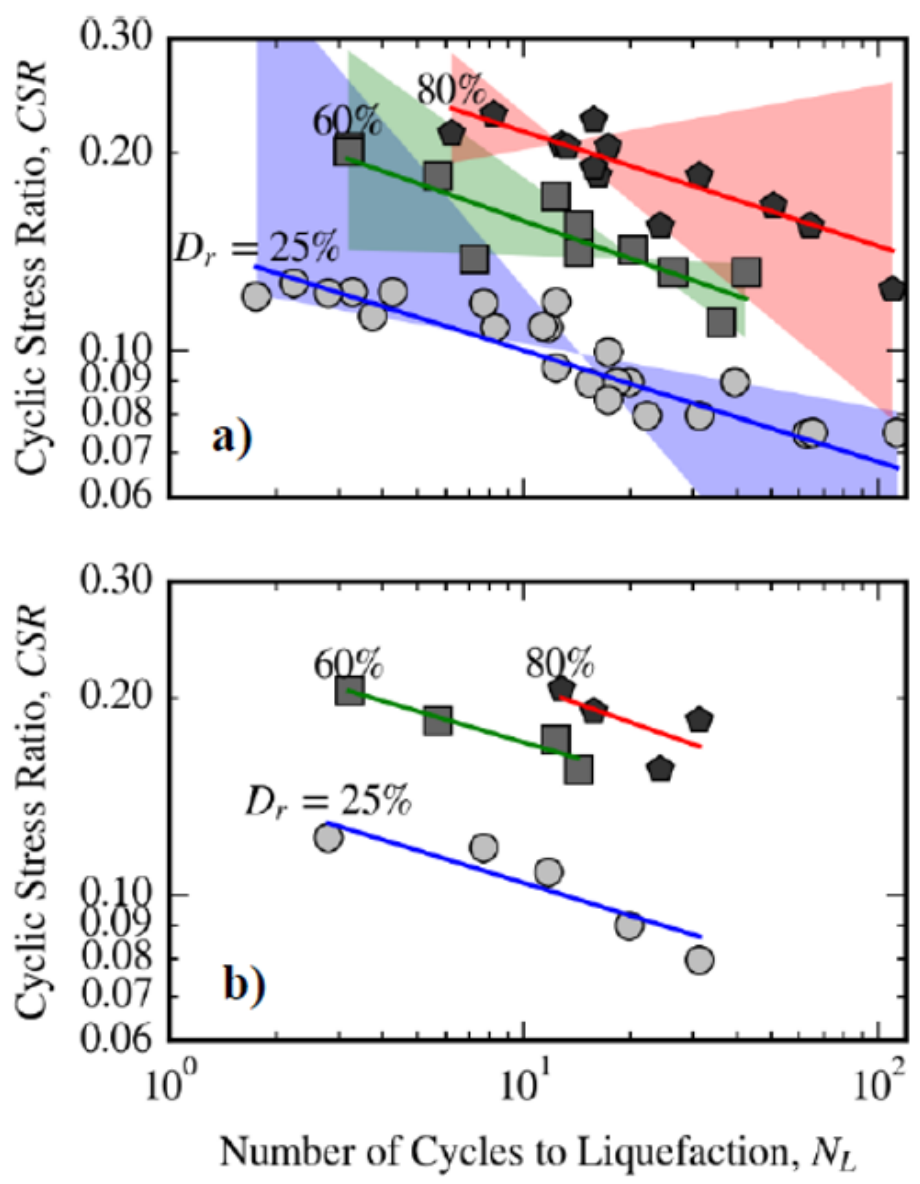

Figure 16. Liquefaction resistance curves after Ulmer et al (2020). Liquefaction is defined as the single strain-amplitude of $\gamma=3.5 \%$ at a consolidation stress of $\sigma_{v}=100 \mathrm{kPa}$. All tests with passive control: a) all tests and b) all tests that passed the acceptance criteria 
Wu 2002

\begin{tabular}{c|c} 
Sand Type & Monterey sand \\
\hline Sample preparation technique & wet pluviation \\
\hline Relative Densities & $35 ; 45 ; 60$ and $80 \%$ \\
\hline Height control & - \\
\hline Failure criterion & - \\
\hline
\end{tabular}

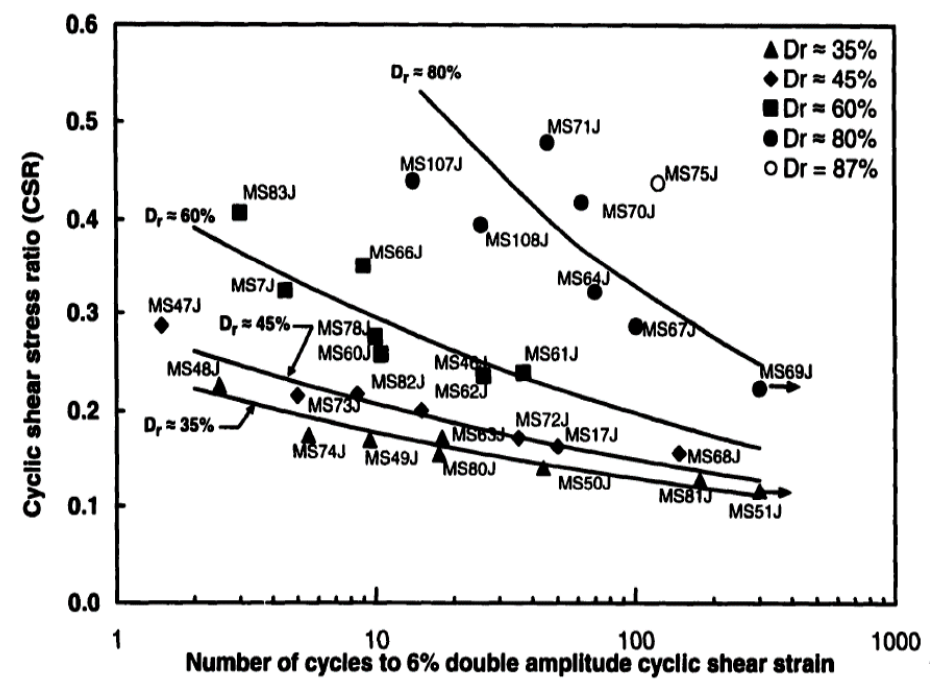

Figure 17. Liquefaction triggering curves for an effective consolidation stress of $\sigma_{v}=40 k P a$ by $\mathrm{Wu}(2002)$ 


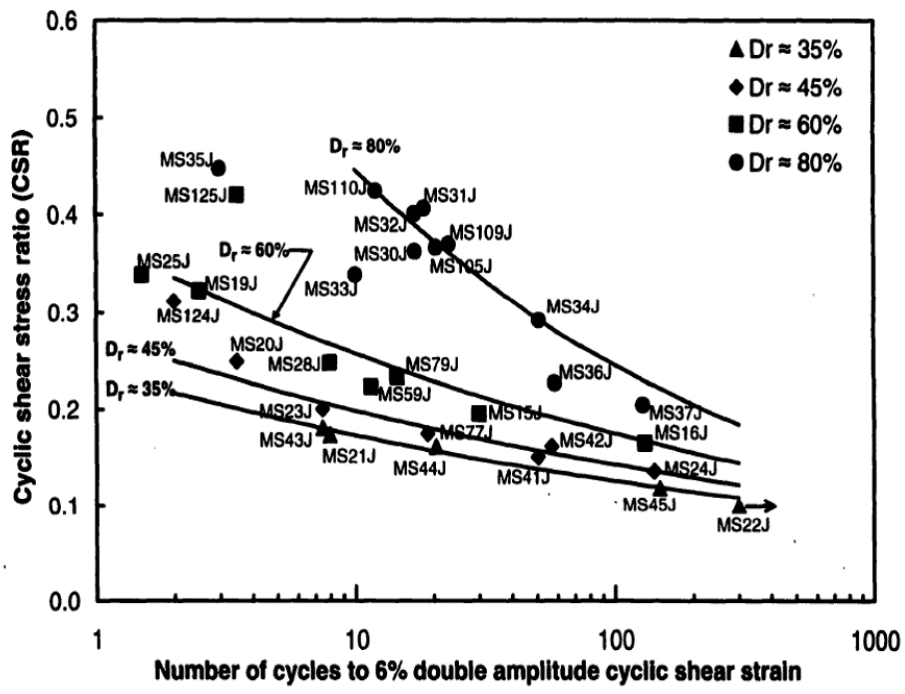

Figure 18. Liquefaction triggering curves for an effective consolidation stress of $\sigma_{v}=80 k P a$ by $\mathrm{Wu}(2002)$

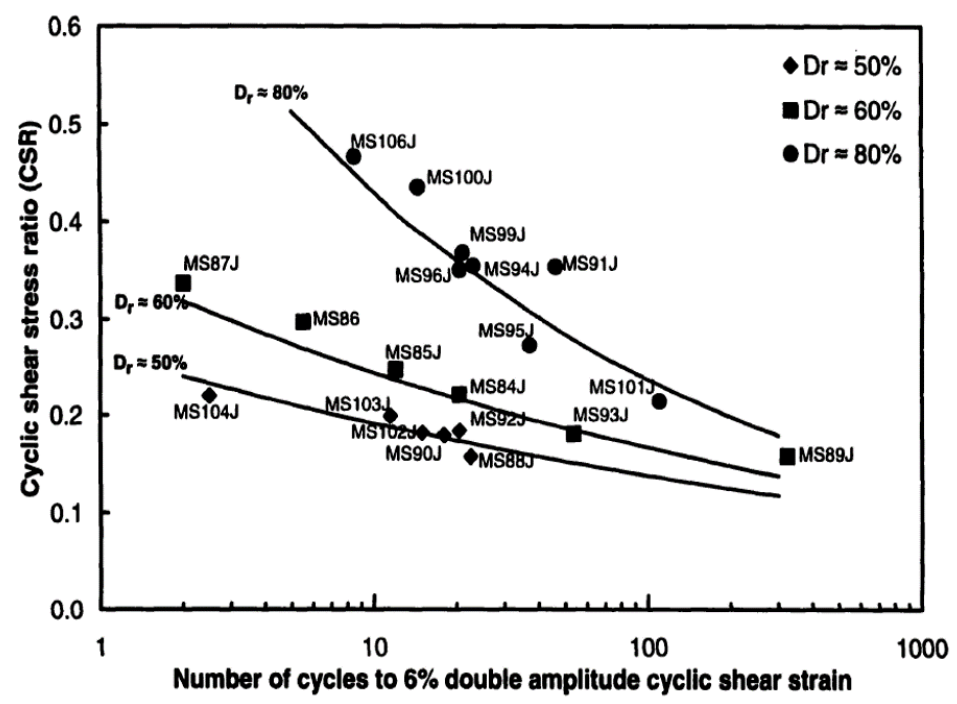

Figure 19. Liquefaction triggering curves for an effective consolidation stress of $\sigma_{v}=180 k P a$ by $\mathrm{Wu}(2002)$ 


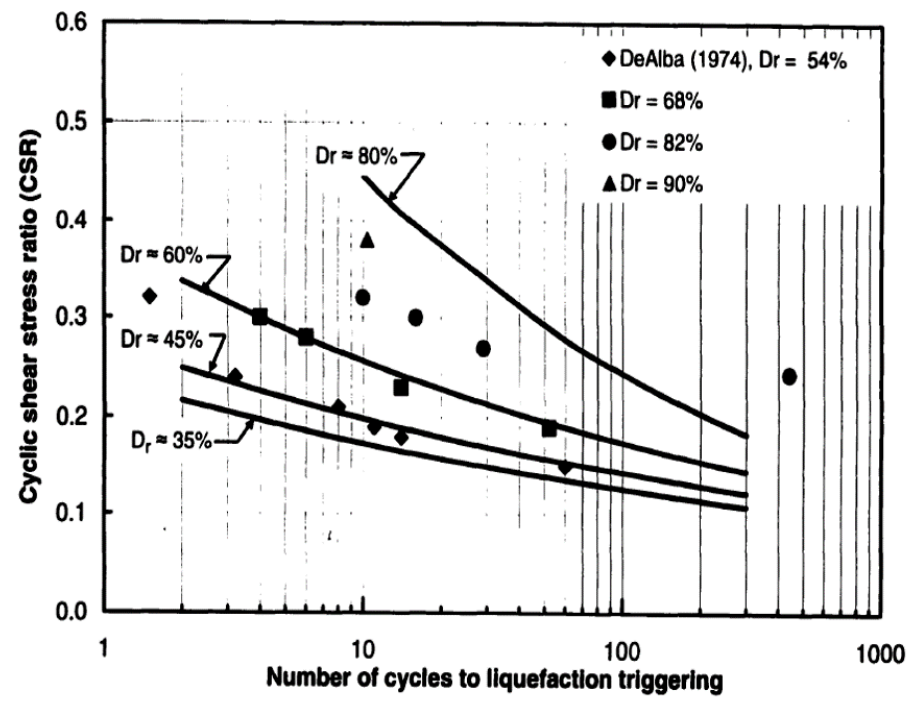

Figure 20. Comparison between liquefaction resistance curves after $\mathrm{Wu}(2002)$ 
Konstadinou et al. (2020)

Konstadinou et al. (2020) performed undrained cyclic direct simple shear tests on Toyoura Sand on two different shear devices to evaluate the influence of equipment stiffness on cyclic direct simple shear results.

\begin{tabular}{c|c} 
Sand Type & Toyoura Sand \\
\hline Sample preparation technique & Dry air pluviation \\
\hline Relative Densities & $80 \%$ \\
\hline Height control & active and passive \\
\hline Failure criterion & - \\
\hline
\end{tabular}

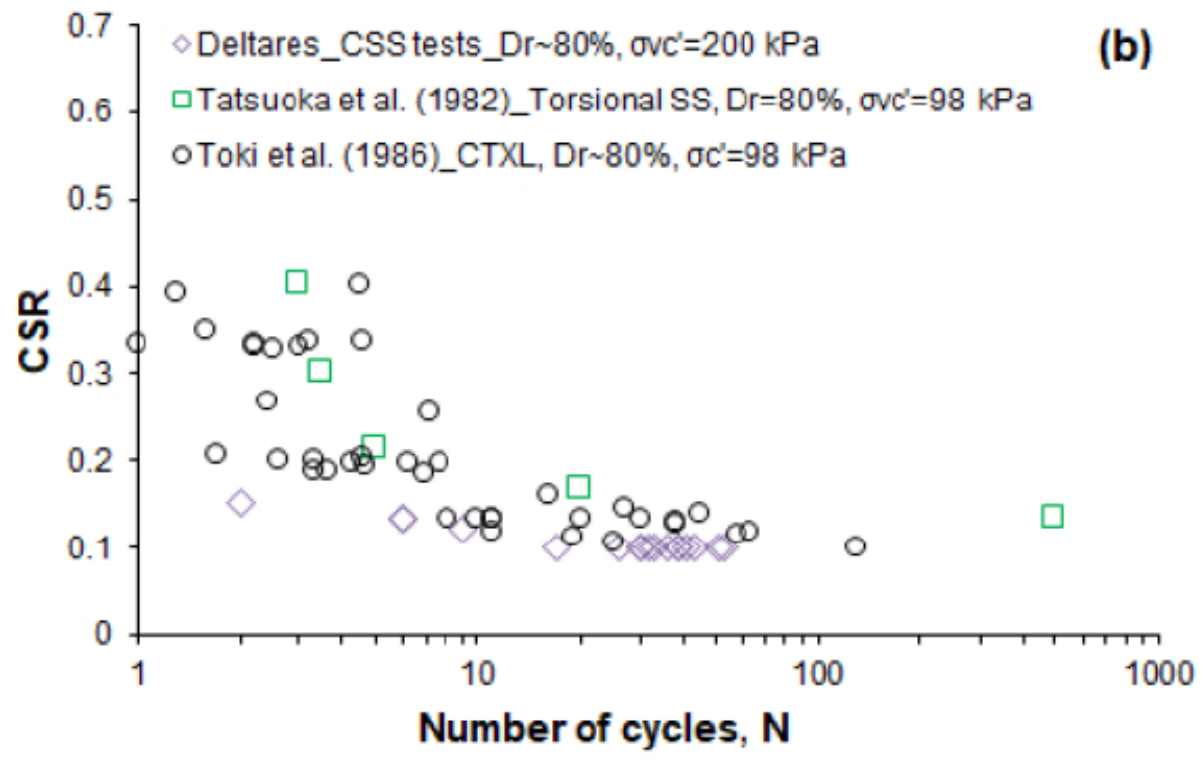

Figure 21. Comparison of CSR versus N data from Konstadinou et al. (2020), Tatsuoka et al. (1982) and Tokimatsu et al. (1986) 


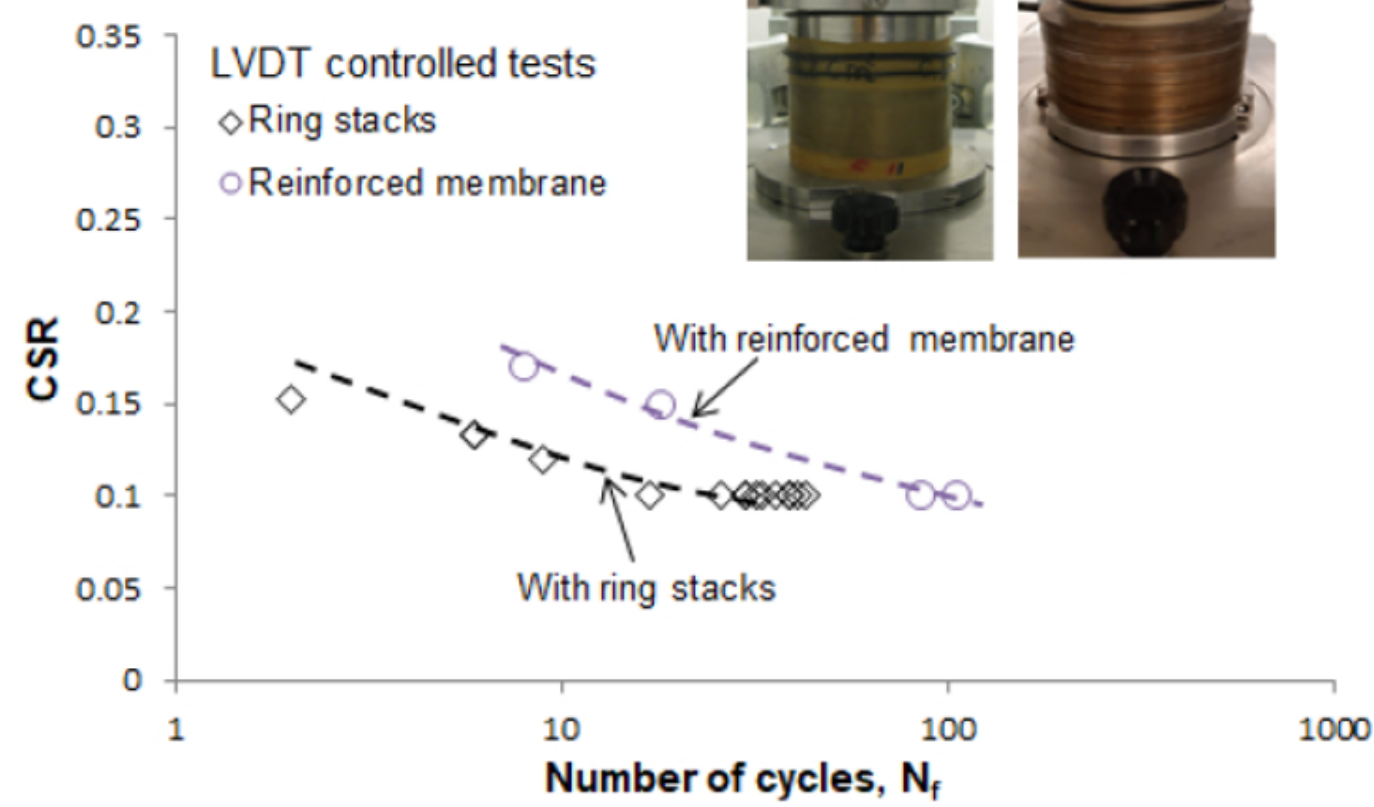

Figure 22. Comparison between cyclic strength resistance curves of samples laterally confined with a wire-reinforced membrane versus confined by stacked Teflon coated rings by Konstadinou et al. (2020) 
Gokyer et al. 2019

Goyker et al (2019) investigated the cyclic response of Ottawa Sand under cyclic triaxial testing as well as unidirectional and multidirectional (rotational, oval and 8-figure shape) direct simple shear testing. Specimen for the cyclic triaxial tests were saturated and isotropically consolidated. The specimen in the direct simple shear tests were conducted on dry sand which were consolidated under K0-Conditions and sheared under constant volume conditions. Correction factors for later comparison between those test conditions were determined.

\begin{tabular}{c|c} 
Sand Type & Ottawa sand \\
\hline Sample preparation technique & dry sand samples \\
\hline Relative Densities & $40-45 \%$ \\
\hline Height control & active control \\
\hline Failure criterion & $r_{u}=1.0$ \\
\hline
\end{tabular}
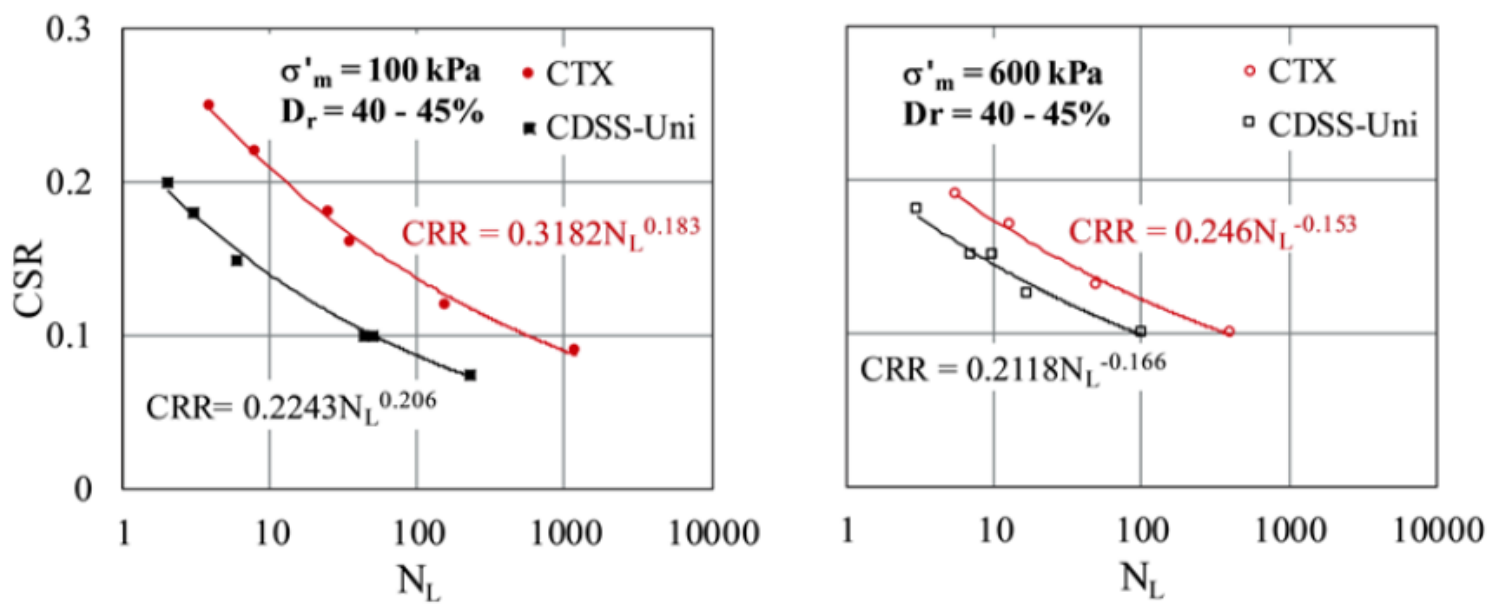

Figure 23. Unidirectional CDSS tests by Gokyer et al. (2019) 

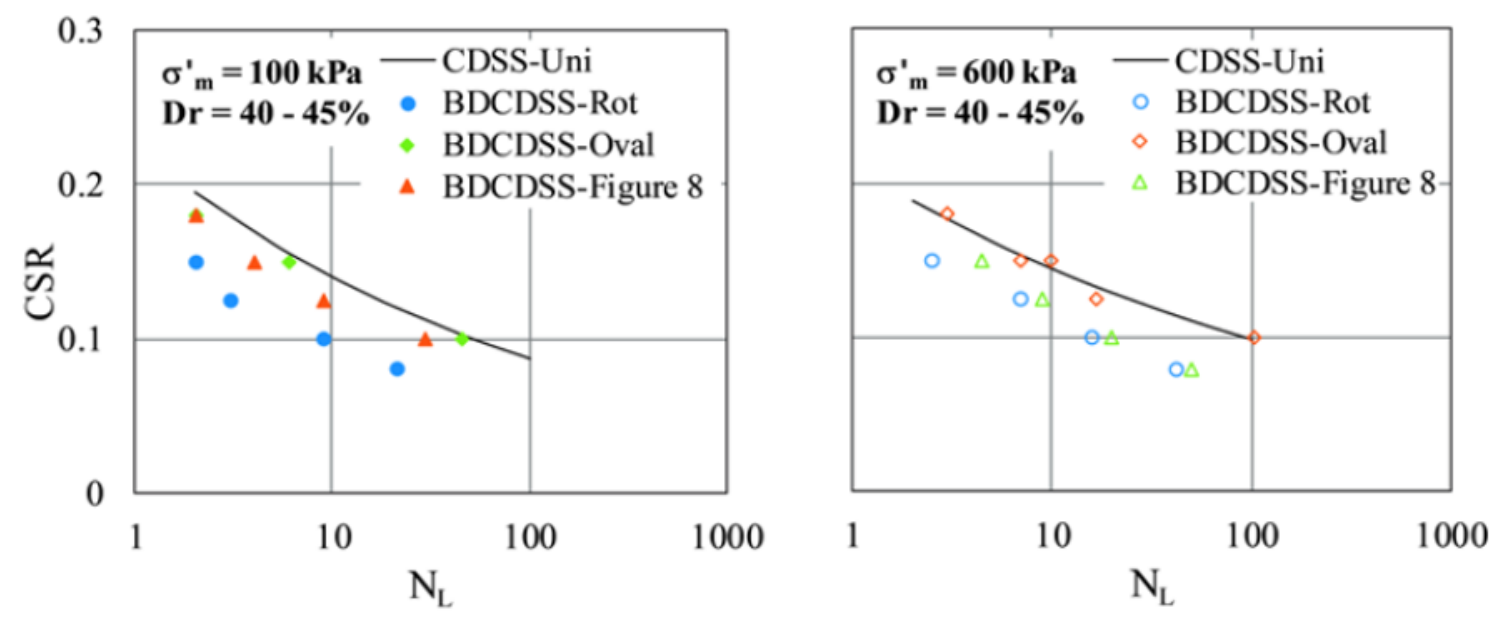

Figure 24. Comparison of Unidirectional and Multidirectional CDSS tests by Gokyer et al. (2019) 


\section{Zehtab et al. 2019}

Zehtab et al. (2019) investigated the influence of inadequate height control on monotonic and cyclic constant volume direct simple shear results. Tests were performed on the Shear Trac II provided by Geocomp Corporation with active control and vertical strains not extending 0.03\% during shear (undrained), inadequate passive control with vertical strains in the range of $0.03-0.05 \%$ (partially drained) and constant load tests (drained).

\begin{tabular}{c|c} 
Sand Type & Ottawa sand \\
\hline Sample preparation technique & dry air-pluviation \\
\hline Relative Densities & $40-45 \%$ \\
\hline Height control & active control \\
\hline Failure criterion & $r_{u}=1.0$ \\
\hline
\end{tabular}

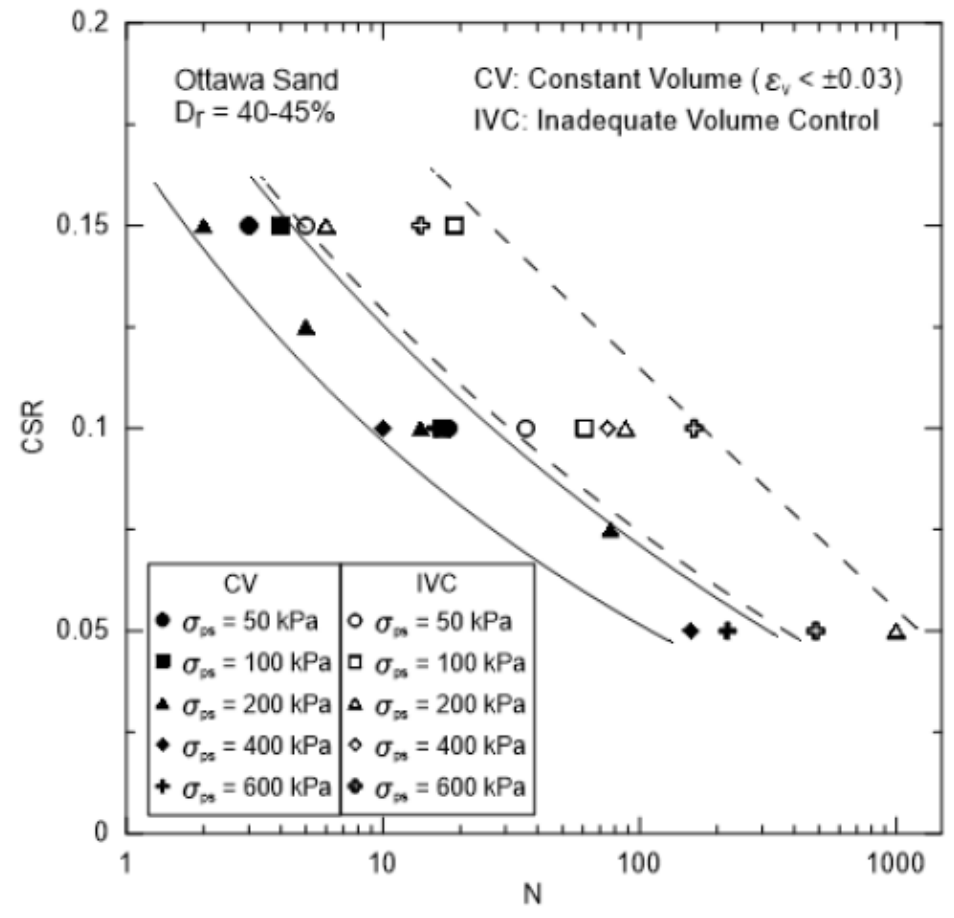

Figure 25. CSR or Ottawa sand for $r_{u}=1.0$ per $\mathrm{N}$ for different consolidation stresses under constant volume conditions $(\mathrm{CV})$ and inadequate volume control (IVC) by Zehtab et al. (2019) 


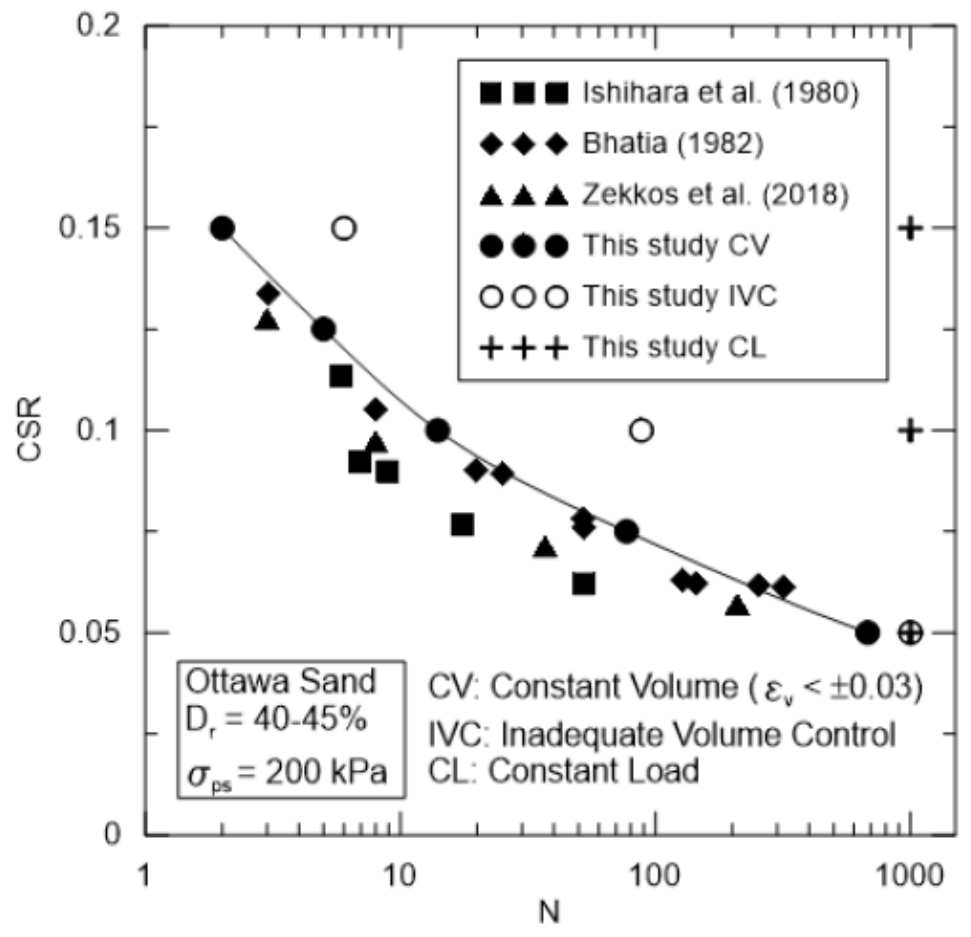

Figure 26. Comparison of cyclic behavior of Ottawa sand with results of Ishihara and Yamazaki (1980), Bhatia (1982) and Zekkos et al. (2018) by Zehtab et al. (2019) 


\section{CHAPTER 3}

\section{CDSS Testing Methodology}

In this study, unidirectional cyclic direct simple shear (cyclic DSS) tests were performed using the Shear Trac II device manufactured by the Geocomp Corporation. All tests were performed on the same device located at the Marine Geotechnics Laboratory on the Narragansett Bay Campus of the University of Rhode Island. Dry air-pluviated samples of Ottawa and Monterey Sand were used for all tests. Constant volume was maintained using an active control system. This chapter describes details about the testing equipment, properties of the soil tested, sample preparation and testing procedures.

\subsection{Testing Equipment}

Figures 27 and 28 show the cyclic direct simple shear apparatus used for this study.

Important features are labeled $\mathrm{A}$ through $\mathrm{M}$ and are described in more detail below.

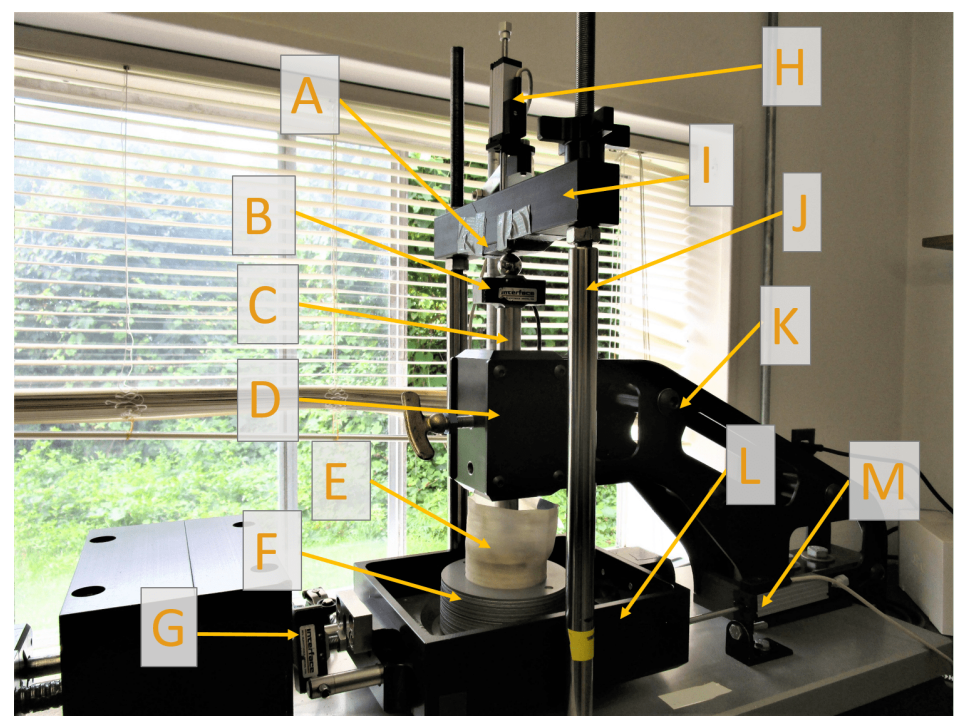

Figure 27. Test setup in the Shear Trac II with labeled components 


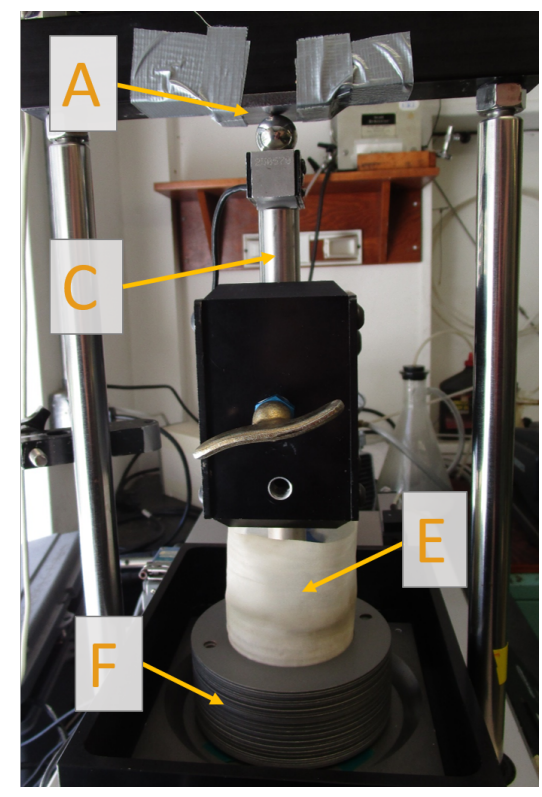

Figure 28. Sample in Shear Trac II with labeled components

(A) Pin connection for vertical load After pre-testing with various different load transfer methods it was decided to use a ball bearing - metal plate connection. This is a loose connection where the ball bearing sits in the dent of the screw hole on top of the load cell and provides a point load against the horizontal cross arm (I), thus preventing any moment development on the load cell.

(B) Vertical Load Cell - A SML 1000lb low-profile load cell was used because of its relatively low vertical stiffness.

(C) Loading piston with top cap - Loading piston and top cap are fixed to the bottom of the load cell. The piston and top cap were weighed and add approximately $3 \mathrm{kPa}$ vertical stress to the sample. Thus, a consolidation stress of e.g. $100 \mathrm{kPa}$ consists of $97 \mathrm{kPa}$ consolidation stress and $3 \mathrm{kPa}$ stress of the weight of the piston and top cap. 
(D) Loading piston bearings - The piston runs in the supporting side arm in two tight bearings (one at the top and one at the bottom within the side arm). The bearings are tight fitting but allow the piston from moving smoothly within them. However, piston rocking and or friction during cyclic shear testing likely still occurs.

(E) Sample in Flexible Membrane - Since the sample is confined by stacked Teflon-coated rings a flexible rubber membrane is used to keep the sand in place. The thickness of the membrane is subtracted from the measured inside diameter of the Teflon rings in order to get the sample diameter.

(F) Teflon Coated Rings - for this study 37 Teflon coated rings are used for lateral confinement. The rings slide easily with almost no friction.

(G) Horizontal load Cell - The horizontal load cell and the water bath are connected through a screw that needs to be tightened at all times during testing. For stress-controlled tests the amount of applied shear stress will be controlled by the horizontal load cell. To prevent the accumulation of horizontal shear stress during consolidation due to pushing down on the water bath it was decided to run the consolidation in stress controlled sate. This means that the shear stress during consolidation will be kept at zero by moving the water bath. This, however, results in shear strain induced in the sample during consolidation.

(H) Vertical Displacement Transducer - during pre-testing the measurement location of the vertical Linear Variable Displacement Transducer (LVDT) was moved from the horizontal cross arm down to the sample's top cap to minimize the influence of the component stiffnesses between cross arm and sample as much as possible. However, due to the fact that proper active 
height control was utilized, it was decided to move the vertical LVDT back to its original location on the horizontal cross arm to match the test setup of Zehtab et al. (2019)

(I) Horizontal Cross Arm - This cross arm is attached to the vertical loading rods and is used to apply a vertical stress to the sample.

(J) Loading Rods - the two vertical, parallel loading rods of the Shear Trac are controlled by the vertical motor and can be raised and lowered. During shear, the rod movement will be controlled by the active control system to keep a constant sample height.

(K) Side Support/Lateral Restraint Arm - This frame houses the vertical piston and provides lateral restraint to the top cap and vertical piston during horizontal cyclic loading. This component is critical for preventing rocking of the top cap during cyclic loading, which has been shown to significantly affect test results.

(L) Water Bath - Once prepared, samples are placed in the water bath. Despite the name, this container is rarely filled with water and instead serves the purpose of connecting the horizontal loading piston with the base of the sample. The water bath sits on four roller bearings to allow for low friction horizontal motion.

(M) Horizontal LVDT - horizontal displacement is measured by the horizontal displacement sensor attached to the water bath. 


\subsection{Properties of Soil Tested}

Two types of sand were tested: i) Monterey 0/30 sand and ii) Ottawa sand (Figure 29). Both of these sands have been tested extensively in the geotechnical literature. Monterey sand is the same sand used by Ulmer et al. (2019), and index properties determined by those authors were used for this study (Table 2). For the Ottawa sand, a sieve analysis was performed and the grain size distribution was compared to the Ottawa sand used by Zehtab et al. (2019) and Gokyer et al. (2019). The grain size distribution showed that the types of Ottawa sand used in the studies by Zehtab et al. (2019) and Gokyer et al. (2019) and Monterey sand used by Ulmer et al. (2019) were similar enough to the type used in this study to use their published values of minimum and maximum void ratios $\left(e_{m i n}\right.$ and $\left.e_{\max }\right)$ (Figures 30 and 31).

Tests on Ottawa sand were performed to directly compare data to results from Zehtab et al. (2019) from tests on Ottawa sand performed on the same shear device model. Once the device settings were set and the data showed similar results, the sand type was changed to Monterey sand. Monterey sand was chosen because it is widely tested for earthquake research purposes in the literature and an extensive database is available.

\begin{tabular}{c|c|c} 
& Monterey Sand & Ottawa Sand \\
\hline$G_{s}$ & 2.56 & 2.56 \\
\hline$e_{\min }$ & 0.562 (Ulmer et al. 2019) & 0.52 (Gokyer et al.2019) \\
\hline$e_{\max }$ & 0.827 (Ulmer et al. 2019) & 0.84 (Gokyer et al.2019) \\
\hline
\end{tabular}

Table 2. Index properties of Ottawa and Monterey sand 


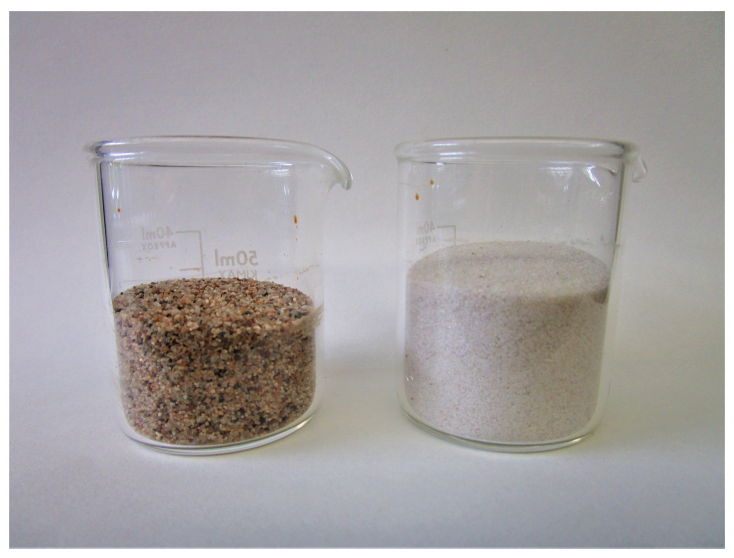

Figure 29. Tested sand types. Left: Monterey sand, Right: Ottawa sand
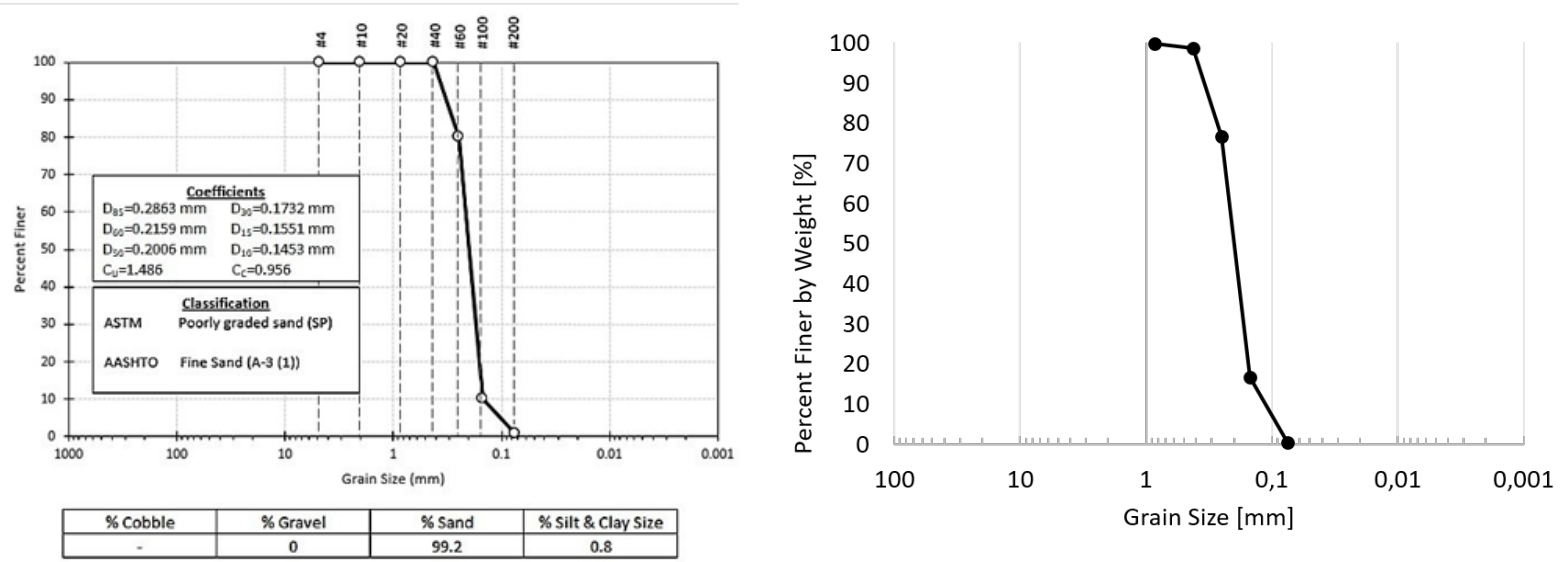

(a) Grain size distribution for Ottawa sand by (b) Grain size distribution for Ottawa sand conducted Gokyer et al. (2019) in this study

Figure 30. Grain size distributions Ottawa sand 

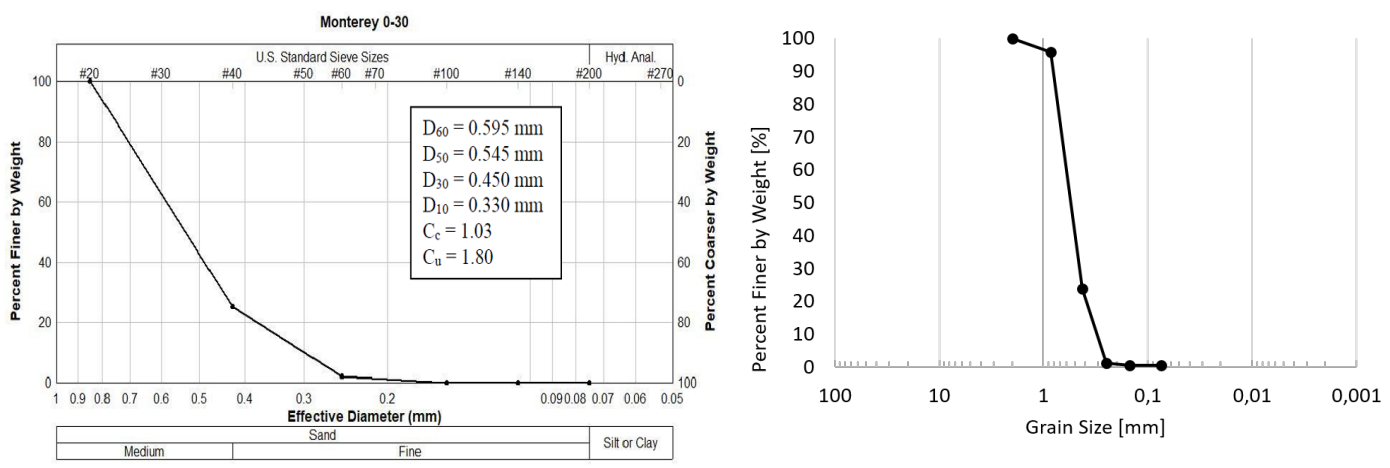

(a) Grain size distribution for Monterey sand by (b) Grain size distribution for Monterey Ulmer et al. (2020) sand conducted in this study

Figure 31. Grain size distributions Monterey sand

\subsection{Sample Preparation and Testing Procedure}

Sample Preparation

Tests were performed on samples of Ottawa Sand and Monterey Sand prepared to a relative density of $40 \% \pm 1 \%$. Relative Density (Dr) is defined as:

$$
D_{r}=\frac{e_{\max }-e}{e_{\max }-e_{\min }} \cdot 100[\%]
$$

where $e_{\min }$ and $e_{\max }$ are the minimum and maximum void ratios (ASTM D4253) and e is the void ratio of the sample.

All samples were prepared outside the Shear Track in the water bath, which was then carefully placed back in the Shear Trac. All samples were prepared by dry pluviation, in which sand was poured through a funnel from a fixed height in a consistent manner to achieve the target relative density. For denser samples, the 
base of the water bath was tapped with a hammer to densify the sample until the target height (and relative density) is achieved. A detailed description of the sample preparation technique and the test setup can be found in the Appendix A.

\section{Testing Procedure}

All tests were performed on the Shear Trac II developed and manufactured by the Geocomp Corporation. All components of the system were carefully leveled, aligned and cleaned to prevent any imperfections in load transfer. Of particular importance was alignment of the sample top cap and vertical load piston with the horizontal cross arm. The weight of the loading piston and top cap was determined to be $1005.34 \mathrm{~g}$ which corresponds to a stress of $3.08 \mathrm{kPa}$ on the sample area of $0.00319 \mathrm{~m}^{2}$ (sample diameter of $63.5 \mathrm{~mm}$ ). Since the loading piston is resting on the sample at all times during testing the sample can not be unloaded completely. The consolidation as adjusted to $97 \mathrm{kPa}$ in order to meet $100 \mathrm{kPa}$ in summary (adjustments were also made at the consolidation stresses of $200 \mathrm{kPa}$ and $300 \mathrm{kPa}$, respectively.). All samples were loaded by a uniform, symmetrical distributed shear stress with a loading rate of 20 s per loading cycle (e.g. with a CSR of 1.0 and a consolidation stress of $100 \mathrm{kPa}$ the shear stress amplitude would be $\pm 10 \mathrm{kPa}$ with a frequency of $\left.0.05 \frac{1}{s}\right)$. Note that the frequency of loading does not affect the liquefaction properties of a soil under undrained testing conditions. A detailed description of the test setup can be found in the Appendix A.

Gain adjustment for Proportional-Integral-Derivative (PID) Control Settings According to Geocomp Corporation the control software needs to be adjusted regarding the soil type and soil density tested. These adjustments can be made by different gains in the DIAGS and the CDSS software. A detailed description 
of all the DIAGS and CDSS options can be found in the Appendix B, however a screenshot of the DIAGS software for inputting the load control settings is shown in Figure 32.

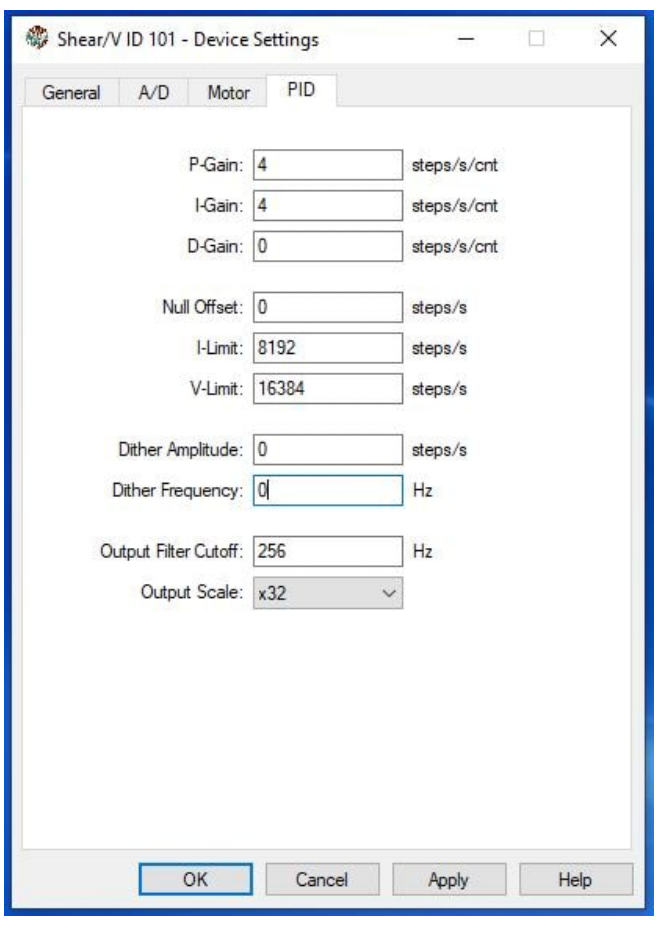

Figure 32. Gain settings in the DIAGS software

The PID setting contains the Proportional gain (P-Gain), the Integral gain (I-Gain) and the Derivative gain (D-Gain). All gains interact with each other and with the Desired Response Gain and the Constant Volume Gain in the CDSS software. Thus, according to Geocomp the settings need to be tuned experimentally for a given soil/density/stress conditions. In order to do that the first setting was set to PID $=1,4,0(\mathrm{P}$-Gain $=1$, I-Gain $=4$ and D-Gain $=0)$. The Desired Response Gain (DRG) was set to 5 and the Constant Volume Gain (CVG) to 1 . Several tests were performed on the same sample, at a low CSR so as not to fail the sample, while increasing the P-Gain with each new test until 
the axial strain during shear didn't exceed the recommended value of $\pm 0.03 \%$. Once the height control was considered as adequate, the Constant Volume Gain was decreased to a value of 0.5 and 0.1 , respectively. This procedure was followed to achieve 1) good height control with an axial strain not exceeding $\pm 0.03 \%, 2$ ) non-saturation of the Desired Response Gain during the first cycle of loading (Figure 33), and 3) symmetrical stress and strain graphs (i.e. ideally no shift in, for example, the strain curve or the axial strain curve). Once adequate settings were found, tests were run on individual samples at different cyclic stress ratios.

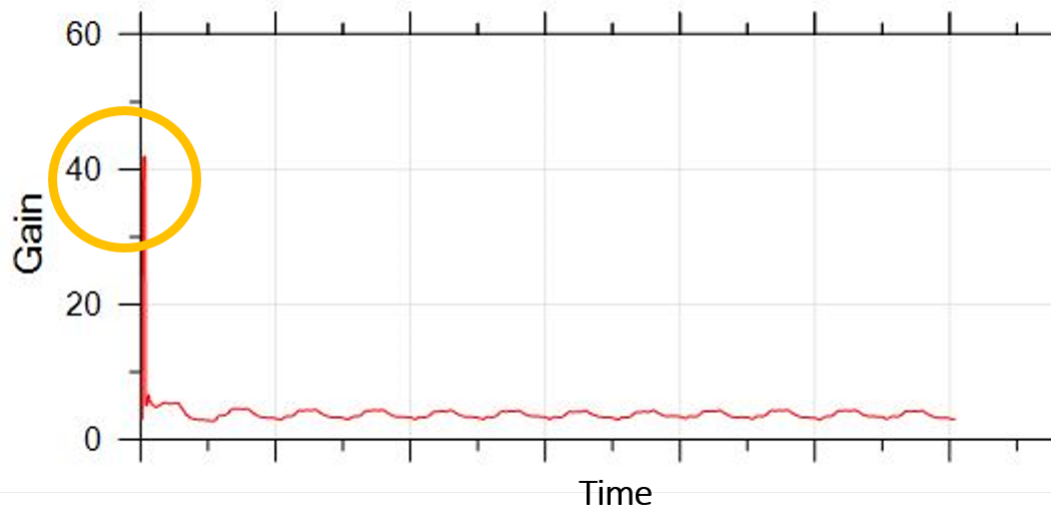

Figure 33. Example of gain saturation extracted from the CDSS software report

It is important to note that this process of gain adjustment is non-standard and was determined by trial-and-error and through communication with Geocomp personnel. In addition, there is potentially not a unique or singular set of values that could yield proper height control. 


\section{CHAPTER 4}

\section{CDSS Testing Results and Discussion}

This chapter presents the results of all tests performed as part of this thesis on samples of Ottawa and Monterey sand prepared to a relative density of $D_{r}=40 \% \pm 1 \%$. The objective of this testing program was to evaluate sample quality in cyclic simple shear testing, with a focus on 1) axial strain during cyclic shear, 2) shear strain development during consolidation and 3) the effect of consolidation stress on cyclic shear strength. Each of these factors will be discussed in more detail.

Table 3 presents a summary of the test results. $D_{r, \text { initial }}$ is the relative density after sample preparation and $D_{r, \text { final }}$ is the relative density after 10 minutes of consolidation at an effective consolidation stresses of $100 \mathrm{kPa}, 200 \mathrm{kPa}$ or 300 $\mathrm{kPa}$. Tests with a star symbol $(*)$ indicate that the direct simple shear device software had issues transitioning from consolidation into shear phase. These tests were aborted and restarted without re-consolidating the sample because the vertical stress was maintained on the sample during the software issue. However, for these tests the consolidation phase of the first test was overwritten by the re-started test, no information about shear strain development during consolidation was recorded. Plots of all the test results are included in Appendix C. 


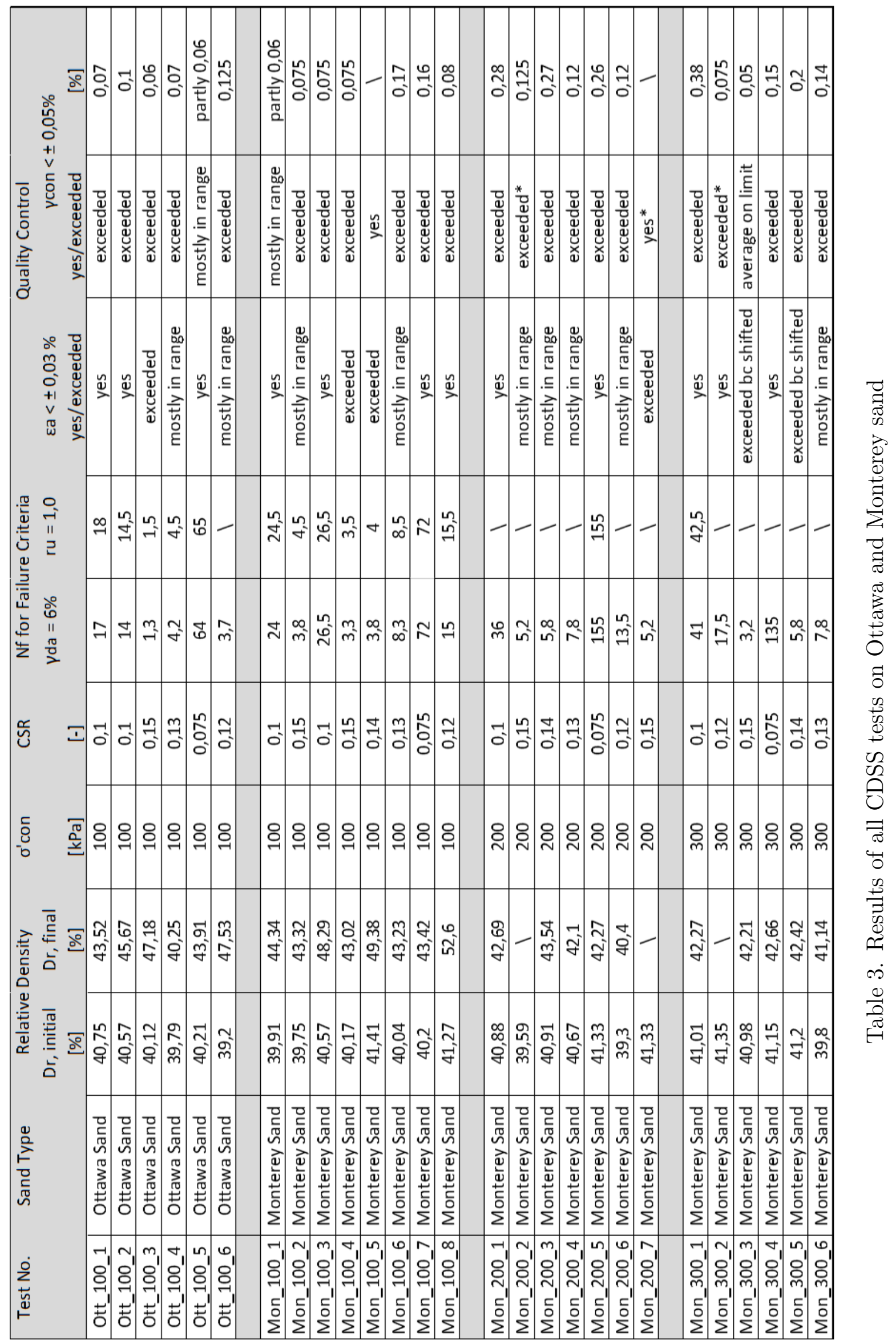




\subsection{Test Results on Ottawa Sand}

All tests on Ottawa sand were performed with the following test parameters exhibited in table 4:

\begin{tabular}{c|c} 
Sand Type & Ottawa sand \\
\hline$D_{r, \text { initial }}$ (after preparation) & $39-41 \%$ \\
$\sigma_{v 0}^{\prime}$ & $100 \mathrm{kPa}$ \\
Stress induced by piston $(3 \mathrm{kPa})$ & Not included in consolidation stress \\
Horizontal stress control during consolidation & stress control (zero stress)
\end{tabular}

Table 4. Test parameters for tests conducted on Ottawa sand

Figure 34 shows plots of shear stress $(\tau)$, shear strain $(\gamma)$ and pore pressure ratio $\left(r_{u}\right)$ versus the number of cycles of loading $(\mathrm{N})$. The chosen failure criteria is a double strain amplitude of $6 \%$ which is indicated by the red dashed lines in the shear strain vs $\mathrm{N}$ plot. A double shear strain amplitude of $6 \%$ was chosen as the failure criterion for liquefaction over the single shear strain amplitude of 3\% because the shear strain is not always increasing symmetrically. Occasionally the shear strain graph is shifted or biased in the positive strain direction. Another failure criteria noted in the excess pore pressure ratio figure is $r_{u}=1.0$, which is the point of initial liquefaction by definition. In most tests the number of cycles to failure was approximately equal using both failure criteria, and the double amplitude strain was determined to yield slightly more consistent results. Also, because the loading piston plus top cap weight was resting on the sample at all times (adding approximately a stress of $3 \mathrm{kPa}$ ) it was physically impossible to completely unload the sample.

Figure 35 shows plots of the axial strain development during shear vs. number of cycles for a test on Ottawa sand consolidated to $100 \mathrm{kPa}$ and sheared with a 

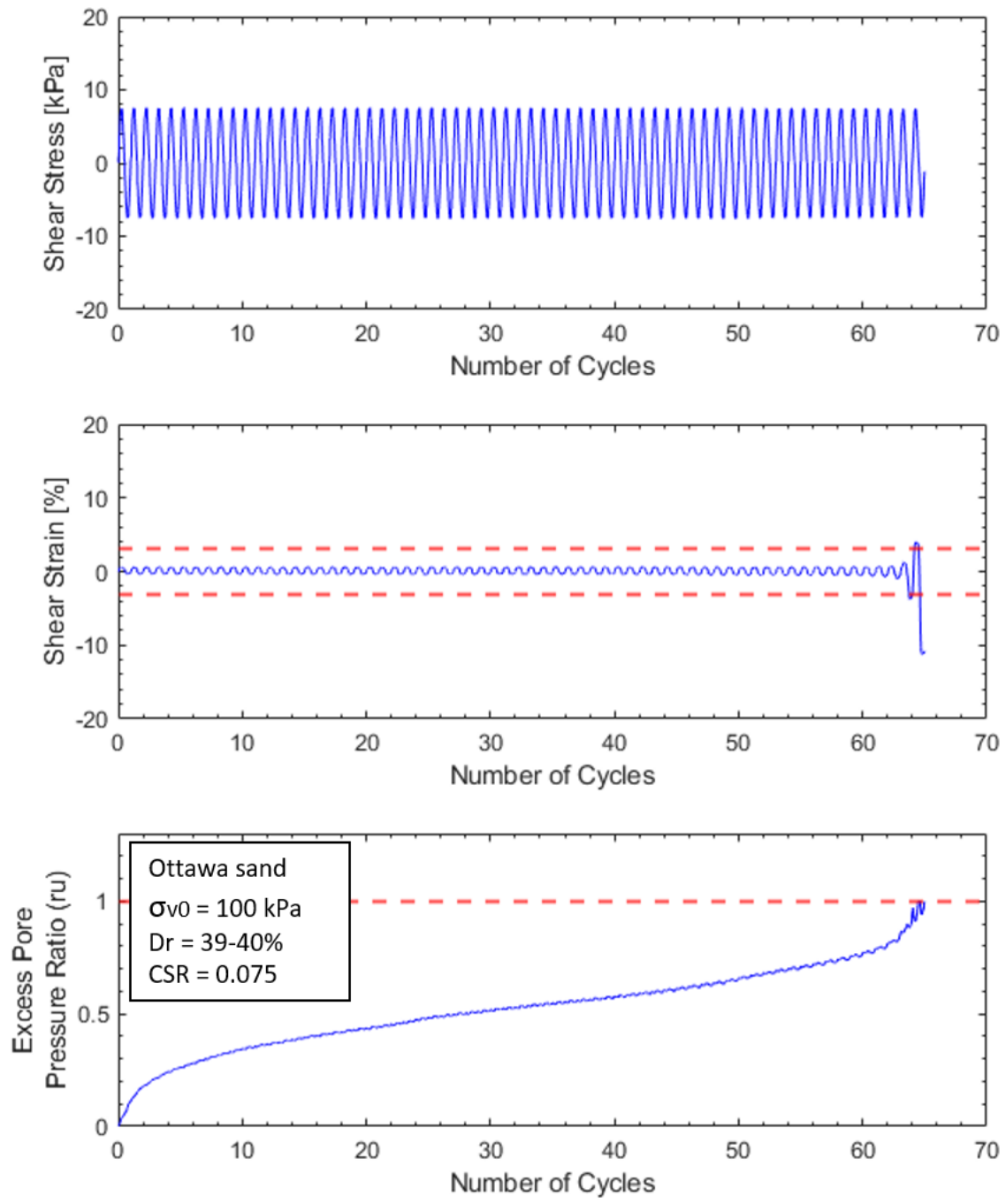

Figure 34. Shear stress, shear strain and excess pore pressure ratio versus number of cycles $(\mathrm{N})$ for tests on Ottawa sand at $\sigma_{v 0}^{\prime}=100 \mathrm{kPa}, D_{r}=39-41 \%$ and $\mathrm{CSR}=0.075$. The red dashed line indicates the used failure criteria (Testnumber: Ott_100_5) 
CSR of 0.075 (Ott_100_5). The top plot again shows the shear strain development during shear phase and the middle and lower figure show the axial strain during shear. It is clear that the axial strain is within $\pm 0.03 \%$ up to the onset of strain softening around cycle 62, and at this point the axial strain exceeds the recommended limit. However, according to Ulmer et al. (2019), exceeding the axial strain limit after initial liquefaction should not affect the numbers of cycles to failure. The second and third plots both show the axial strain development during shear phase, in which the third plot is an enlargement of the second plot.

The red dashed lines in the axial strain plots indicate the axial strain limits of $\pm 0.03 \%$ as recommended by Zehtab et al. (2019). The grey dashed lines indicate the limit of $\pm 0.05 \%$ axial strain as recommended by ASTM for monotonic DSS tests. In this test and most of the other tests the axial strain during shear was not exceeded, which means that the active control system maintained a good height control of the sample and therefore ensured constant volume conditions. This was a significant achievement for this project considering that several previous studies at URI were unable to achieve constant volume conditions during CDSS testing (Baxter, personal communication).

Figure 36 shows the stress-strain hysteresis loops and the stress path for the same test. In the stress path the same issue of more pointed cycles in one shear direction and more rounded cycles in the other shear direction previously described by Ulmer et al. (2019) can be observed. It is not yet clear where this deformation is coming from. This issue was only observed in some stress paths. 

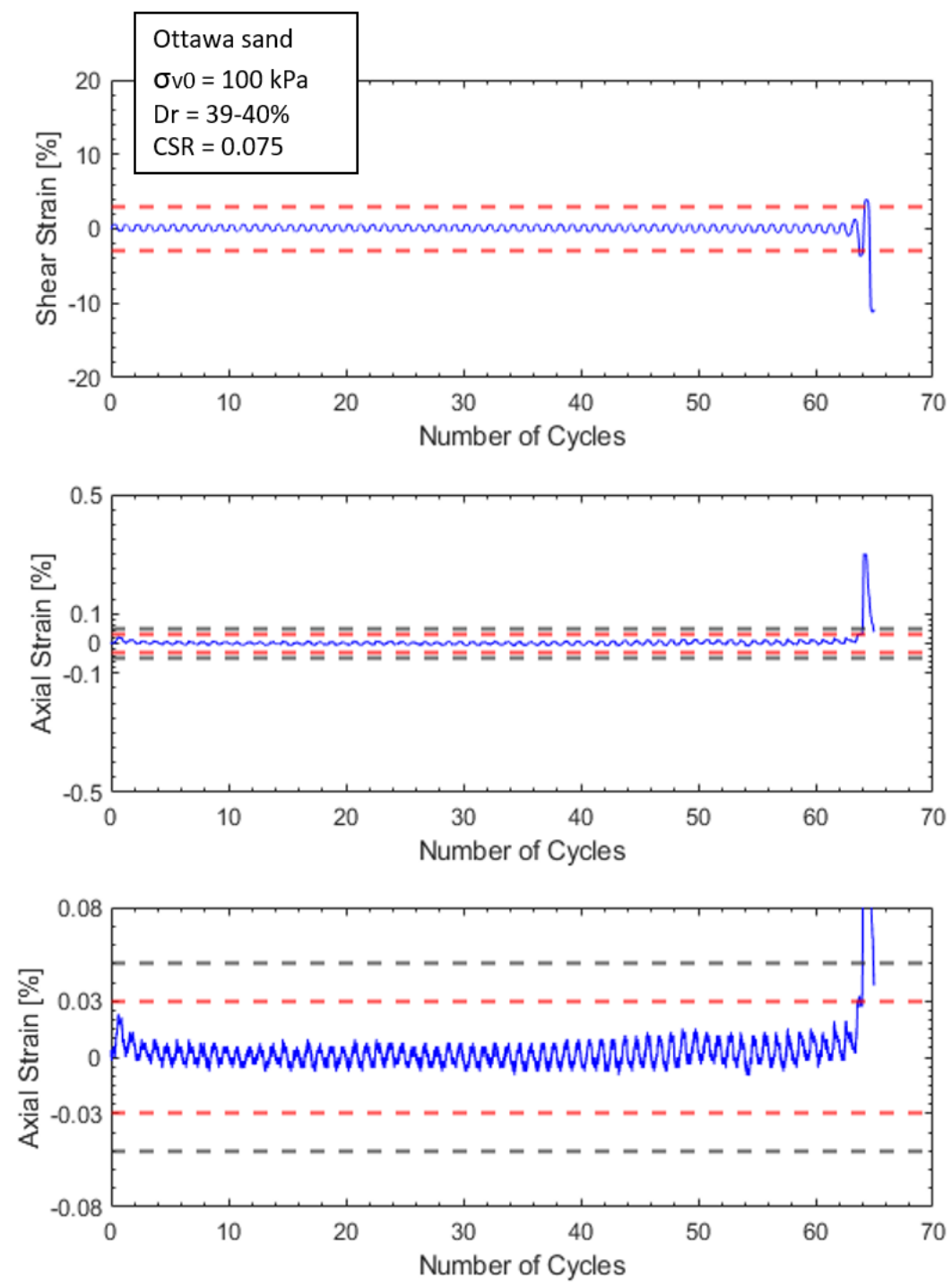

Figure 35. Shear strain and axial strain versus number of cycles (N) for tests on Ottawa sand at $\sigma_{v 0}^{\prime}=100 \mathrm{kPa}, D_{r}=39-41 \%$ and $\mathrm{CSR}=0.075$. Note that the third plot of axial strain vs $\mathrm{N}$ shows a zoom in of the second axial strain vs $\mathrm{N}$ plot. The red dashed line indicates the axial strain limit of $\pm 0.03 \%$ (recommended by Zehtab et al. 2019), the grey dashed line the limit of $\pm 0.05 \%$ (recommended by ASTM for monotonic DSS tests),(Testnumber: Ott_100_5) 

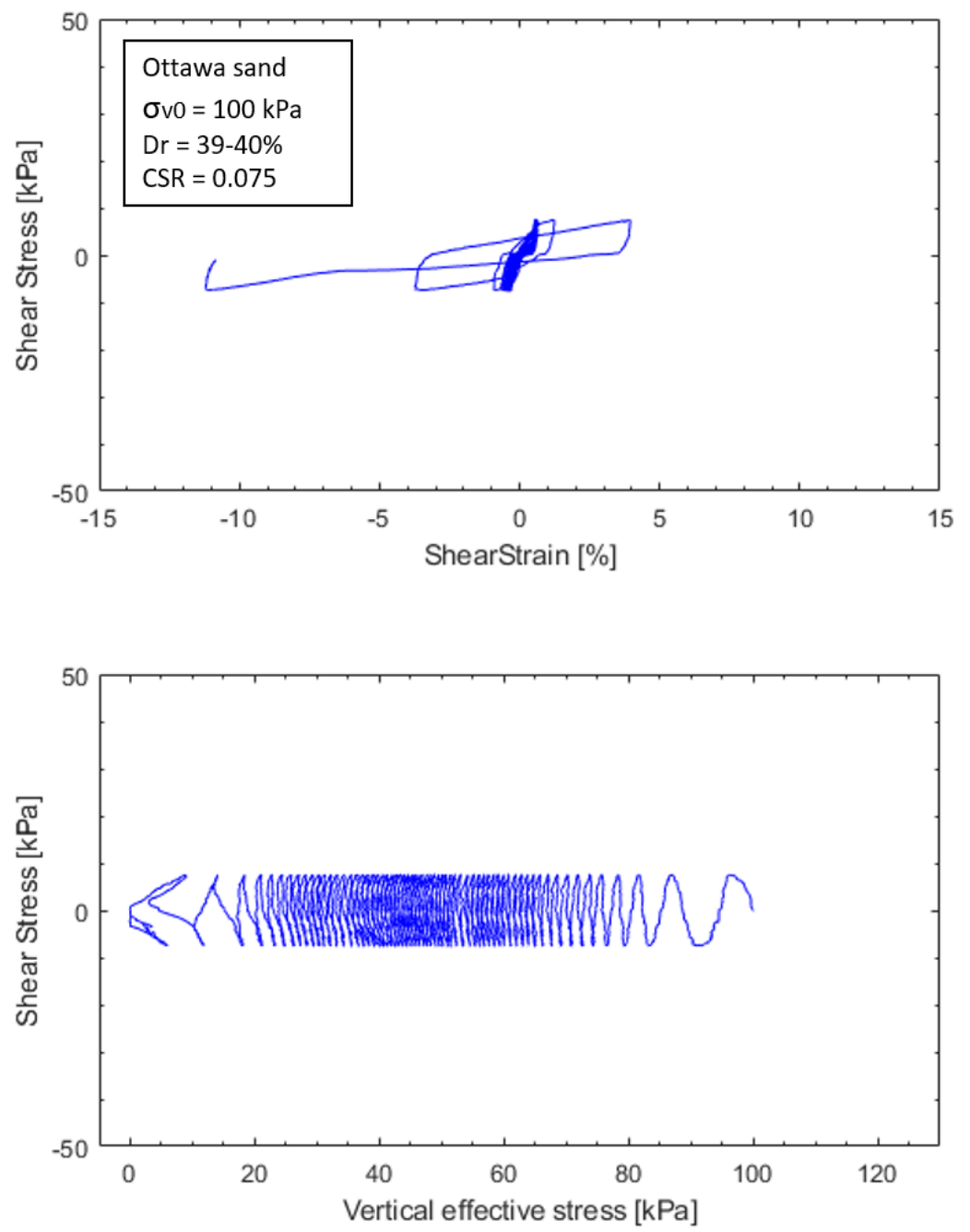

Figure 36. Stress-strain hysteresis loops and stress path for tests on Ottawa sand at $\sigma_{v 0}^{\prime}=100 \mathrm{kPa}, D_{r}=39-41 \%$ and CSR $=0.075$ (Testnumber: Ott_100_5) 
The last figure, Figure 37 shows the shear stress and shear strain development during consolidation phase. The machine settings were set to stress control during consolidation phase which means that the water bath will be moved to keep zero horizontal stress on the sample. However, this water bath movement induces a shear strain which should not exceed $\pm 0.05 \%$ as according to Ulmer et al. (2019). The problem with the stress control settings in the consolidation table of the CDSS software is that there are only settings "none" for no control and "stress" for keeping the shear stress at zero during consolidation. The first setting ("none") induces a large shear stress on the sample before the shear phase begins and it was decided early in the study that it would be better to maintain zero horizontal stress during consolidation. It is not yet clear whether or not this has any effect on the results. The other setting ("stress") will keep the shear stress at zero throughout the consolidation phase but induces a shear strain which pre-strains the sample and potentially affects results. The second plot of Figure 37 shows the shear strain development with the red dashed lines indicating the recommended shear strain limits of $\pm 0.05 \%$ recommended by Ulmer et al. (2019). This test is the only one that only partly exceeds the limit. All the other tests exceed the limit by far (see plots in Appendix C and Table 3).

CDSS tests on Ottawa sand were performed to be able to directly compare the results to data by Zehtab et al. (2019), which were performed on the same model of cyclic direct simple shear device. Significant trial-and-error was employed in adjusting the control settings (PID) to try to achieve constant volume conditions during shear. Figure 38 shows a plot of CSR versus number of cycles to failure for the data from this study and that of Zehtab et al. (2019), Bhatia (1982) and 

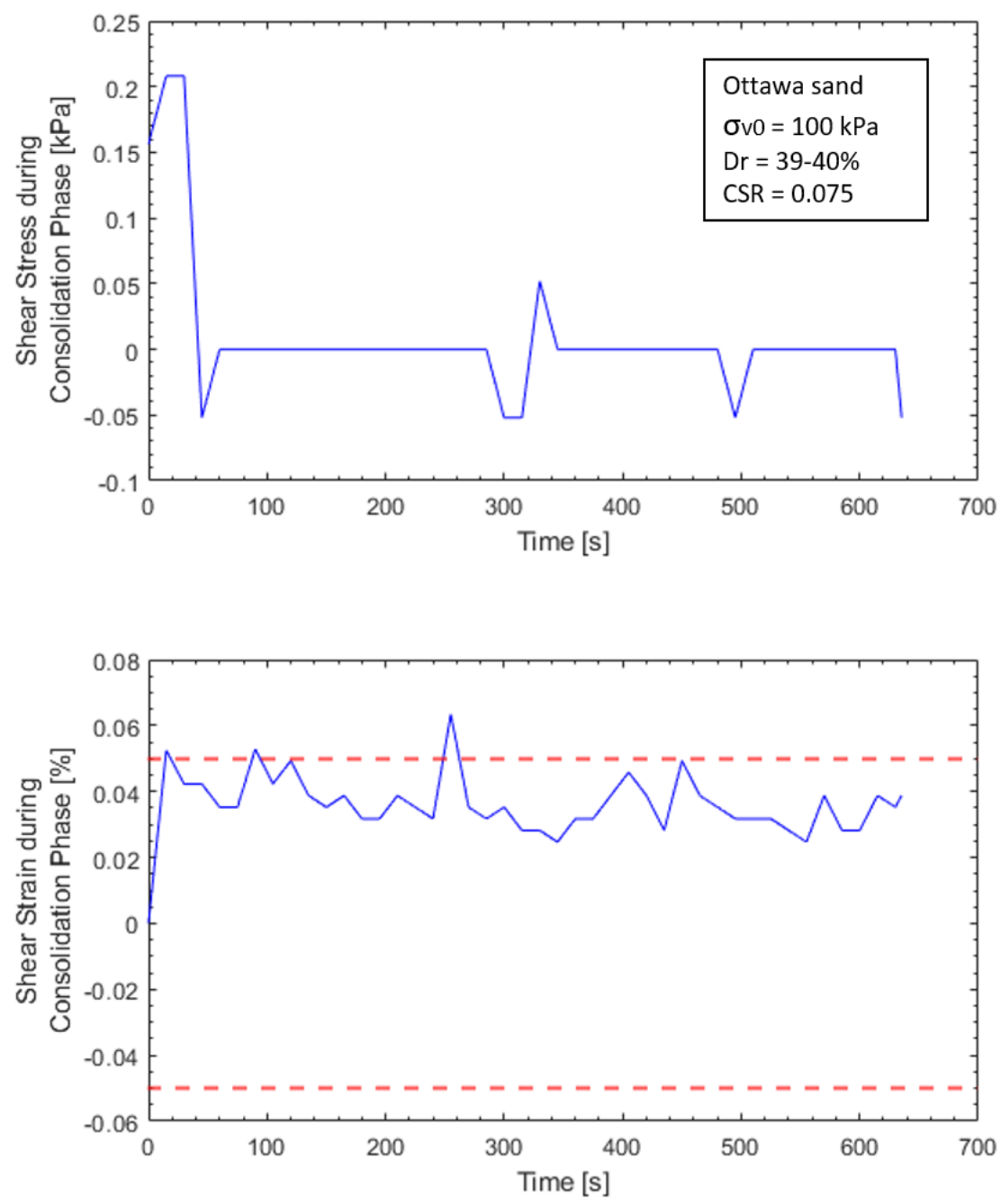

Figure 37. Shear stress and shear strain development during consolidation phase versus time for tests on Ottawa sand at $\sigma_{v 0}^{\prime}=100 \mathrm{kPa}, D_{r}=39-41 \%$ and CSR $=$ 0.075. Red dashed lines indicate the shear strain limits for consolidation phase of $\pm 0.05 \%$ (recommended by Ulmer et al. 2019). Note that the consolidation settings were set to "stress control" meaning that the Shear Trac keeps zero shear stress during consolidation phase by moving the water bath (Testnumber: Ott_100_5) 
Zekkos et al. (2019). Included in the plot are data from Zehtab et al. (2019) with both good and bad height control to show how that affects the cyclic results. Tests performed by Zehtab et al. (2019), Bhatia (1982), Zekkos et al. (2019) and this study were all conducted on Ottawa sand samples prepared by air-pluviation and tapping the sample for further densification to reach the desired relative density. Test data from the literature was conducted under an effective consolidation stress of $\sigma_{v 0}=200 \mathrm{kPa}$ and data from this study was conducted under an effective consolidation stress of $100 \mathrm{kPa}$. It is important to mention that tests performed under different consolidation stresses are not necessarily comparable because of the effective stress effect. Figure 4 in Chapter 2 shows that the overburden correction factor for air-pluviated samples under effective consolidation stresses of $100 \mathrm{kPa}$ and $200 \mathrm{kPa}$ ranges between 0.8 and 1.0 and can therefore be neglected in this case.

There are several important findings from this comparison. First, there is a significant shift in the CSR- $N_{f}$ curve to the right when proper height control is not achieved. This is shown both with the data from this study and results from Zehtab et al. (2019) when they purposely relaxed height control settings. Such a shift would suggest an artificially higher cyclic resistance, which would be unconservative if this data were used for estimating the cyclic resistance to loading. The second finding is that when adequate height control is achieved, there is good agreement with both recent test results on the sample equipment (Zehtab et al. 2019) and high quality data from the literature (Zekkos et al. 2019; Bhatia 1982). 


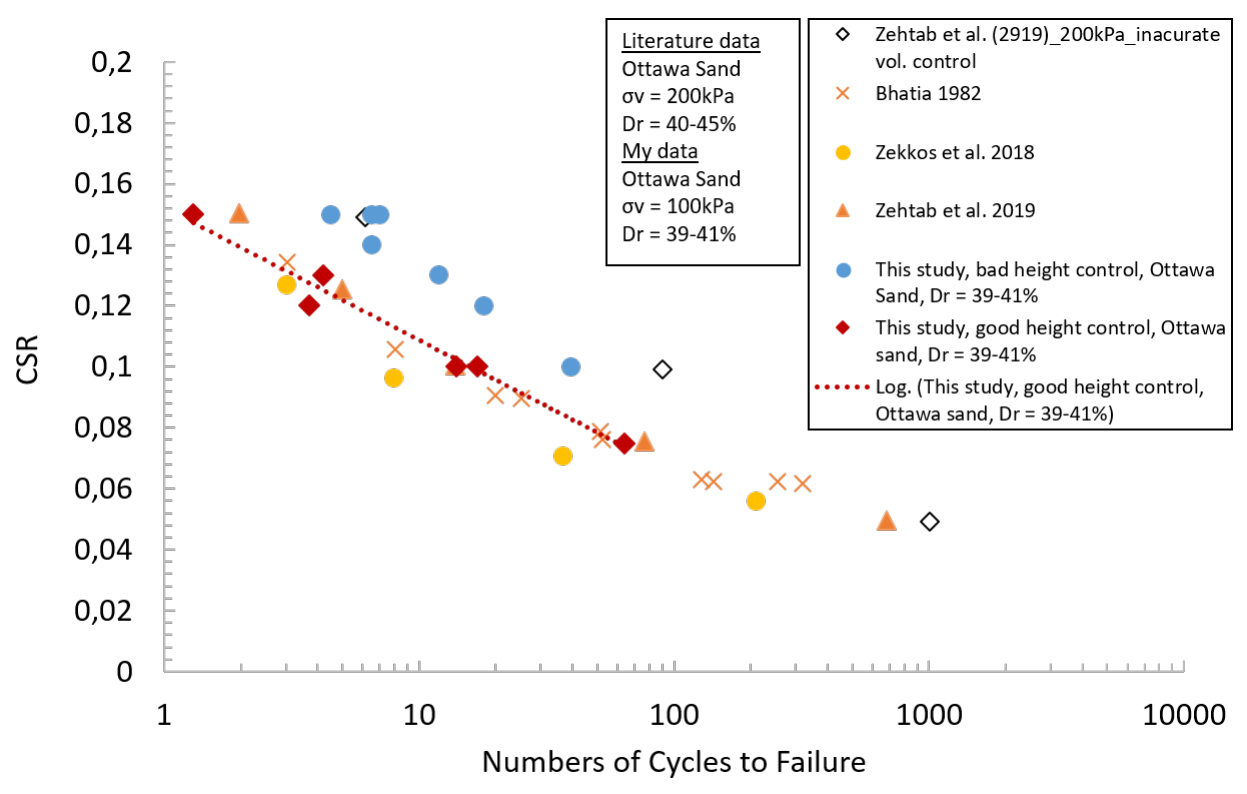

Figure 38. Comparison of CSR versus number of cycles to failure for CDSS tests on Ottawa sand. Data with good and with bad height control from this study and from Zehtab et al. (2019) are included. 


\subsection{Test Results on Monterey Sand}

CDSS tests were performed on samples of Monterey sand prepared to an initial relative density of $39-41 \%$ and consolidated to one of three vertical effective stresses: $100 \mathrm{kPa}, 200 \mathrm{kPa}$ and $300 \mathrm{kPa}$. Details of the test setup are shown in Table 5:

\begin{tabular}{c|c} 
Sand Type & Monterey sand \\
\hline$D_{r, \text { initial }}$ (after preparation) & $39-41 \%$ \\
$\sigma_{v 0}^{\prime}$ & 100,200 and $300 \mathrm{kPa}$ \\
Stress induced by piston $(3 \mathrm{kPa})$ & $\begin{array}{c}\text { Included in consolidation stress } \\
\text { stress control (zero stress) }\end{array}$
\end{tabular}

Table 5. Test parameters for tests conducted on Monterey sand

Figures 39 and 40 show plots of shear stress, shear strain, excess pore pressure ratio and axial strain development versus number of cycles (N) (Mon_100_1). Furthermore, Figure 41 shows the stress-strain hysteresis loops and the stress path and Figure 42 shows the shear stress and shear strain development during consolidation phase. This test is the only test on Monterey Sand that came close to meeting the $\pm 0.05 \%$ shear strain during consolidation criterion. All other tests on Monterey sand exceed this limit by far. Further, the stress path distortion of more pointed and more rounded cycles in the positive and negative direction can be observed in some tests. 

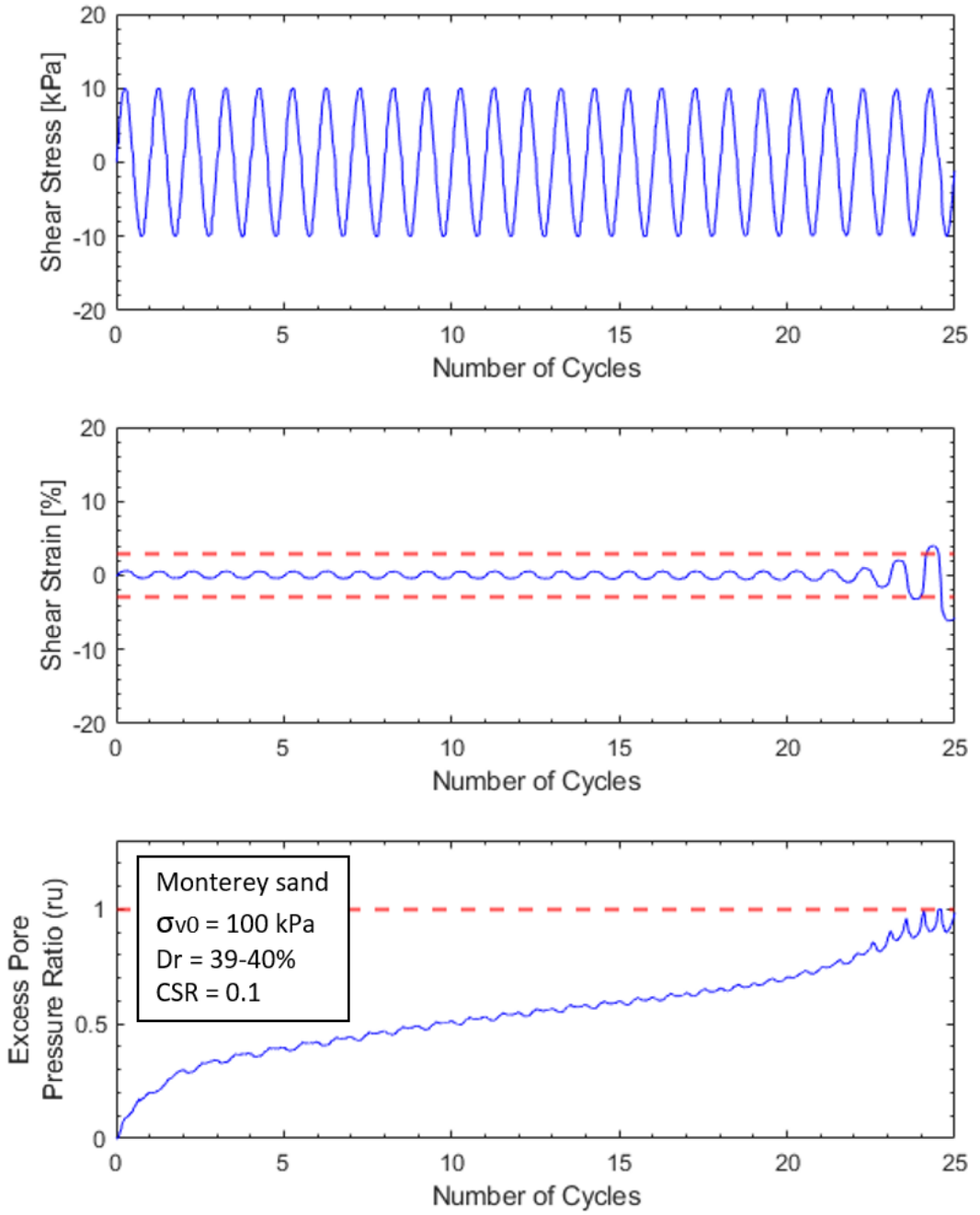

Figure 39. Shear stress, shear strain and excess pore pressure ratio versus number of cycles (N) for tests on Monterey sand at $\sigma_{v 0}^{\prime}=100 \mathrm{kPa}, D_{r}=39-41 \%$ and $\mathrm{CSR}=0.1$. The red dashed line indicates the used failure criteria (Mon_100_1) 

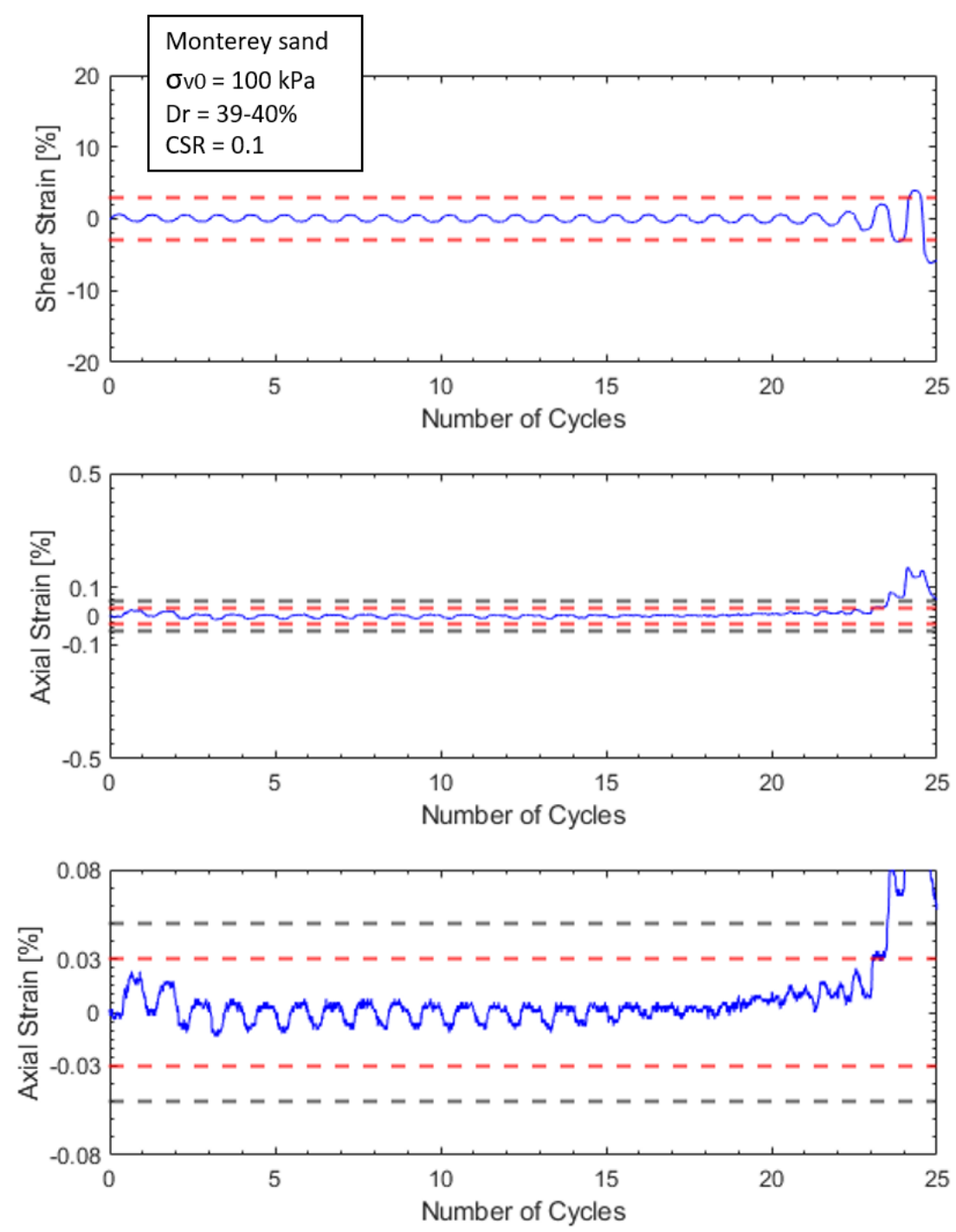

Figure 40. Shear strain and axial strain versus number of cycles $(\mathrm{N})$ for tests on Monterey sand at $\sigma_{v 0}^{\prime}=100 \mathrm{kPa}, D_{r}=39-41 \%$ and $\mathrm{CSR}=0.1$. Note that the third plot of axial strain vs $\mathrm{N}$ shows a zoom in of the second axial strain vs $\mathrm{N}$ plot. The red dashed line indicates the axial strain limit of $\pm 0.03 \%$ (recommended by Zehtab et al. 2019), the grey dashed line the limit of $\pm 0.05 \%$ (recommended by ASTM for monotonic DSS tests), (Mon_100_1) 

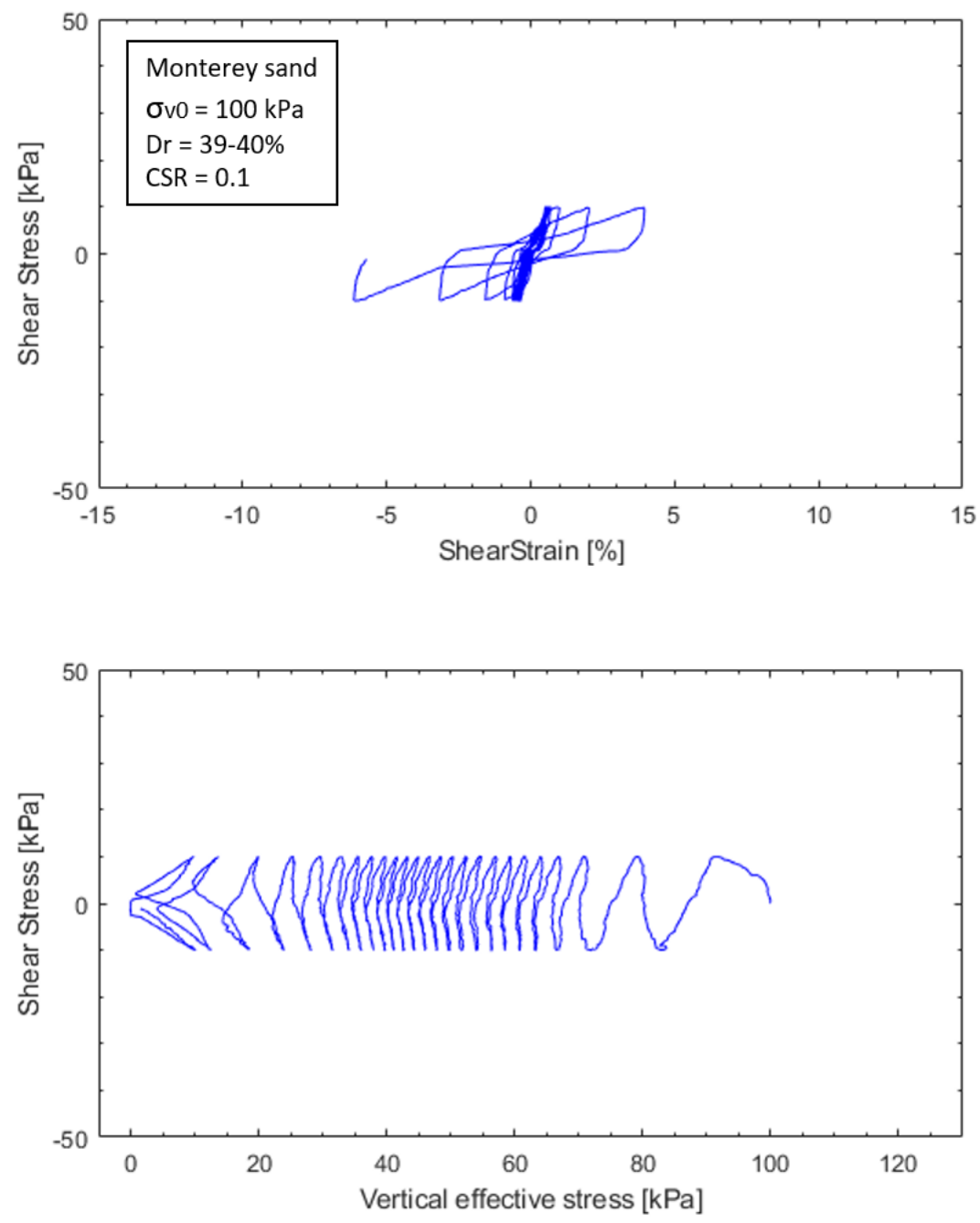

Figure 41. Stress-strain hysteresis loops and stress path for tests on Monterey sand at $\sigma_{v 0}^{\prime}=100 \mathrm{kPa}, D_{r}=39-41 \%$ and CSR $=0.1$ (Mon_100_1) 

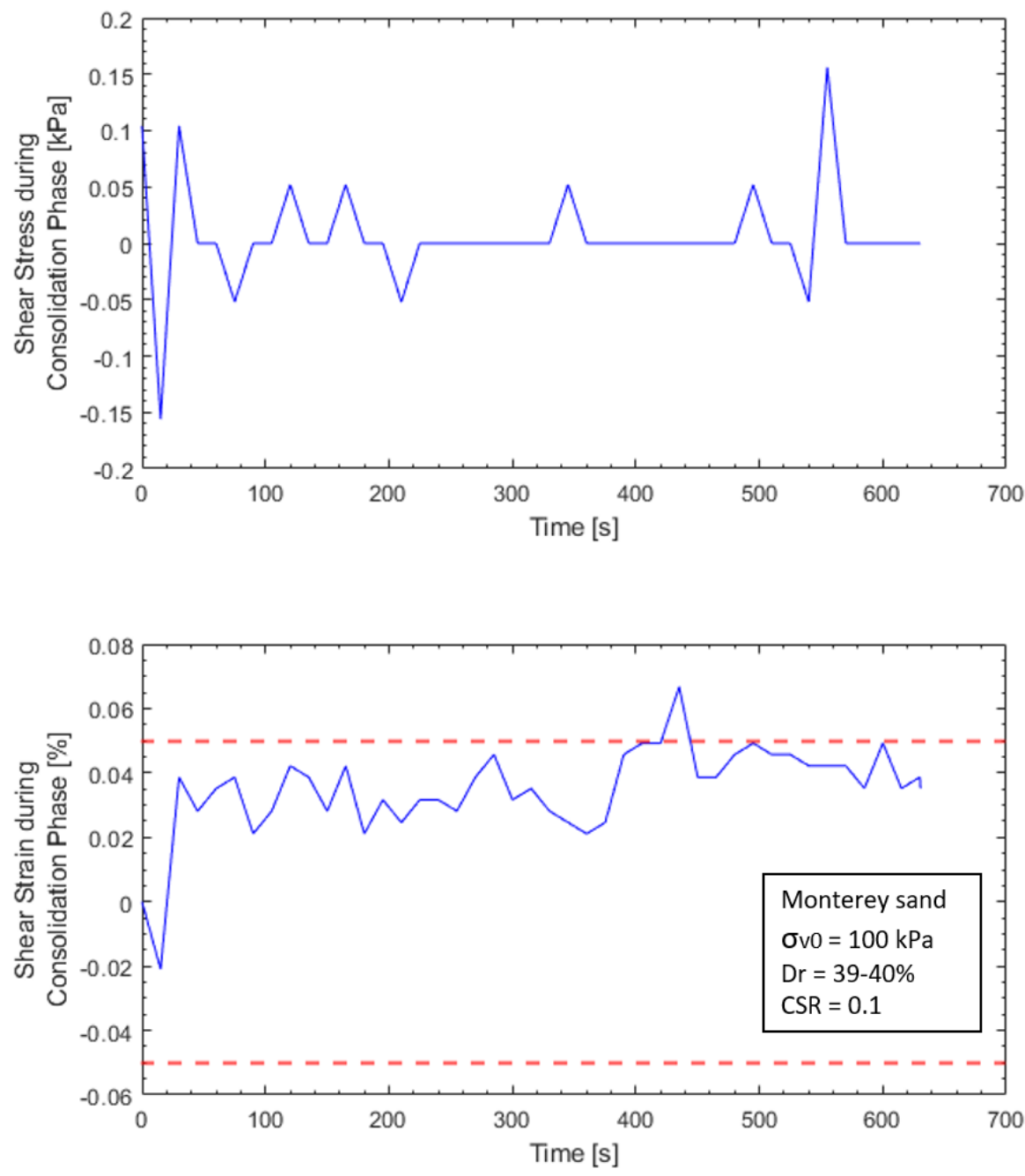

Figure 42. Shear stress and shear strain development during consolidation phase versus time for tests on Monterey sand at $\sigma_{v 0}^{\prime}=100 \mathrm{kPa}, D_{r}=39-41 \%$ and CSR $=0.1$. Red dashed lines indicate the shear strain limits for consolidation phase of $\pm 0.05 \%$ (recommended by Ulmer et al. 2019). Note that the consolidation settings were set to "stress control" meaning that the Shear Trac keeps zero shear stress during consolidation phase by moving the water bath (Mon_100_1) 
Figure 43 shows the CSR versus $N_{f}$ data for all the tests performed on samples of Monterey sand in this study. Within each stress grouping (100 - $300 \mathrm{kPa})$, the agreement of the data is excellent as shown by the linear relationship in the CSR-log N space. The $100 \mathrm{kPa}$ data showed lower cyclic strengths than the 200 and $300 \mathrm{kPa}$ data, which were approximately equal.

Despite the internal consistency for each effective stress, the increase in cyclic resistance with increasing consolidation stress is counter to published results that show the cyclic resistance ratio decreases with increasing stress ( $K_{\sigma}$ approach). If cyclic strength can be normalized, theory suggests that tests performed at the same relative density and same CSR but different effective consolidation stresses should lay on the same curve because the CSR is dimensionless. However, this is not the case. Tests confined by higher consolidation stresses show less resistance to cyclic loading and therefore should appear at lower $N_{f}$ than tests confined by lower consolidation stresses. In Figures 43 and 44 it can clearly be seen that tests confined at higher effective consolidation stresses show higher cyclic resistance. Compared to data from Zehtab et al. (2019) which were conducted on the same shear device it appears that their data (for the same CSR and same CSR but different confining stress) partly shifts in the wrong direction as well (see Figure 5). All samples from both studies (this study and the study by Zehtab et al. (2019) were prepared by air pluviation of dry sand to a relative density of 40-45\%. These facts suggest that there are still issues with the Shear Trac II shear device that are not fully resolved yet. Possible causes could be excessive densification of the sand during consolidation, stress dependent friction of the bearings beneath the water bath, or piston rocking at different degrees for different consolidation 
stresses. Each of these will be discussed below.

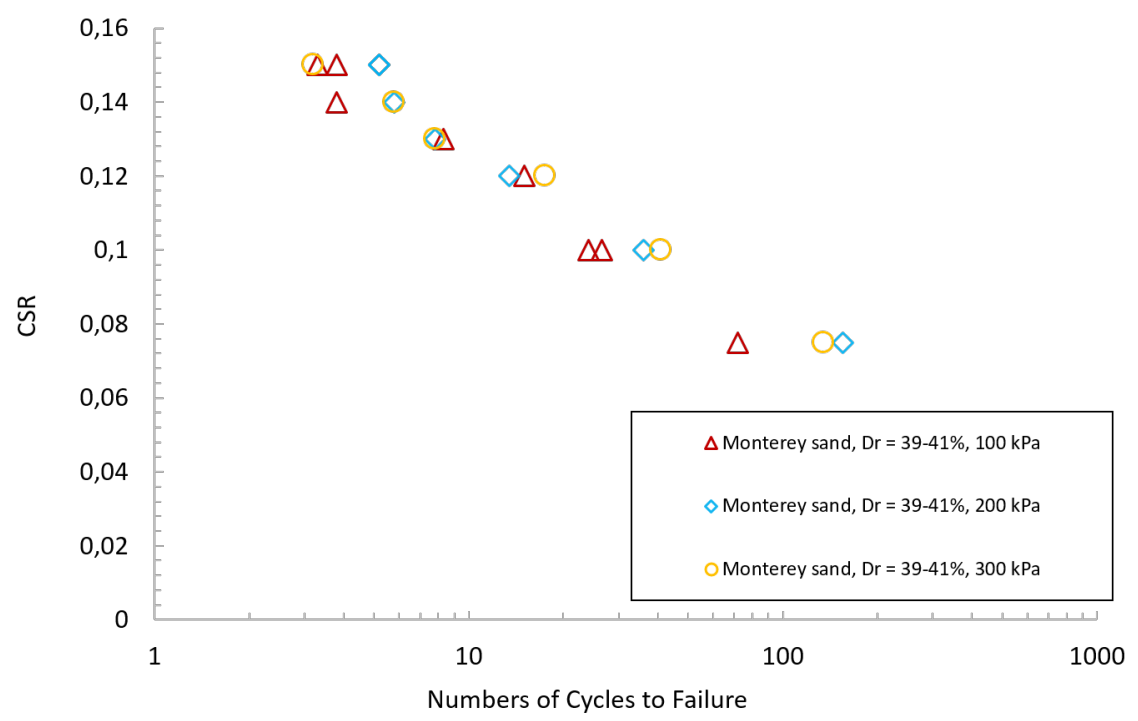

Figure 43. All data for Monterey sand at $D_{r}=40 \%$ and effective consolidation stresses of $\sigma_{v 0}^{\prime}=100,200$ and $300 \mathrm{kPa}$

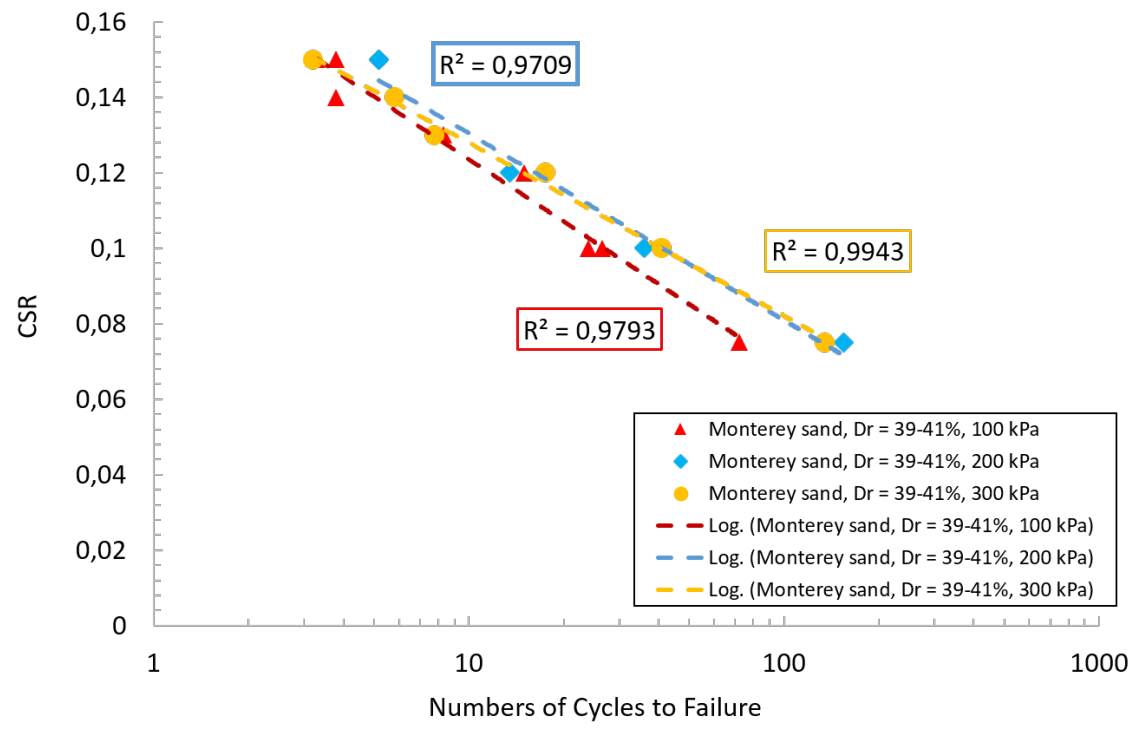

Figure 44. Stress-strain hysteresis loops and stress path for tests on Monterey sand at $\sigma_{v 0}^{\prime}=100 \mathrm{kPa}$ and $D_{r}=39-41 \%$ ) 


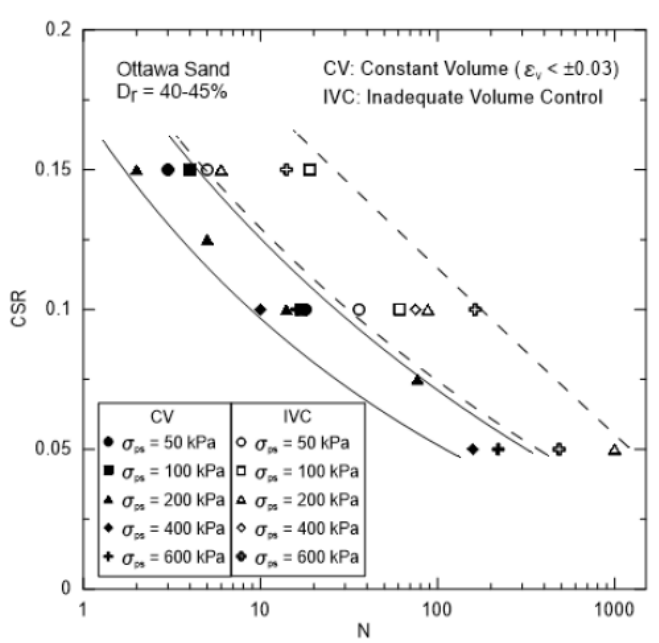

(a) CDSS data by Zehtab et al. (2019) at dif- (b) Data extracted from CSR versus $N_{f}$ plot ferent consolidation stresses

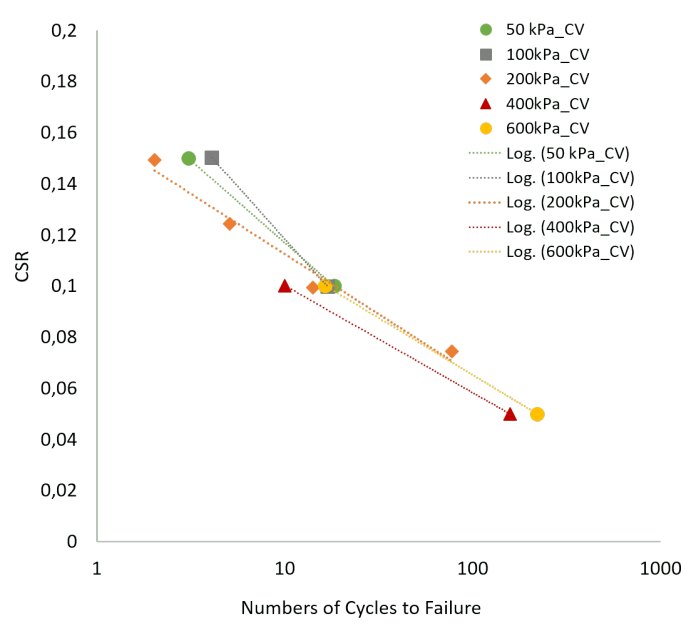

by Zehtab et al. (2019)

Figure 45. CSR versus $N_{f}$ plot for CDSS tests performed by Zehtab et al. (2019) on Ottawa sand at different consolidation stresses

Wu 2002 performed tests on the U. C. Berekley bi-directional shear device on saturated sand samples. His data was digitized and plotted in a CSR versus $N_{f}$ plot for tests conducted on different effective consolidation stresses on samples of the same relative density (Figure 46). The plots exhibit that Wu's data also shows a partly shift of tests conducted at higher effective consolidation stresses in the wrong direction. 


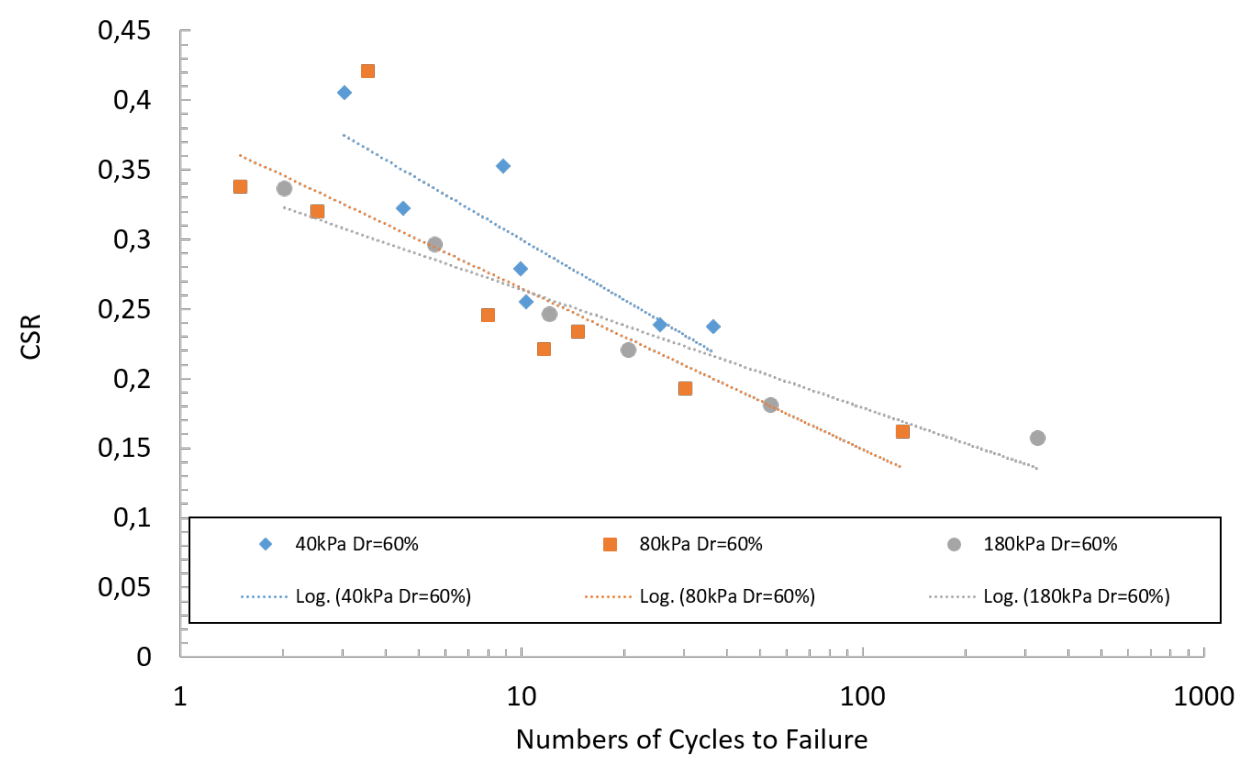

(a) Samples of $\mathrm{Dr}=60 \%$

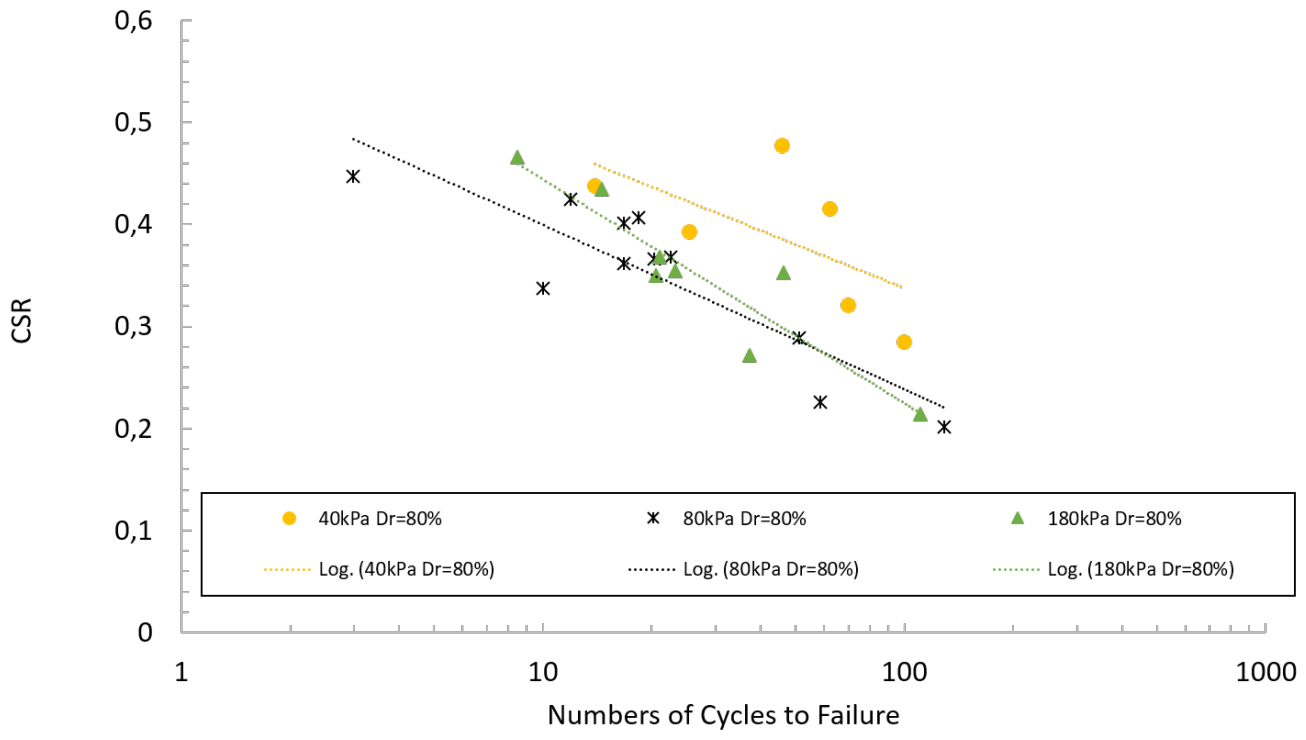

(b) Samples of $\mathrm{Dr}=80 \%$

Figure 46. CDSS data of Wu 2002 for effective consolidation stresses of $40 \mathrm{kPa}, 80$ $\mathrm{kPa}$ and $180 \mathrm{kPa}$ of saturated samples of Monterey sand 
Figure 47 shows a CSR- $N_{f}$ plot of all data from this study performed on Monterey sand at effective consolidation stresses of 100, 200 and $300 \mathrm{kPa}$ in comparison to CDSS data by Ulmer et al. (2019) on Monterey sand for the same relative density of $D_{r}=40 \%$. The plot clearly shows that both studies determined different numbers of cycles to failure for the same type of sand for samples prepared with the same preparation technique (air pluviation) and at the same relative density of 40\%. However, it is known that Ulmer et al. (2019) performed tests on a different shear device (GCTS SSH-100 cyclic simple shear apparatus) and the axial strain development during shear as well as the shear strain during consolidation phase did not exceed the recommended limits. Thus, the differences in CDSS results can result from either i) influence of shear strain development during consolidation phase in this study and/or ii) lack in apparatus stiffness in either one or both apparatuses.

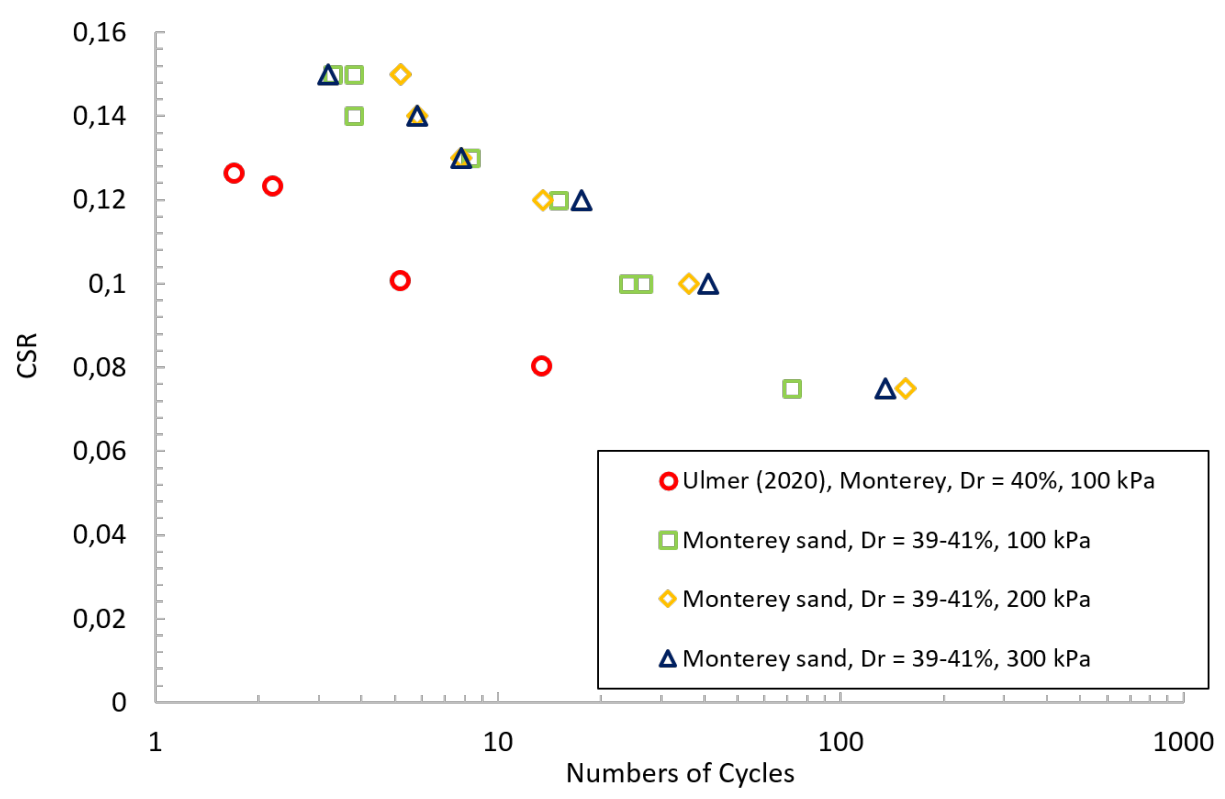

Figure 47. Data comparison of Ulmer et al. (2019) and data of this study at $D_{r}=40 \%$ and $\sigma_{v 0}^{\prime}=100 k P a$ 


\subsection{Discussion of Quality Control Measures that Affected CDSS Re- sults}

This section presents a discussion of the possible quality control measures presented in Chapter 2 that may have affected the laboratory results and possible recommendations to improve these factors in the future. These include stiffness of the CDSS system, axial strain during the cyclic shear phase, shear strain or shear stress during the consolidation phase.

\section{Stiffness of Shear Device and Equipment Components}

There are two types of system stiffness that can affect CDSS results. The first is vertical stiffness and its importance in height control, particularly for passive control, was clearly demonstrated by Konstadinou et al. (2020). Care was taken to align and stiffen the original Shear Trac II system, including the vertical loading rods (I in Figure 27), the horizontal cross arm $(\mathrm{J})$, and the side support arm (K) as much as possible with little modifications. The actual vertical device stiffness, including the stiffness of components between the load cell, vertical displacement sensor and the sample are not known and it may be useful to determine this stiffness for further studies. That being said, vertical stiffness is less critical for tests using active height control as was used in this study.

The second type of stiffness that affects CDSS results is the horizontal stiffness. In the Geocomp Shear Trac system, this is controlled by the side support arm. Horizontal system stiffness is necessary to prevent rocking of the top cap during cyclic shear, and becomes increasingly important as the soil density increases. Horizontal stiffness has been recognized as being an issue for the Geocomp system (e.g. Morales-Velez 2015), and it was originally hoped that samples of varying density would be evaluated in this study. However, once it was observed that 
other quality control criteria were not being met for the loose samples (i.e. shear strain during consolidation and $K_{\sigma}$ effects), it was decided to not expand the study to dense samples. It is hypothesized that the lack of horizontal stiffness is responsible for the increasing CRR with consolidation stress, and more research is needed to address this issue. It is recommended that the side support arm be replaced with a stiffer frame.

Axial Strain during Shear Phase

A highly influential factor is the development of axial strain during cyclic shear, which violates the constant volume assumption of the CDSS test. Tests with inaccurate height control and therefore change in volume cannot be considered as fully undrained. Further, cyclic soil resistance will be overestimated. The latest study by Zehtab et al. (2019) therefore recommends that the axial strain must not exceed $\pm 0.03 \%$. Figure 48 shows an example of bad height control and resulting axial strain development during the cyclic shear phase for a sample of Monterey sand sheared at a CSR of 0.14. The red dashed line indicates the axial strain limit recommended by Zehtab et al. (2019) of $\pm 0.03 \%$ whereas the grey dashed line exhibits the axial strain limits recommended by the ASTM for monotonic shear tests of $\pm 0.05 \%$. In this test (Figure 48) the axial strain limit was exceeded right after the beginning of the shear phase. In contrast, Figure 49 shows an example of good height control throughout cyclic loading up until failure.

The achievement of good height control (i.e. constant volume conditions during cyclic loading) is the major accomplishment of this study. Previous work at URI using this Geocomp CDSS was unable to achieve good height control, and the success of this study was due to a combination of software improvements by 
Geocomp and a careful trial-and-error study of the control systems of the CDSS. There is no software manual from Geocomp that describes the PID settings in detail, and it is hoped that this thesis will aid users of the Geocomp system when testing different soils.

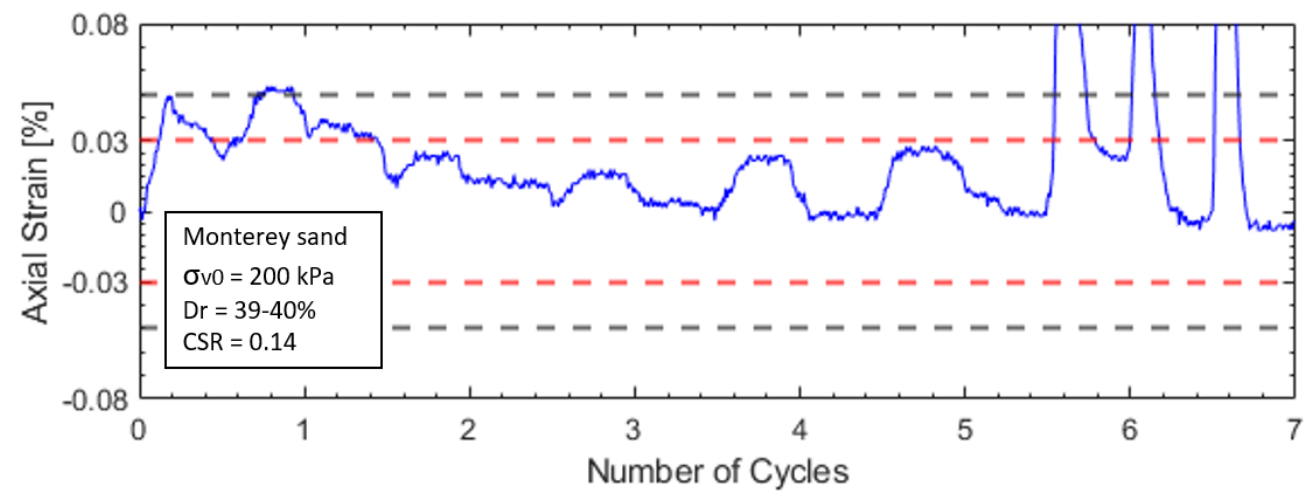

Figure 48. Example of exceeding axial strain during shear phase on Monterey sand at $\sigma_{v 0}^{\prime}=200 \mathrm{kPa}, D_{r}=40 \%$ and $\mathrm{CSR}=0.14$

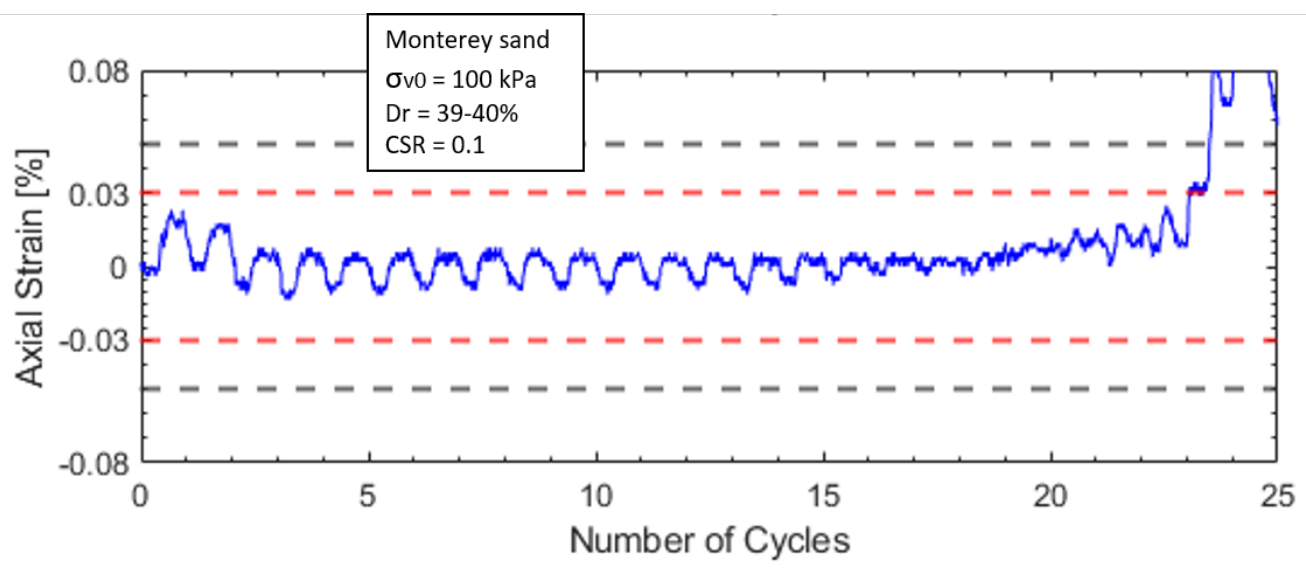

Figure 49. Example a non exceeding axial strain during shear phase on Monterey sand at $\sigma_{v 0}^{\prime}=100 \mathrm{kPa}, D_{r}=40 \%$ and $\mathrm{CSR}=0.1$ 
Shear Strain during Consolidation Phase

The software settings for the consolidation phase can either be set to "none" for no stress control or "stress" for keeping the shear stress at zero during consolidation by moving the water bath and thus unloading the horizontal load cell. All tests were performed at stress control during consolidation phase which means that shear strains were induced to maintain zero load on the horizontal load cell. The horizontal load cell in the Geocomp CDSS is fixed to the water bath, and application of a vertical load to the water bath induces some load on the horizontal load cell. During pre-testing, the horizontal load cell connection was optimized and tests were also performed at no stress control during consolidation phase. It is recommended by Ulmer et al. (2019) to keep the shear strain development during consolidation phase in the range of $\pm 0.05 \%$. For tests at no stress control there was no induced shear strain but shear stress at the end of consolidation phase. Figures 50 and 51 show examples of an exceeding and a non exceeding shear strain development during consolidation phase.

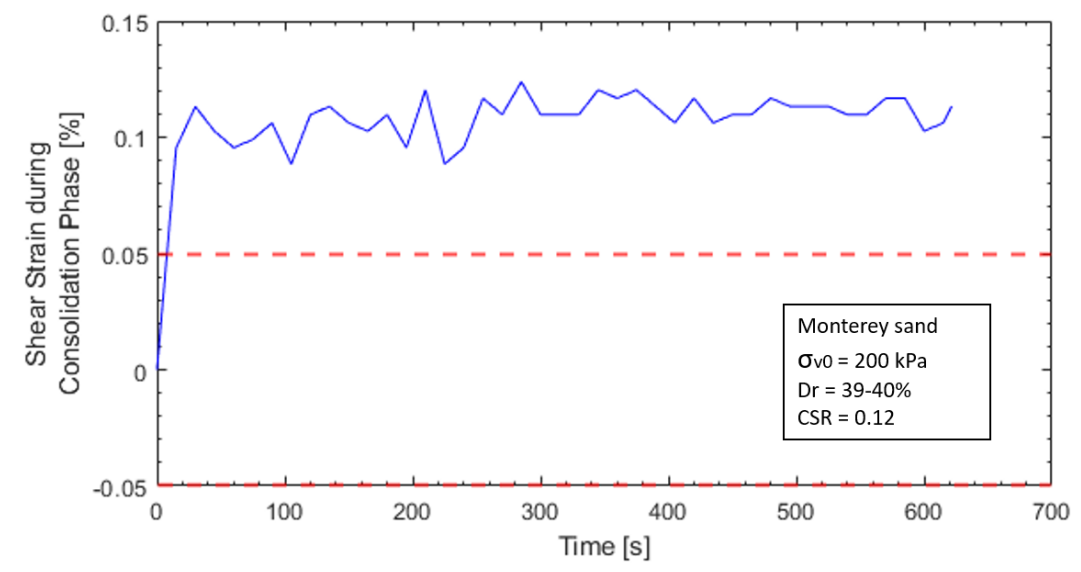

Figure 50. Example of shear strain development during consolidation that exceeded recommended values for good quality tests at $\sigma_{v 0}^{\prime}=100 \mathrm{kPa}, D_{r}=40 \%$ and CSR $=0.1$ 


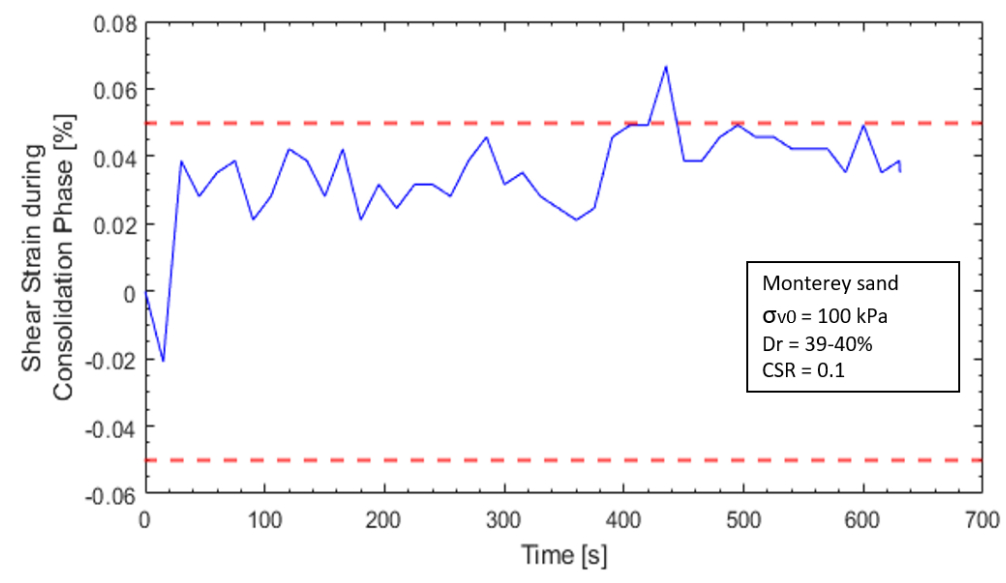

Figure 51. Example of shear strain development during consolidation that only slightly exceeded recommended values for good quality tests at $\sigma_{v 0}^{\prime}=100 \mathrm{kPa}$, $D_{r}=40 \%$ and $\mathrm{CSR}=0.1$

The shear strain during consolidation exceeded the recommended values for almost all the tests performed in this study. As mentioned above, it was decided to maintain zero horizontal load during consolidation because in pre-testing the results were more consistent with this setting. However, more work is needed to both evaluate the effect of initial shear strain (or shear stress) on the cyclic results, and to improve the design of the Geocomp system. Specifically, it is recommended that the horizontal load cell be decoupled from the water bath during consolidation, and that the water batch be modified so that it held in place (i.e. no horizontal movement) during consolidation.

$\underline{\text { Effect of consolidation stress on cyclic shear strength }}$

The cyclic stress ratio (CSR) is a dimensionless parameter defined as the cyclic shear stress over the effective consolidation stress. Tests performed at equal CSR and equal relative sample density but different effective consolidation stresses 
should therefore exhibit the same number of cycles to failure. However, this is not the case due to the volume change characteristics of the soil (i.e contractive vs. dilative) with varying effective stress. Data from samples confined by lower effective consolidation stresses show a higher cyclic strength, i.e. a higher number of cycles to failure than those confined at higher effective consolidation stresses. This approach can be used as another criteria to evaluate data quality.

For tests in this study, conducted at three different consolidation stresses, data showed a shift to the "wrong direction". Tests at $\sigma_{v 0}^{\prime}=100 \mathrm{kPa}$ exhibited lower cyclic resistance than tests conducted at $\sigma_{v 0}^{\prime}=300 \mathrm{kPa}$ (Figures 43 and 44). As mentioned above, this could be the result of insufficient system stiffness in the horizontal direction, but also friction in the piston bearing and or between the water bath and its bearings that increases with increasing consolidation stress. Interestingly, some of the data presented by Zehtab el al. (2019) also shows a shift for tests conducted at higher consolidation stresses to higher cyclic resistance, which suggests that their data might also be affected by this issue. However, it is difficult to evaluate the effect of effective confining stresses on the cyclic resistance of soils without accounting for the relative density of the sample as it is consolidating. With higher applied effective confining stresses a sample's void ratio may decrease more than for a sample confined at lower effective consolidation stress. In this study it was observed that changes in relative density during consolidation varied significantly for identically prepared samples. More work is needed to investigate and reduce this variability. 


\section{CHAPTER 5}

\section{Conclusion}

One of the most common tests to evaluate the cyclic strength of soils are constant volume (undrained) cyclic direct simple shear tests. They best represent in-situ stress conditions during earthquakes and are deceptively easy and fast to perform and best represent in-situ stress conditions during earthquakes. Over the past 15 years the interest in cyclic direct simple shear testing has increased and with this the number of companies developing and manufacturing cyclic direct simple shear devices has also increased. Despite this, the American Society of Testing Materials does not provide any guidelines for cyclic direct simple shear tests, which leads to the issue that testers are left on their own in terms of data quality evaluation. Several recent studies, such as Zehtab et al. (2019), Ulmer et al. (2019) and Konstadinou et al. (2020) have focused on identifying and evaluating factors that can be used to assess sample quality in cyclic direct simple shear test results.

The objective of this thesis was to apply published quality control measures for cyclic direct simple shear (CDSS) to tests performed on a commercially available CDSS apparatus manufactured by the Geocomp Corporation. Tests were performed on samples of Monterey and Ottawa sand, two commonly tested materials in the geotechnical literature. Samples were prepared to a relative density of $40 \%$ and samples were consolidated to $100 \mathrm{kPa}, 200 \mathrm{kPa}$, or $300 \mathrm{kPa}$

prior to stress-controlled cyclic shearing. No modifications were made to the CDSS apparatus for this study. 
The objective was accomplished by carefully aligning and stiffening the provided direct simple shear apparatus, and experimentally changing the gain settings of the cyclic direct shear software to achieve good height control with the active control system. Once the axial strain development remained within the recommended limits, tests at varying cyclic stress ratios and effective consolidation stresses were performed and the data was analyzed with focus on three quality control measures: 1) axial strain during cyclic shear (i.e. constant volume conditions); 2) shear strain development during consolidation; and 3) the effect of consolidation stress on cyclic strength (i.e. $\left.K_{\sigma}\right)$.

The major conclusions from this study based on the test results are as follows:

- It was not possible to perform tests that fully met the criteria for good cyclic shear tests. After an iterative process with the gain settings of the Geocomp software, good height control was achieved for all the tests, but the shear strain development during consolidation still exceeded the recommended limit of $\pm 0.05 \%$. There was no software manual provided by Geocomp which makes it difficult to evaluate data quality.

- Exceeding axial strain development during shear phase has a significant influence on cyclic shear resistance; tests that exceed axial strain during shear will overestimate cyclic soil resistance. The fact that good height control (i.e. constant volume conditions during cyclic loading) was achieved in all the tests is the major accomplishment of this study. Previous work at URI using this Geocomp CDSS was unable to achieve good height control, and the success of this study was due to a combination of software 
improvements by Geocomp and a careful trial-and-error study of the control systems of the CDSS. There is no software manual from Geocomp that describes the PID settings in detail, and it is hoped that this thesis will aid users of the Geocomp system when testing different soils.

- The results of tests performed on the Shear Trac II in this study and tests performed by Ulmer et al. (2019) on a GCTS SSH-100 cyclic simple shear apparatus were not comparable despite the fact that they were performed on samples of the same sand (Monterey 0/30), at the same relative density $\left(D_{r}=40 \%\right)$, with the same sample preparation technique (dry air pluviation) and at the same effective consolidation stress $\left(\sigma_{v 0}^{\prime}=100 \mathrm{kPa}\right)$.

- Test results from this study and the studies by Zehtab et al. (2019) and Gokyer et al. (2019) conducted on the same model of cyclic direct simple shear device all show a shift in the CRR curve for tests consolidated to higher effective consolidation stresses (for same relative density) to higher soil resistance, which should actually show less resistance ( $K_{\sigma}$ effect). This suggests that the Geocomp Corporations CDSS apparatus is not stiff enough in the horizontal direction. It should be said that data from Ulmer et al. (2019) on a different CDSS apparatus also show inconsistent trends in terms of $K_{\sigma}$.

- To properly evaluate data for the effect of differing effective consolidation stresses it is recommended to use the final relative density of the samples after consolidation rather than the initial relative density after preparation. 
Sample fabric, and the applied effective consolidation stress can cause large variations between initial and final relative density which then may cause variability in the results.

Test results presented herein will be used to further evaluate the quality of cyclic direct simple shear tests on the shear apparatus provided by Geocomp Corporation. For future work, it is of interest to evaluate the vertical and horizontal apparatus stiffness and friction of the device's water bath and the friction of the loading piston within the bearings. It is recommended to evaluate the changes in device friction with increasing consolidation stresses and correct data for deviations. To determine friction in the water bath bearings separately from piston friction in the side arm bearings the consolidation stresses can be imitated by adding weight blocks to the empty water bath and running straincontrolled cyclic shear phases while measuring the shear stress. Further, possible improvements can be made in reducing piston rocking by using air bearings and providing a software manual to better understand and set the software settings in the cyclic direct shear software. It may also be possible that the gains apply high frequency vibration on the sample that would affect fabric and cyclic strength. 


\section{Appendix A: Detailed Step by Step Testing Procedure}

The testing procedures and sample preparation techniques are closely following the work of Jordan C. Bogden (2019) who has performed cyclic direct simple shear tests in the same laboratory and on the same shear device using passive control. He used a rigid steel frame which was placed around the Shear Trac II in order to support the devices' stiffness. The rigid frame will not be used in this study but the test setup and sample preparation procedures will mostly following the instructions by Jordan C. Bogden (2019).

\section{Detailed Description of the Sample Preparation}

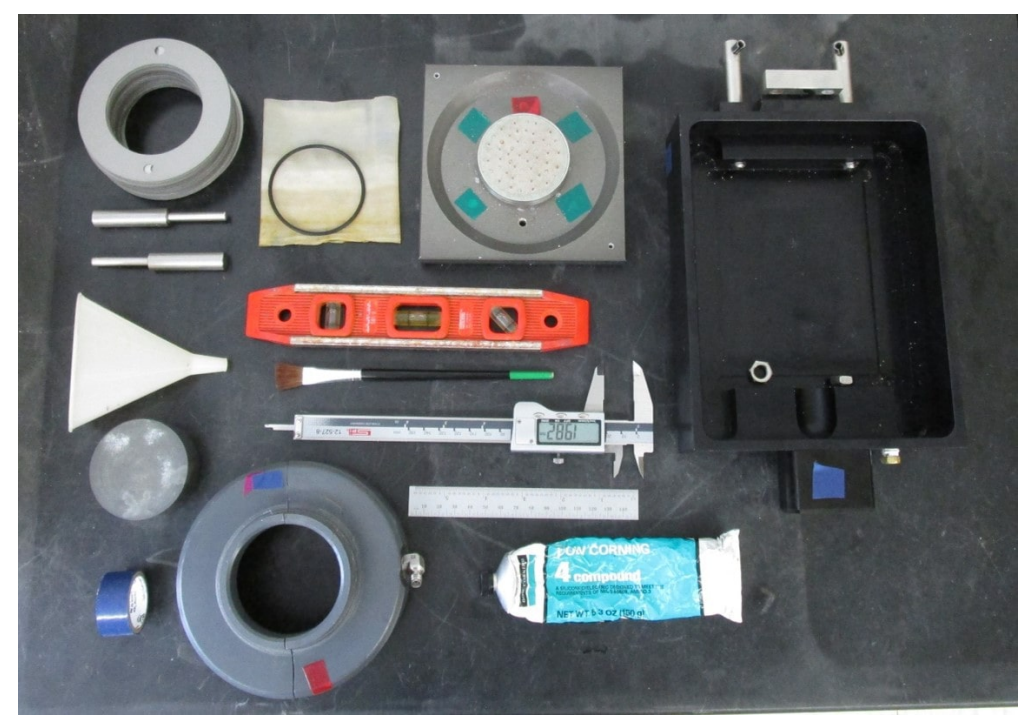

Figure .52. Tools used for Sample preparation

1. Samples are prepared in the water bath on a base plate with bottom cap which is placed inside the bath and fixed by two screws to keep it in place. The base plate has two grooves that need to be in line with the ledge on the 
bottom of the water bath. When placed right the base plate should interlock with the ledges and not slip to any side. Place two nuts as spacers between the right inside wall of the water bath and the shear box and tighten the left screws on the water bath to fix the shear box in that position.

2. Use a flexible (non-reinforced) rubber membrane and slide it over the bottom cap on the shear box. Gently secure it with a rubber O-ring so that it seals. Smooth out all folds and pinches in the membrane.

3. For this study 37 Teflon-coated confining rings are used. Put the rings over the membrane and secure them by pinning the confining ring pins in the ring holes. Keep the stacked rings leveled and aligned.

4. Take the split molds and clean off all sand grains on the bottom to ensure a steady vacuum during sample preparation. Remove the confining ring pins and gently place the mold around the rings. Ensure that the mold pieces are flush together before switching on the vacuum. It may also help to put on a little bit of vacuum grease.

5. Turn on the vacuum pump and stretch and fold the rubber membrane over the edge of the mold. Again ensure that all the folds and pinches in the membrane are smoothed out.

6. Sample dimensions such as initial height and initial diameter can now be obtained from the empty membrane form. A metal ruler placed over the membrane hole can be helpful for measuring the height in the middle of the mold. Take at least ten measures at different location to determine the average dimensions. 


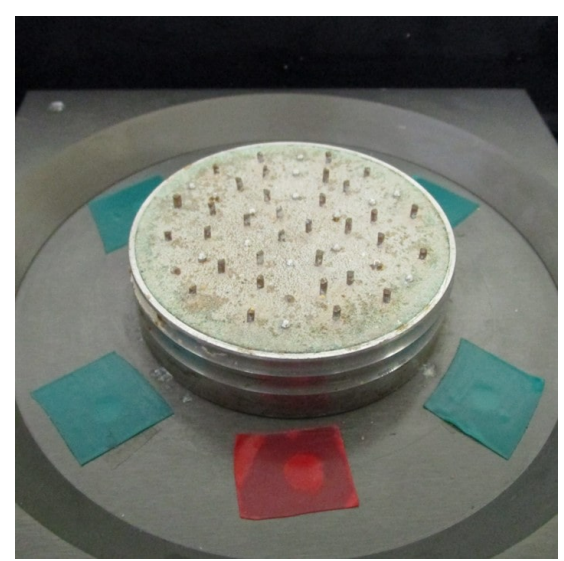

(a) Bottom cap

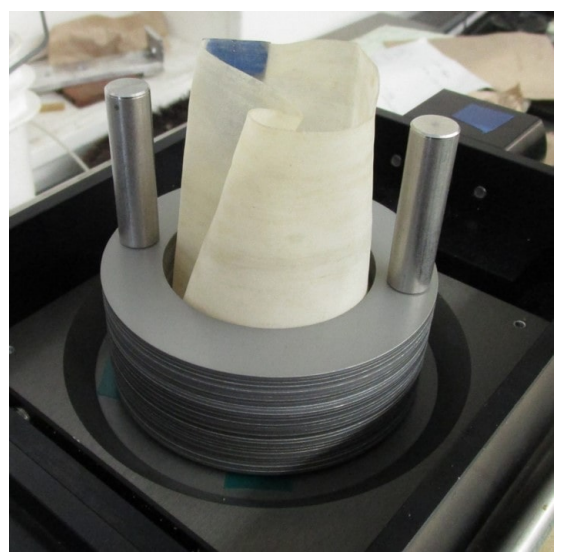

(c) Teflon-Rings

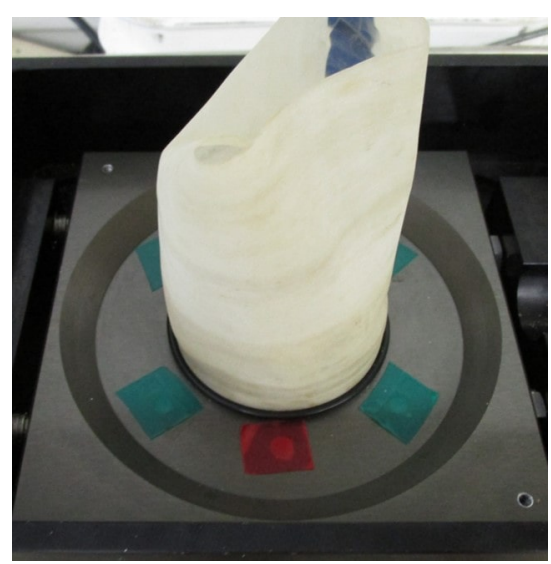

(b) Membrane sealed with O-Ring

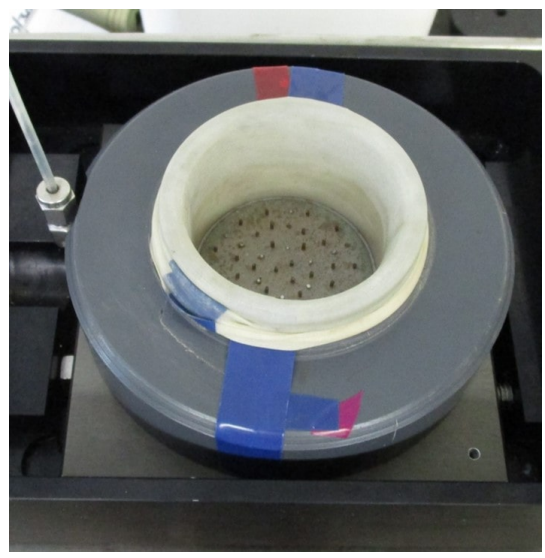

(d) Split-Molds 
7. Samples were prepared at a medium relative density of $D_{r}=40 \%$. In order to keep track of sample height and void ratio at the same time an excel calculation sheet was used. For medium samples 121,5g of sand was used.

8. Pour the sand into the membrane using a funnel. It is important to first fill all the pre-weighted sand into the funnel before pouring to ensure a constant flow rate. While pouring, gently circle the funnel around the molds to provide an even sand distribution/dispersion in the membrane. Take some height measures and gently even out the sample surface.

9. Compact the sample by tapping the water bath on each side and in vertical direction by placing the hard plastic cylinder on the sand and tapping it with the hammer as much as needed to reach the desired height and density.

10. After the surface is smoothed out and the sample is compacted take the final sample height by taking the average of at least ten measures in different locations. Again use a metal ruler to take measurements in the middle and at a constant level. The actual sample height can be obtained by subtracting the average final height from the initial empty mold height.

\section{Detailed Description of the Testing Procedure}

1. Before testing it is very important to ensure that the shear device is leveled and all its components are aligned. Most important hereby is a proper alignment of all the load transferring components, such as the horizontal metal crossbar with attached load cell down to the load transferring vertical metal rod and the sample top cap. Imperfect and inconsistent alignment can affect test results due to development of horizontal load components in consolidation phase (vertical loading). A level is used to adjust longitudinal 
and lateral alignment before testing. Also check the alignment after tests, because the Shear Trac can drift during tests causing misalignment.

2. Place water bath with prepared sample in the Shear Trac. Note that the vacuum pump must run at all times during sample preparation and test setup. Slide the load piston into the side arm bearing and fold the side arm down onto the sample. Ensure the vertical alignment of top and bottom cap by moving the water bath horizontally using the 'jog' function of the Shear Trac before lowering the top cap onto the sample's surface. Once the weight of the loading piston is resting on the sample the vacuum pump can be switched off.

3. Tighten the screw on the horizontal black supporting side arm and also gently tighten the screw connection horizontal load cell and water bath. Place the horizontal LVDT on the side of the water bath and tighten it.

4. Swing in the horizontal crossarm and level it with the nuts below. Tighten the crossarm on the loading rods to $10 \frac{l b}{f t^{3}}$ using the torque wrench. Place the vertical LVDT on top mid of the crossarm.

5. Open the CDSS software and type in all the test parameters. Put in 600 seconds of consolidation in the consolidation table. Hit run - start to start the consolidation phase and let the sample consolidate for 10 minutes. The software will automatically jump into the shear phase after that. 


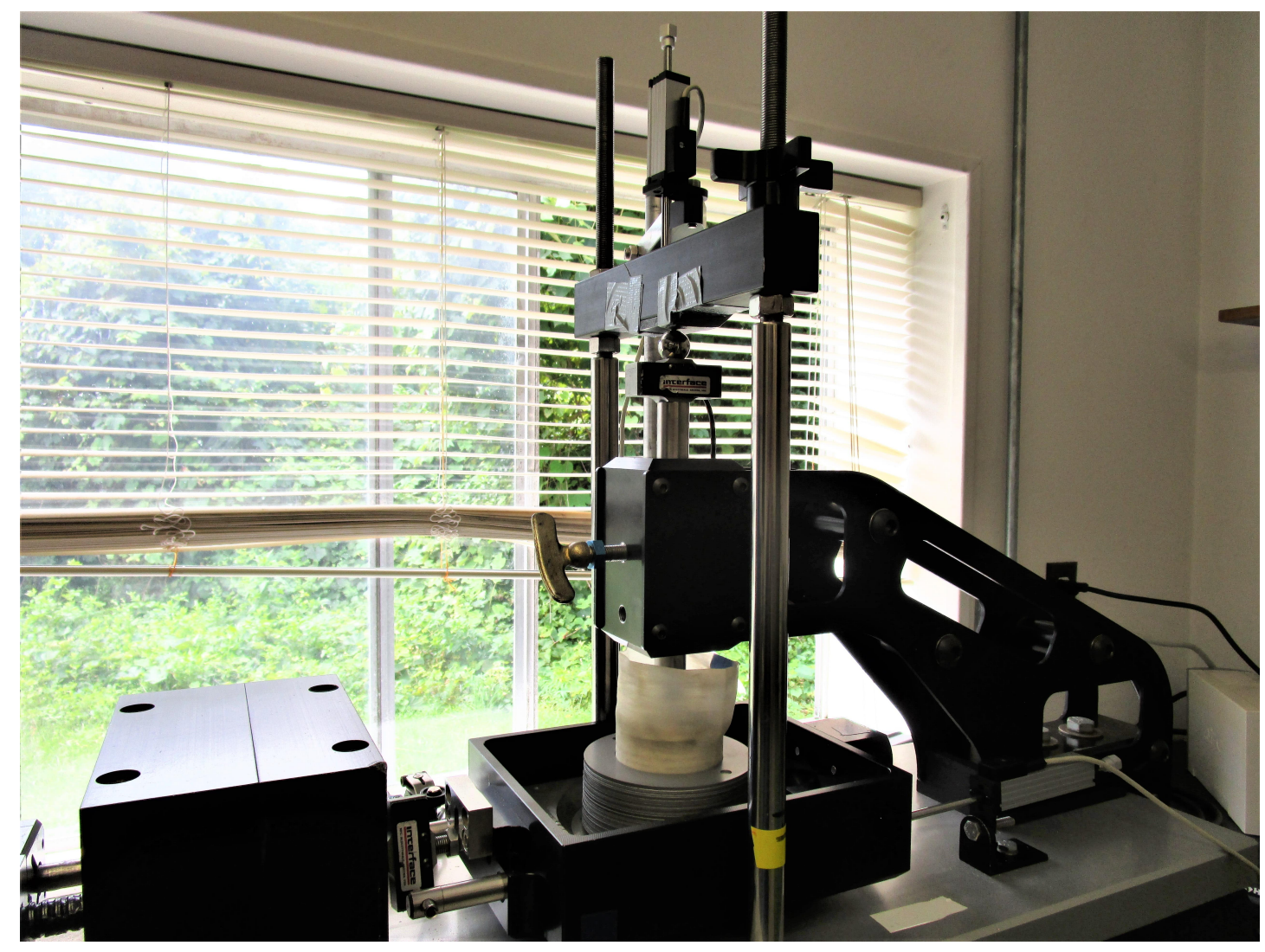

Figure .53. Finished test setup 


\section{Appendix B: Software Input for CDSS Constant Volume Height Control}

\section{Input Parameter DIAGS}

The DIAGS (or Diagnosis) software by Geocomp provides basic settings for the

Shear Trac Motor, the A/D, and the PID (gain settings). DIAGS setting can be set for the vertical control (Controller ID: 101) and the horizontal control (Controller ID: 102) separately.

DIAGS $\rightarrow$ "Controller ID" (101 or 102) $\rightarrow$ file $\rightarrow$ settings

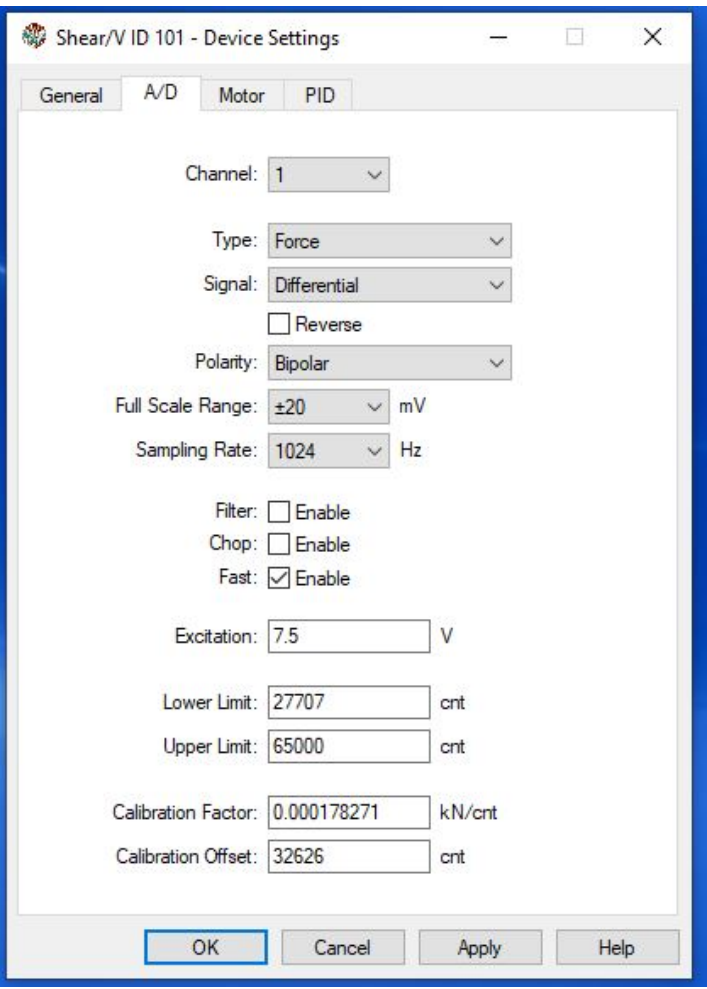

Figure .54. Screenshot of DIAGS - vertical controller - file - settings - A/D Channel 1 (force)

$\mapsto \mathrm{A} / \mathrm{D}$ 
- Channel and Type: Note that in A/D there is a drop down menu to change the channel you are in: Channel $1=$ Force and Channel $2=$ Displacement. The following bullet points refer to channel 1 - force

- Signal

- Polarity

- Full Scale Range

- Sampling Rate [Hz]: Should be at $256 \mathrm{~Hz}$ for all Channels (Artur Apostolov)

- Filter, Chop, Fast

- Excitation Voltage: The excitation voltage is important for the load cell that is being used. For the s-shaped load cell a value of $6.5 \mathrm{~V}$ was used. For the SML load cells it was set to $7.5 \mathrm{~V}$

- Lower Limit

- Upper Limit

- Calibration Factor: This should be the same as the calibration factor for the load cell in the CDSS software

- Calibration Offset 


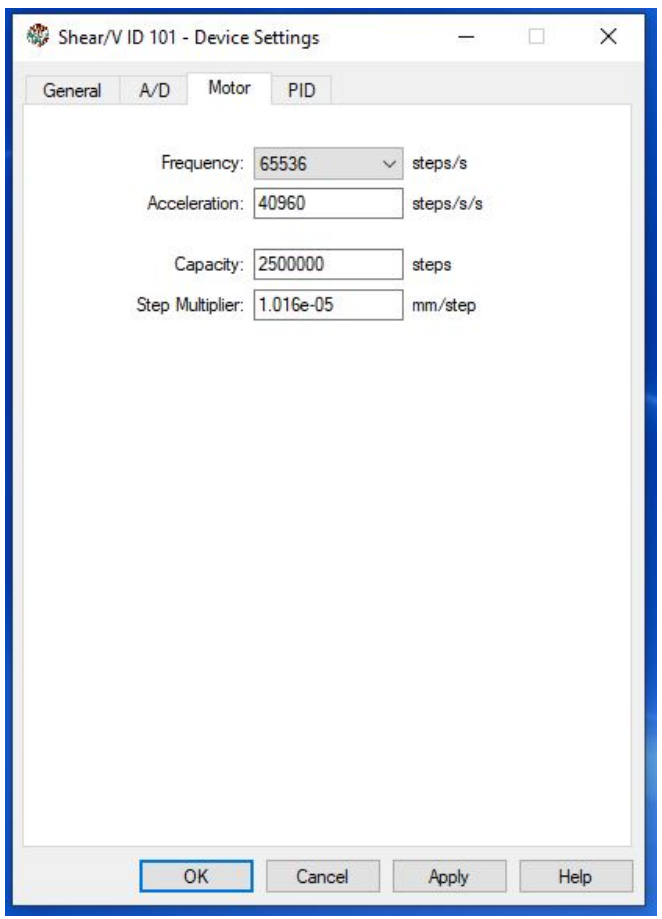

Figure .55. Screenshot of DIAGS - vertical controller - file - settings - Motor

$\mapsto$ Motor

- Frequency

- Acceleration

- Capacity

- Step Multiplier

$\mapsto$ PID

The vertical and horizontal PIDs are connected to the constant volume gain and the desired response gain (in the cyclic table of the CDSS software). According to Geocomp, the gains regulate how the motor approaches the set target. The gain settings in the CDSS software overwrite the gain settings in the DIAGS system. 


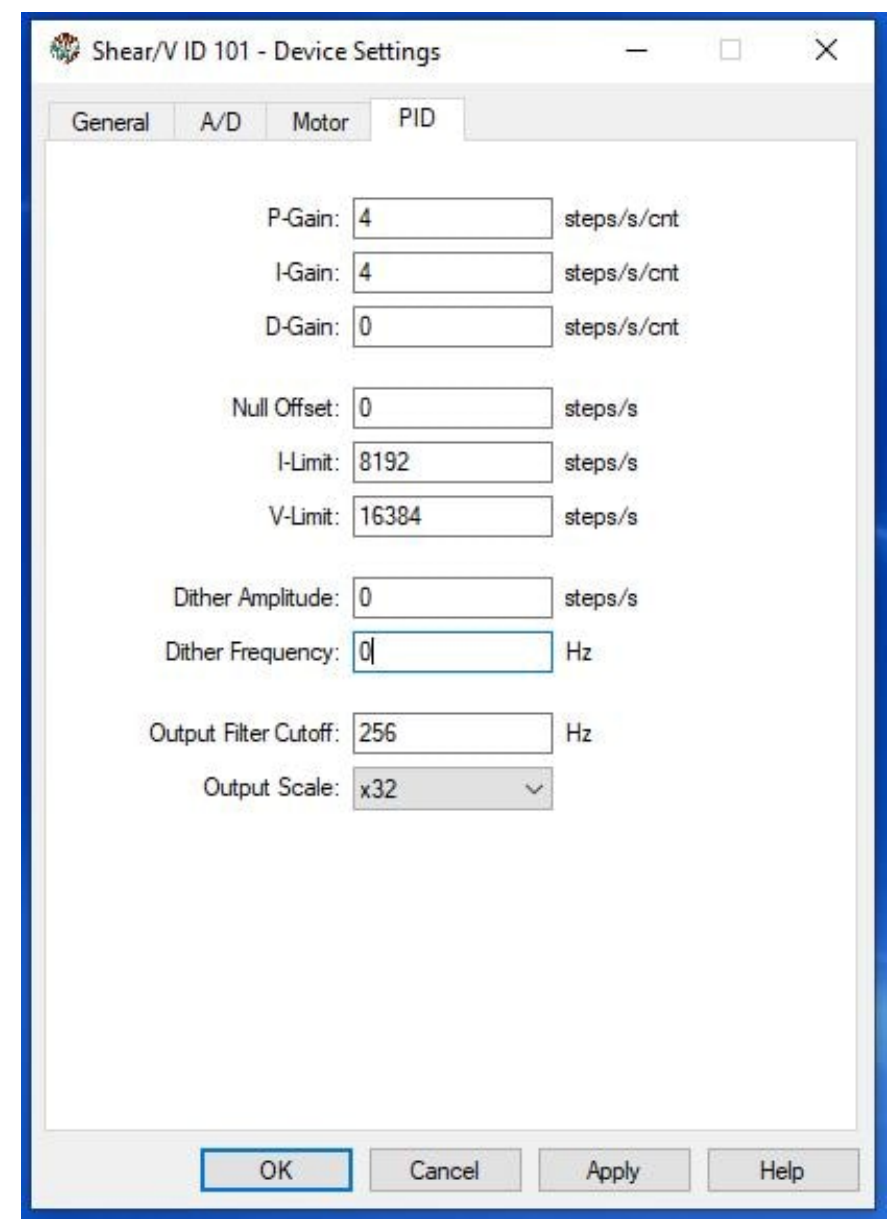

Figure .56. Screenshot of DIAGS - vertical controller - file - settings - PID

According to Geocomp the DIAGS settings are only used when the machine is controlled manually. Note: If the gains are changed in the CDSS software they won't be uploaded to the machine but still govern the settings and the machine will be controlled by them.

To optimize the vertical control system for a particular soil and density the following procedure is recommended by Geocomp:

a) Set the constant volume gain in the CDSS software, cyclic table to 1 , set the vertical P-Gain to 1 and leave the D-Gain at 0 
b) In the CDSS software the motor can be tasked to maintain a load. This can be set under "Control - Vertical Load". Without a sample, set the vertical load control to any load and increase the I-Gain (while the motor is running) from 0 until the vertical motor accelerates. In this study this was not manageable because the vertical motor would not accelerate to a value up to 16. After further correspondence with Geocomp it was recommended to further increase the I-Gain until the vertical motor eventually accelerates.

\section{Short explanaitions to individual settings:}

- Proportional Gain (P-Gain): Controls the speed of approaching the target

- Integral Gain (I-Gain): Controls the acceleration

- Deriviative Gain (D-Gain): Was already set to "0" and is recommended by Geocomp to leave it at zero. The Deriviation Gain makes the control more "noisy" but also rapid. It is not used for CDSS testing.

- Null offset: Was already set to "0"

- I-Limit: Should be set to "8192" (vertical) and "32768" (horizontal)

- V-Limit: Should be set to "16384" (vertical) and "32768" (horizontal)

- Dither Amplitude: Was already set to "0"

- Dither Frequency: Was already set to "0"

- Output Filter Cutoff: Was already set to "256". Used for internal integration on the drive. Helps reduce noise (Artur Apostolov) 
- Output Scale: Geocomp recommends the standard setting for the vertical output scale of x128 for controller ID 101

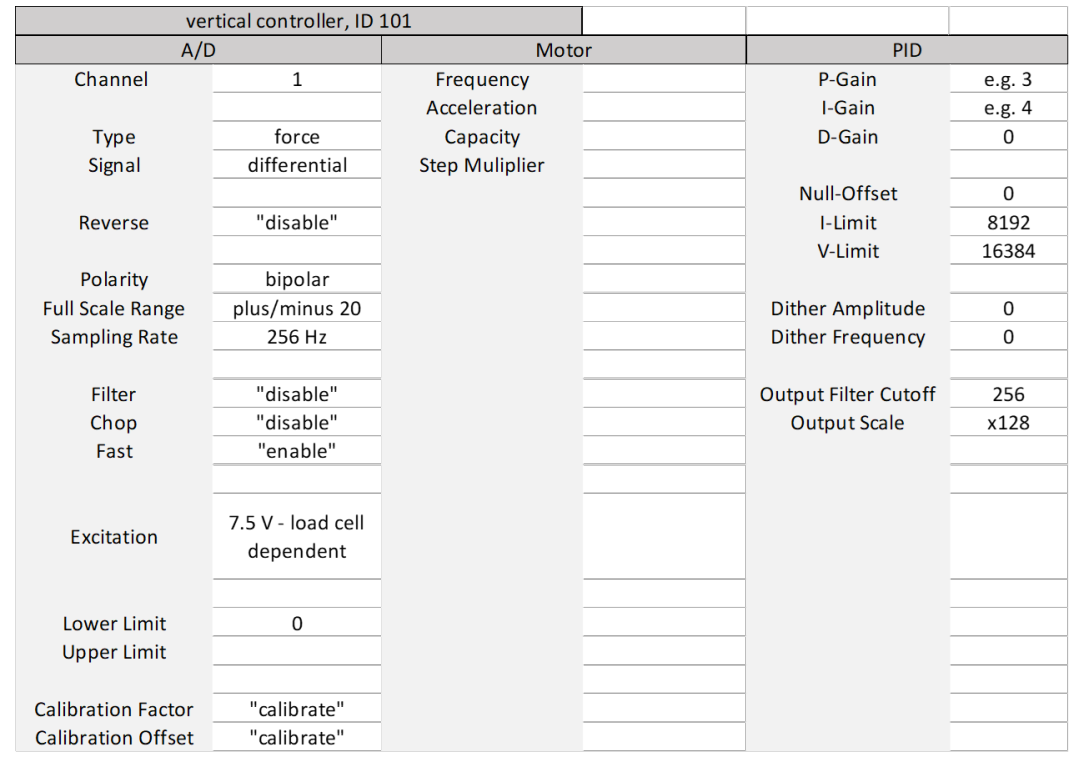

Figure .57. Vertical DIAGS settings overview

\begin{tabular}{|c|c|c|c|c|}
\hline \multicolumn{3}{|c|}{ horizontal controller, ID 102} & & \\
\hline \multicolumn{2}{|c|}{$A / D$} & Motor & \multicolumn{2}{|l|}{ PID } \\
\hline \multirow[t]{2}{*}{ Channel } & 1 & \multirow{20}{*}{$\begin{array}{c}\text { Frequency } \\
\text { Acceleration } \\
\text { Capacity } \\
\text { Step Muliplier }\end{array}$} & \multicolumn{2}{|l|}{ P-Gain } \\
\hline & & & \multirow{10}{*}{$\begin{array}{l}\text { Dither Amplitude } \\
\text { Dither Frequency }\end{array}$} & e.g. 2 \\
\hline Type & force & & & 0 \\
\hline \multirow[t]{2}{*}{ Signal } & differential & & & \\
\hline & & & & 0 \\
\hline \multirow[t]{2}{*}{ Reverse } & \multirow[t]{2}{*}{ "disable" } & & & 32768 \\
\hline & & & & 32768 \\
\hline \multirow{3}{*}{$\begin{array}{c}\text { Polarity } \\
\text { Full Scale Range } \\
\text { Sampling Rate }\end{array}$} & bipolar & & & \\
\hline & plus/minus 20 & & & 0 \\
\hline & $256 \mathrm{~Hz}$ & & & 0 \\
\hline Filter & "disable" & & & 256 \\
\hline Chop & "disable" & & \multirow{9}{*}{$\begin{array}{l}\text { Output Filter Cutoff } \\
\text { Output Scale }\end{array}$} & $\times 128$ \\
\hline Fast & "enable" & & & \\
\hline & & & & \\
\hline Excitation & $\begin{array}{c}7.5 \mathrm{~V} \text { - load cell } \\
\text { dependent }\end{array}$ & & & \\
\hline & & & & \\
\hline Lower Limit & 0 & & & \\
\hline Upper Limit & 65535 & & & \\
\hline \multirow{2}{*}{$\begin{array}{l}\text { Calibration Factor } \\
\text { Calibration Offset }\end{array}$} & "calibrate" & & & \\
\hline & "calibrate" & & & \\
\hline
\end{tabular}

Figure .58. Vertical DIAGS settings overview 


\section{Appendix C: Plots of CDSS data}

Ottawa Sand, $\mathrm{Dr}=40 \%, 100 \mathrm{kPa}$
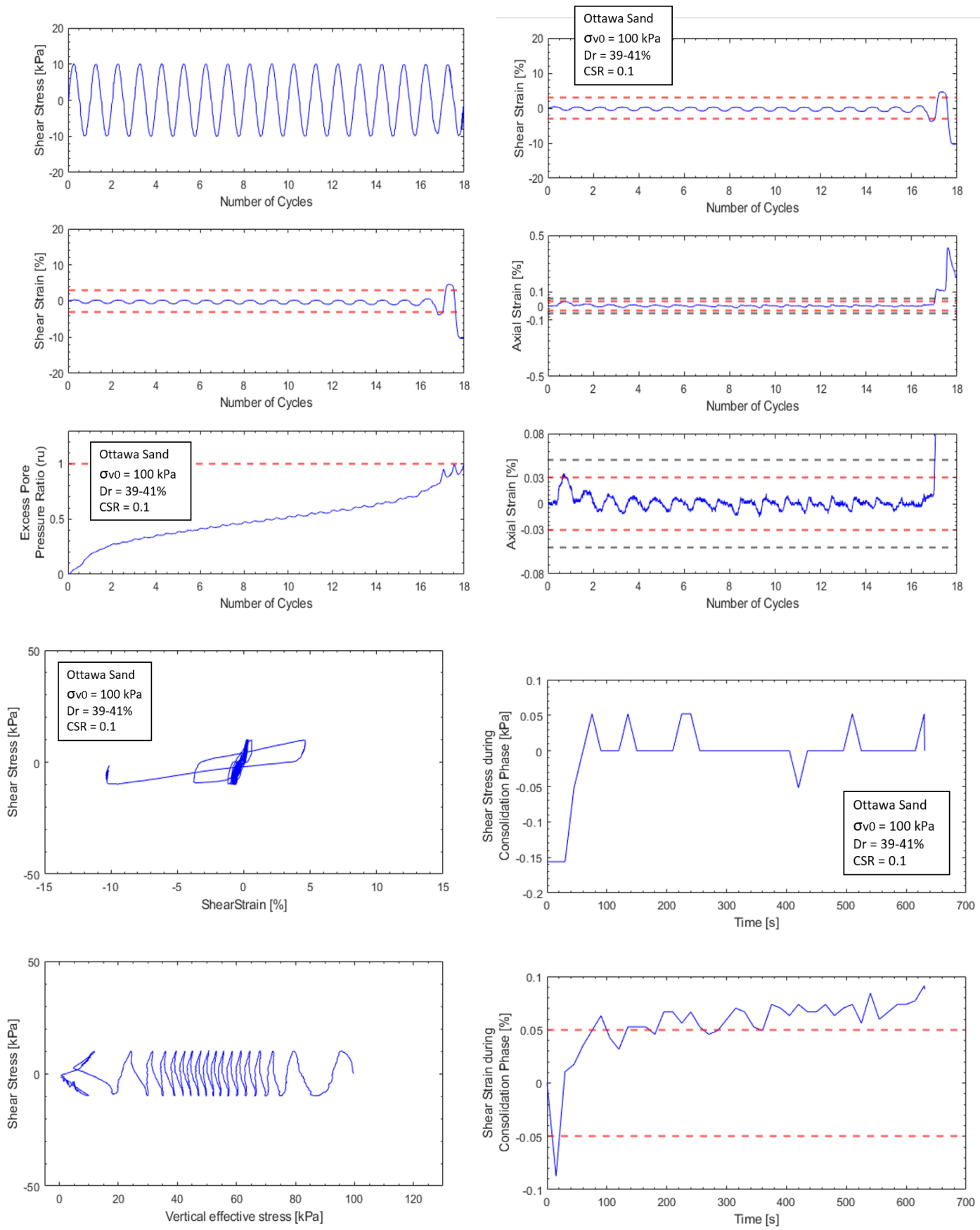

Figure .59. Ottawa sand, $\sigma_{v 0}^{\prime}=100 \mathrm{kPa}, \mathrm{Dr}=40 \%, \mathrm{CSR}=0.1$ 

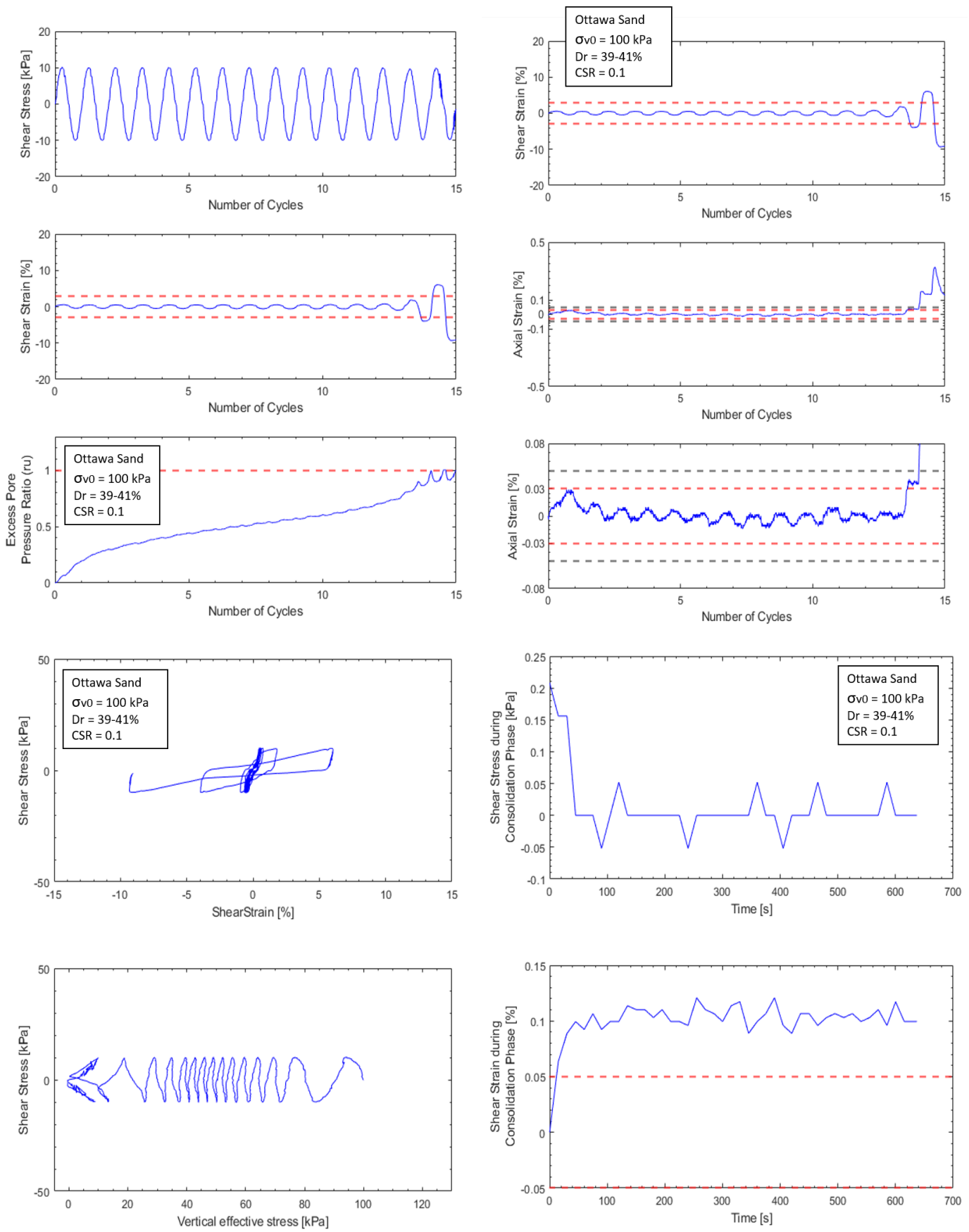

Figure .60 . Ottawa sand, $\sigma_{v 0}^{\prime}=100 \mathrm{kPa}, \mathrm{Dr}=40 \%, \mathrm{CSR}=0.1$ 

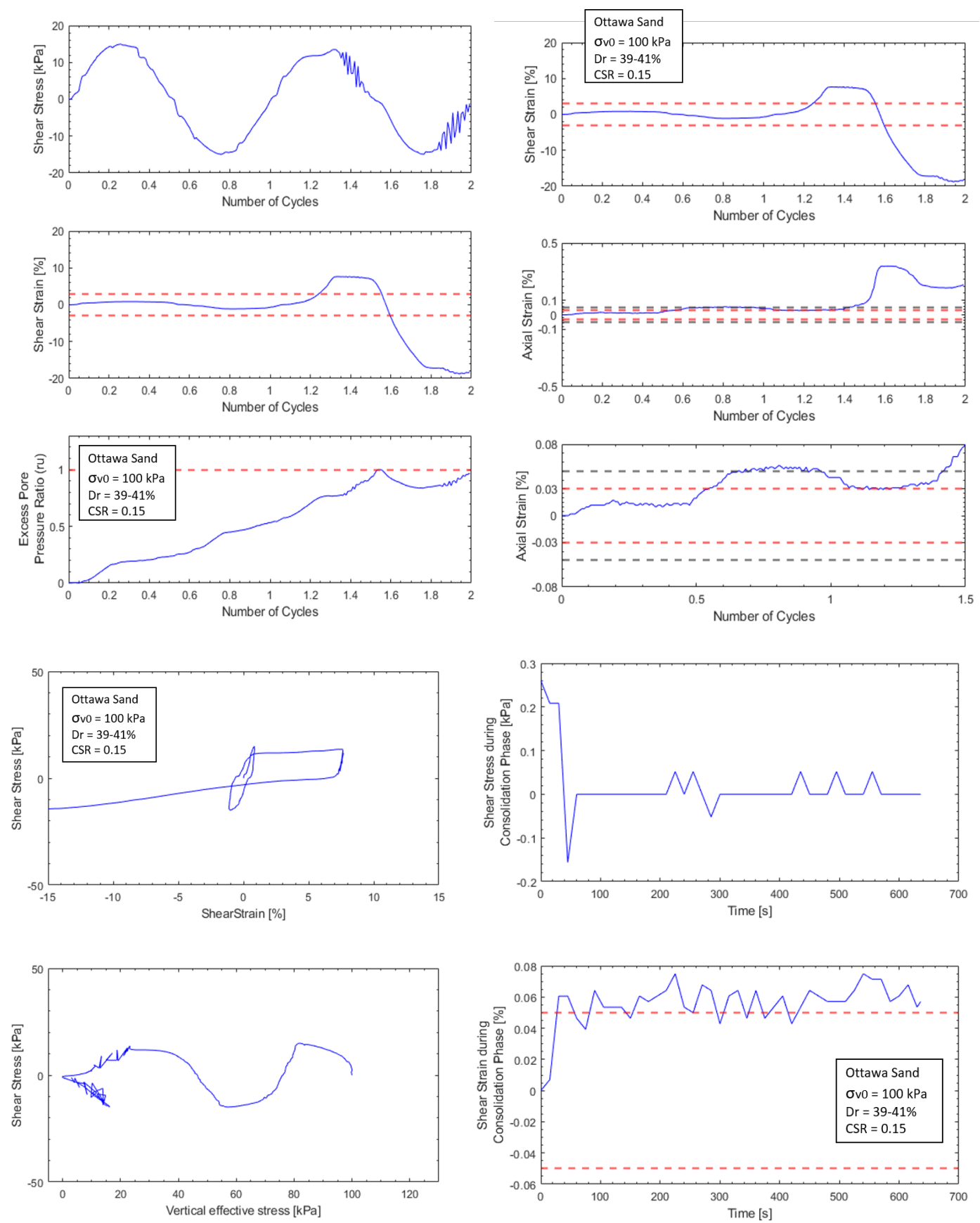

Figure .61. Ottawa sand, $\sigma_{v 0}^{\prime}=100 \mathrm{kPa}, \mathrm{Dr}=40 \%, \mathrm{CSR}=0.15$ 

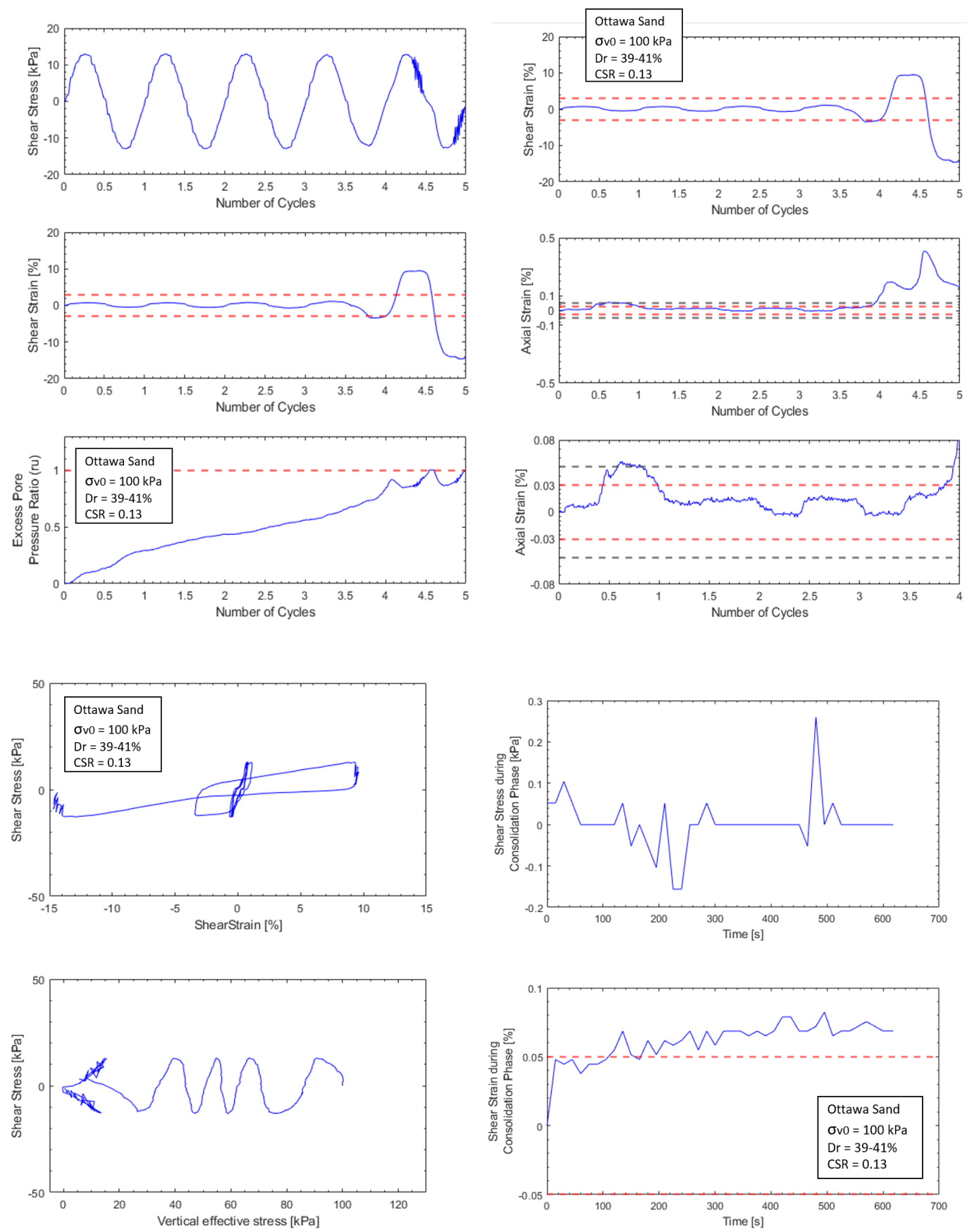

Figure .62. Ottawa sand, $\sigma_{v 0}^{\prime}=100 \mathrm{kPa}, \mathrm{Dr}=39 \%, \mathrm{CSR}=0.13$ 

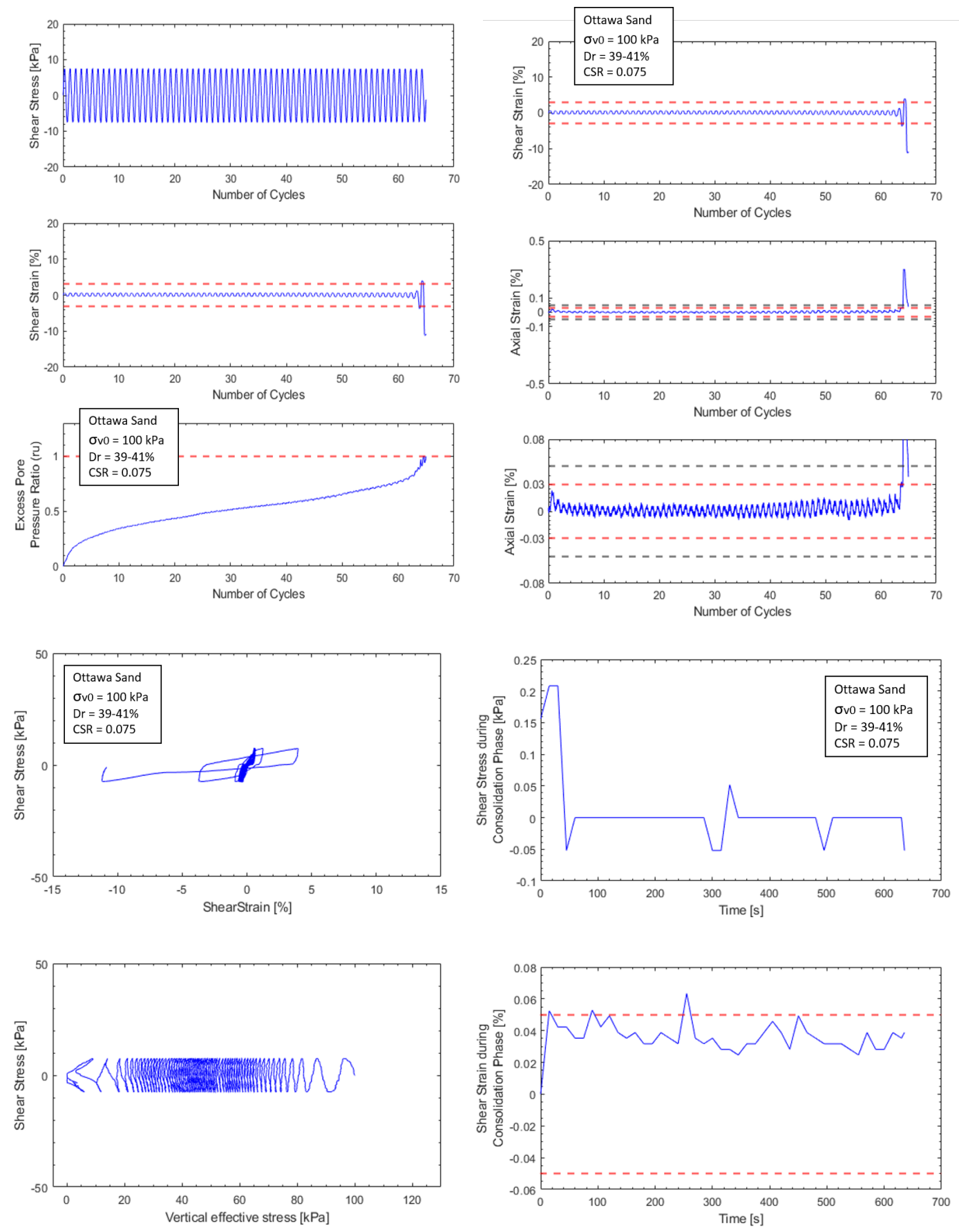

Figure .63. Ottawa sand, $\sigma_{v 0}^{\prime}=100 \mathrm{kPa}, \mathrm{Dr}=40 \%, \mathrm{CSR}=0.075$ 

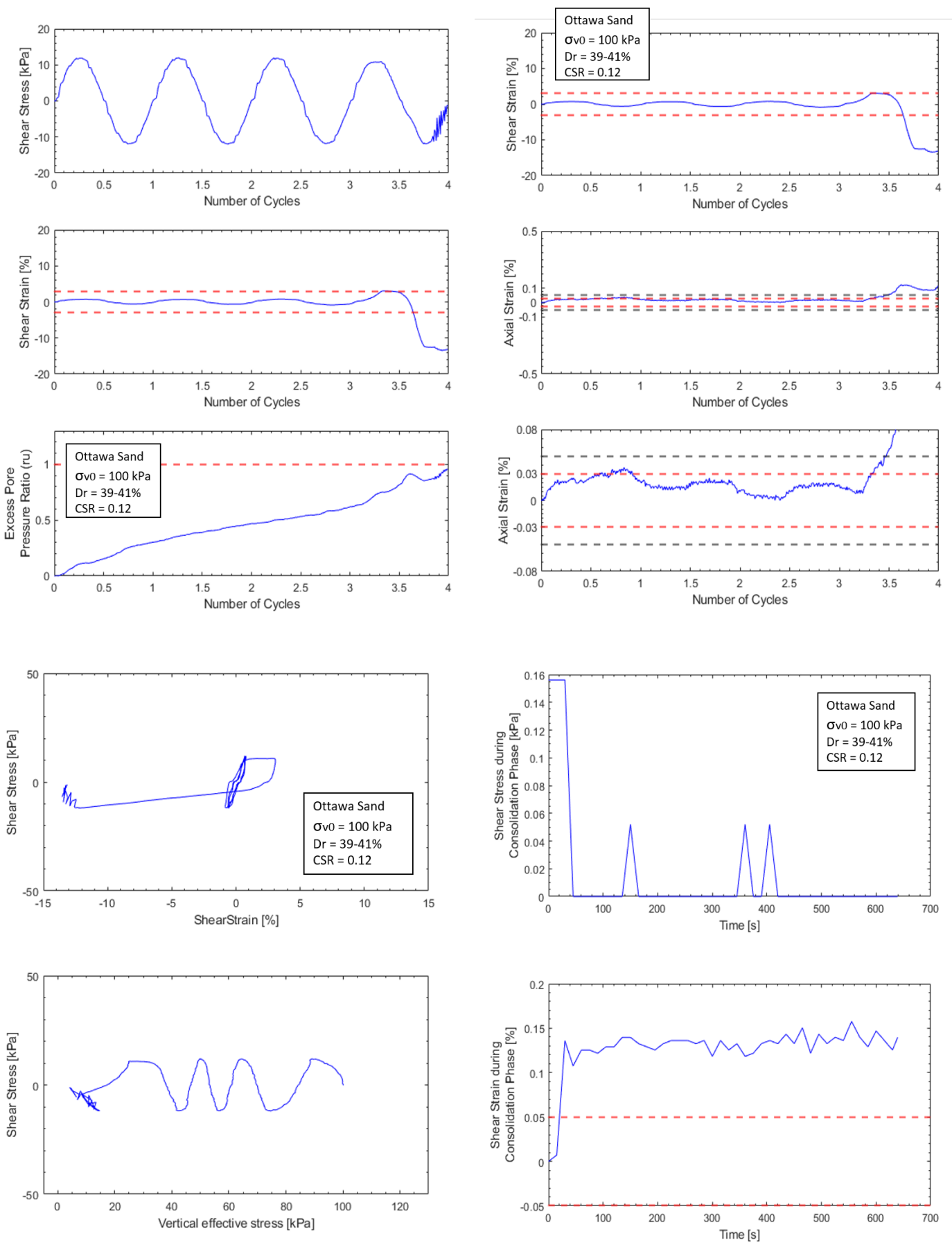

Figure .64. Ottawa sand, $\sigma_{v 0}^{\prime}=100 \mathrm{kPa}, \mathrm{Dr}=39 \%, \mathrm{CSR}=0.12$ 
Monterey Sand, $\mathrm{Dr}=40 \%, 100 \mathrm{kPa}$
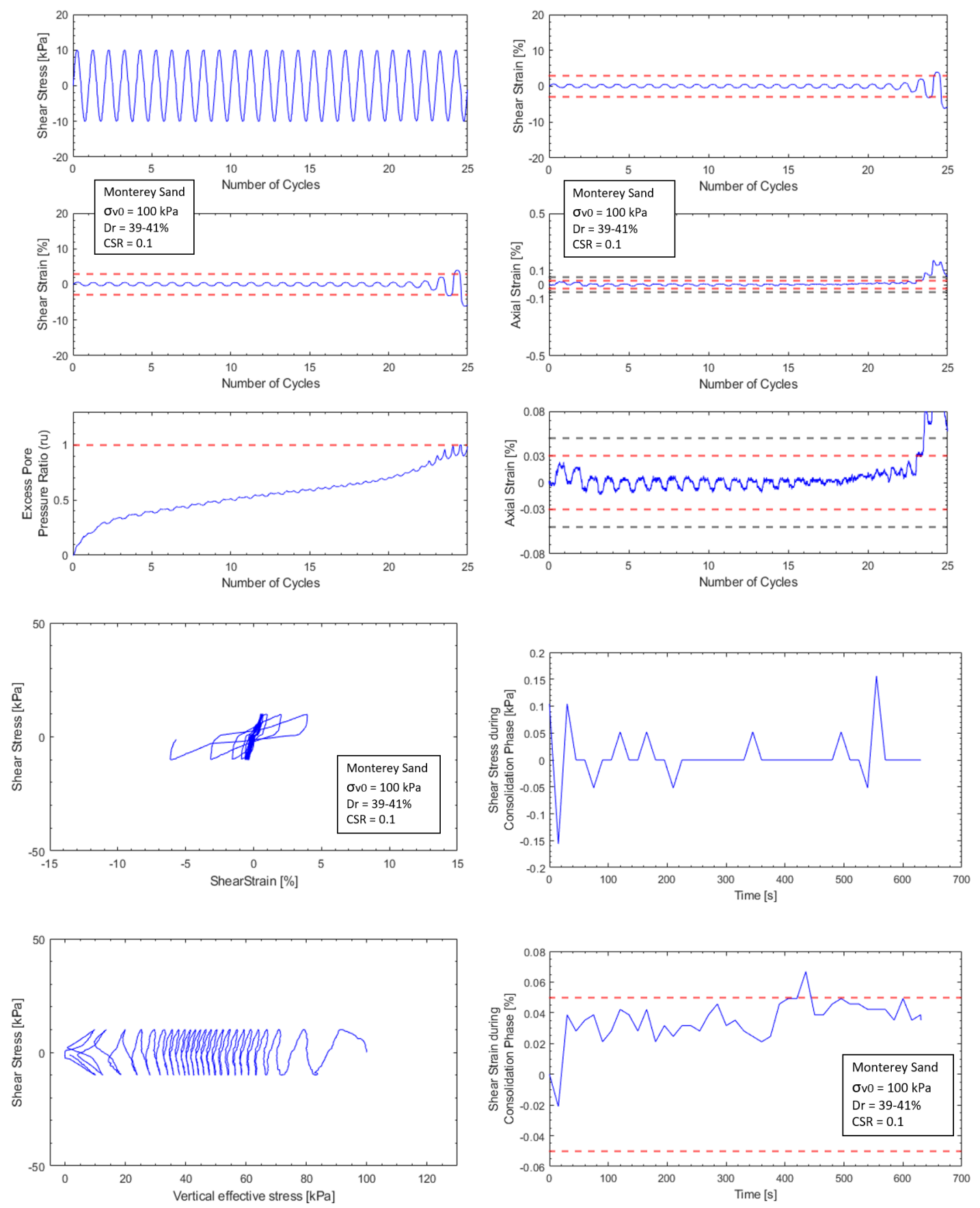

Figure .65 . Monterey sand, $\sigma_{v 0}^{\prime}=100 \mathrm{kPa}, \mathrm{Dr}=39 \%, \mathrm{CSR}=0.1$ 

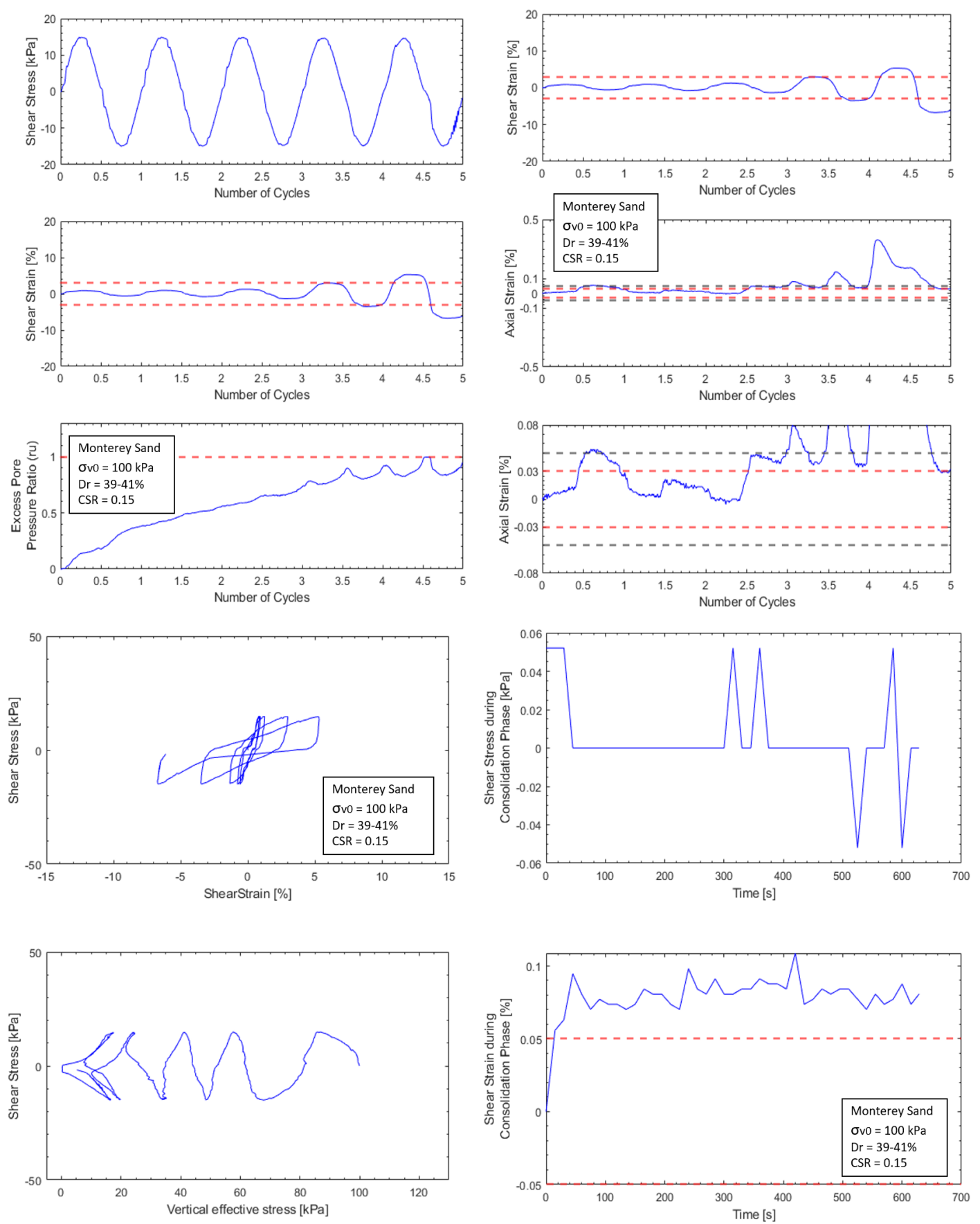

Figure .66. Monterey sand, $\sigma_{v 0}^{\prime}=100 \mathrm{kPa}, \mathrm{Dr}=39 \%, \mathrm{CSR}=0.15$ 

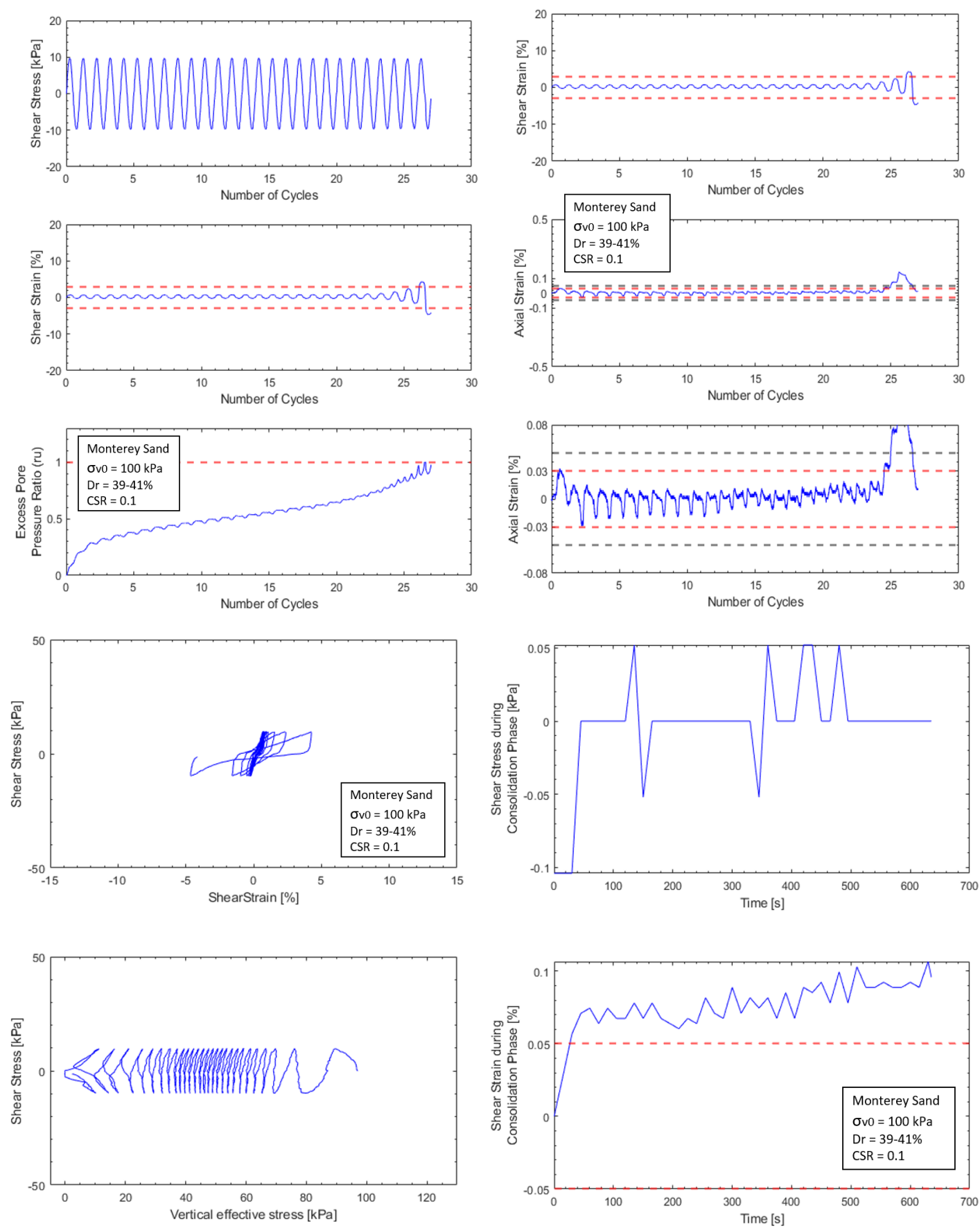

Figure .67 . Monterey sand, $\sigma_{v 0}^{\prime}=100 \mathrm{kPa}, \mathrm{Dr}=40 \%, \mathrm{CSR}=0.1$ 

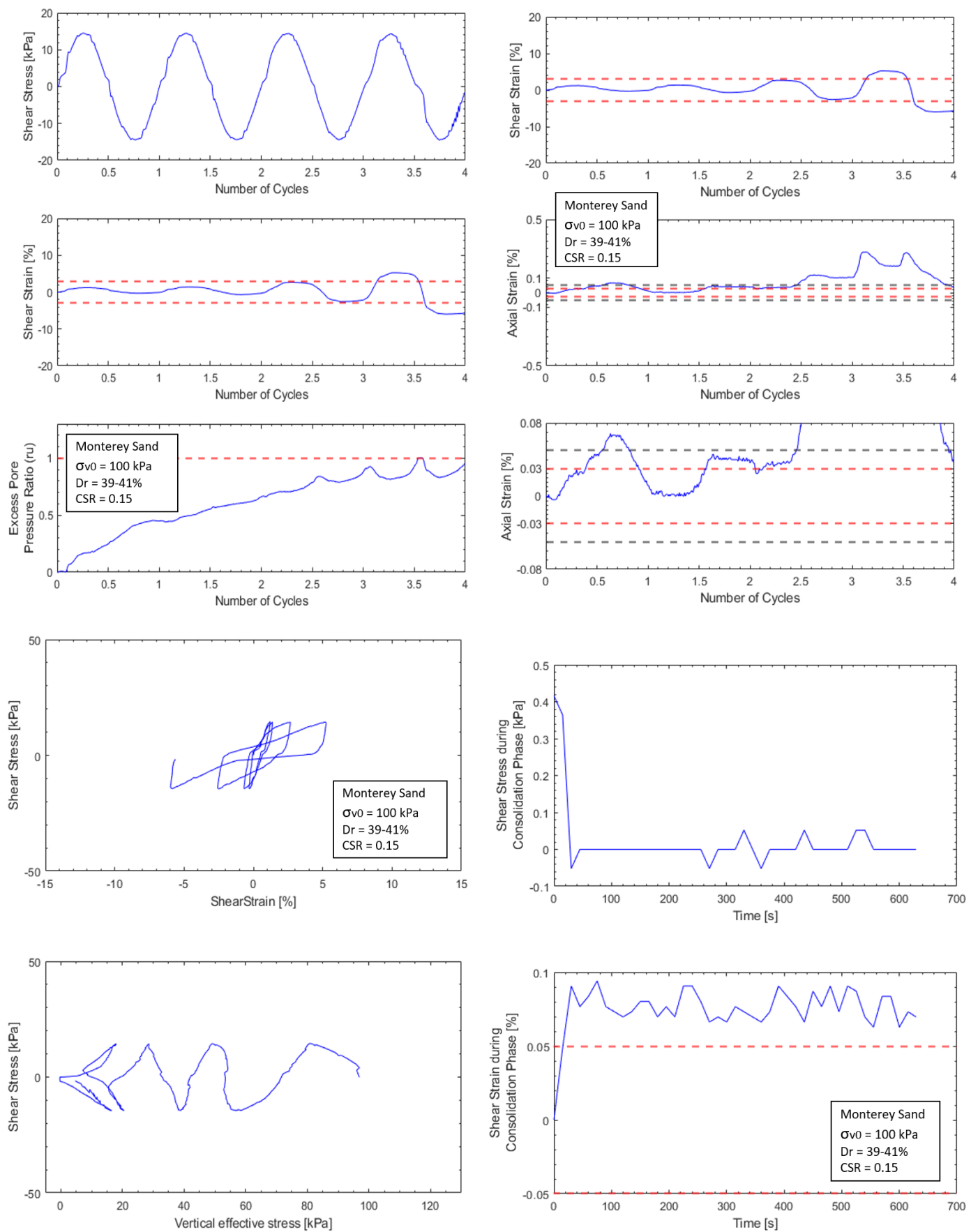

Figure .68. Monterey sand, $\sigma_{v 0}^{\prime}=100 \mathrm{kPa}, \mathrm{Dr}=40 \%, \mathrm{CSR}=0.15$ 

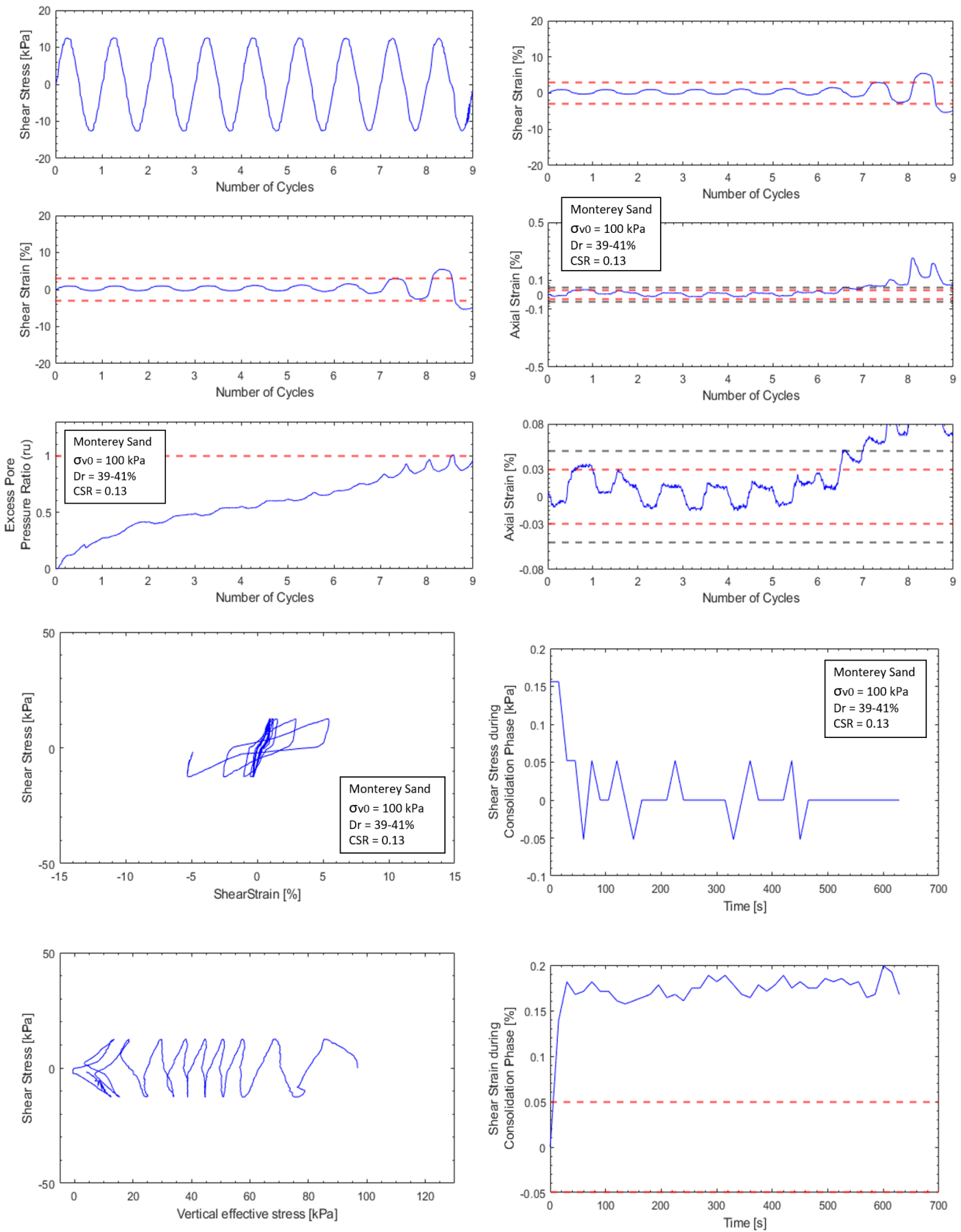

Figure .69 . Monterey sand, $\sigma_{v 0}^{\prime}=100 \mathrm{kPa}, \mathrm{Dr}=40 \%, \mathrm{CSR}=0.13$ 

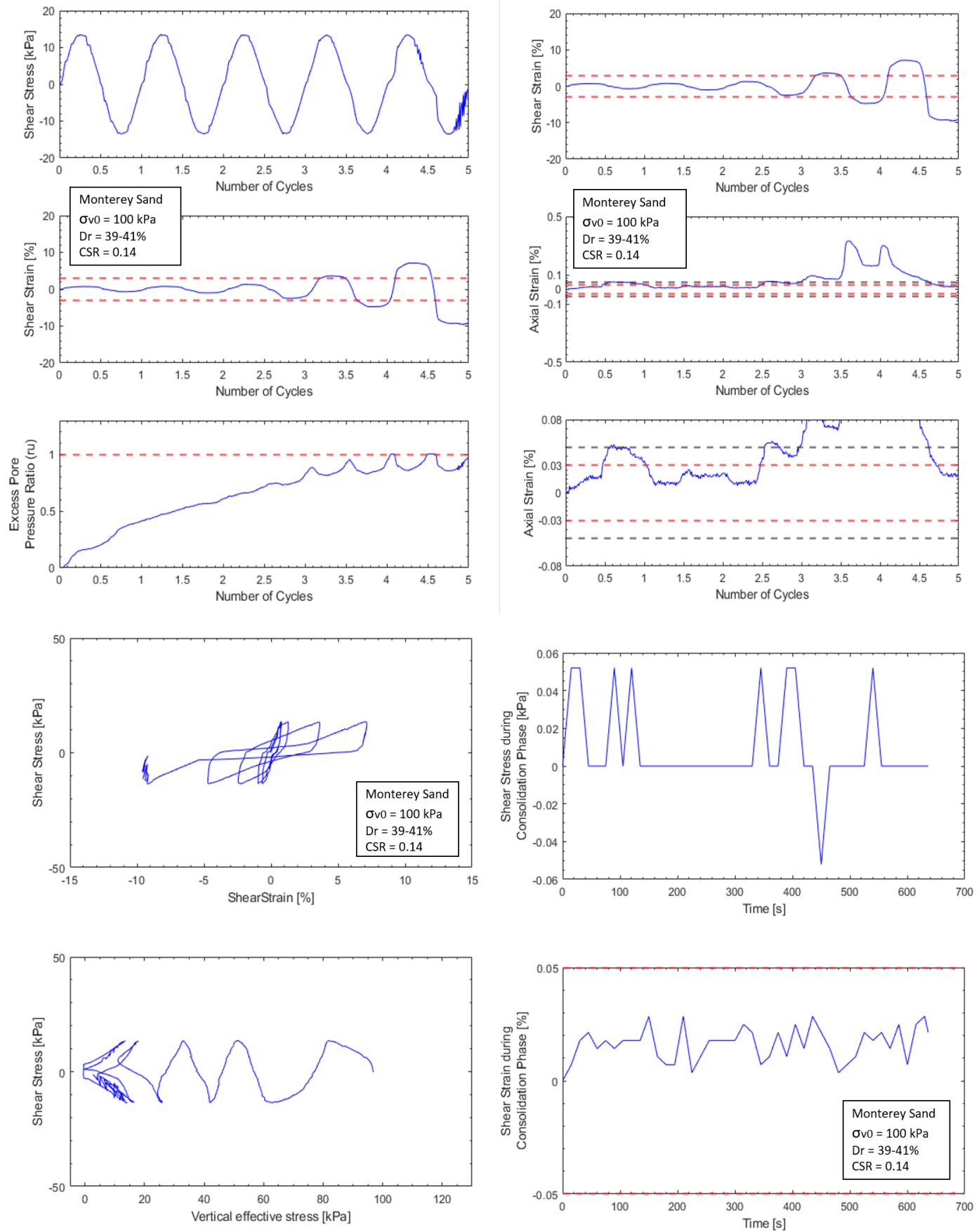

Figure .70 . Monterey sand, $\sigma_{v 0}^{\prime}=100 \mathrm{kPa}, \mathrm{Dr}=41 \%, \mathrm{CSR}=0.14$ 

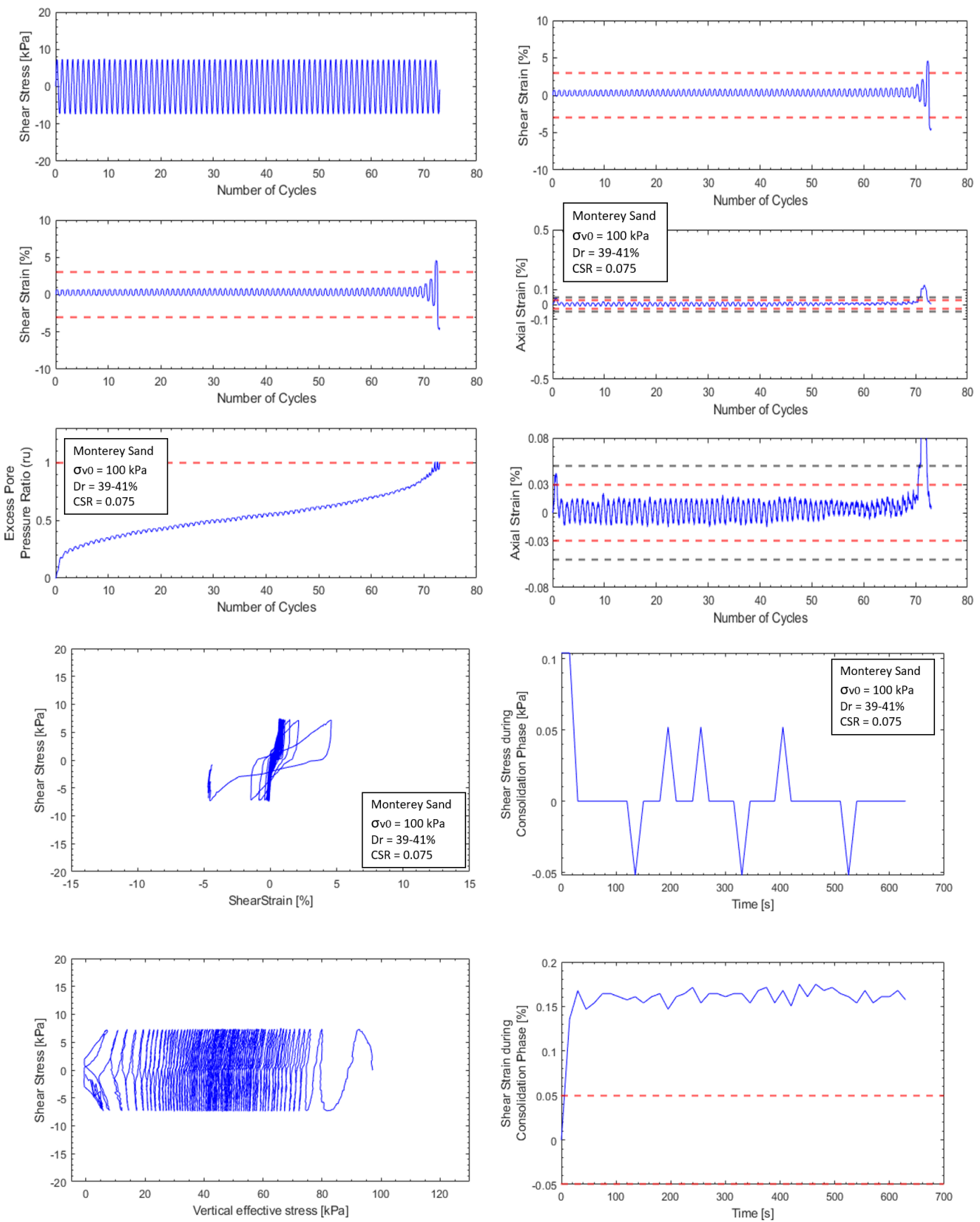

Figure .71. Monterey sand, $\sigma_{v 0}^{\prime}=100 \mathrm{kPa}, \mathrm{Dr}=40 \%, \mathrm{CSR}=0.075$ 

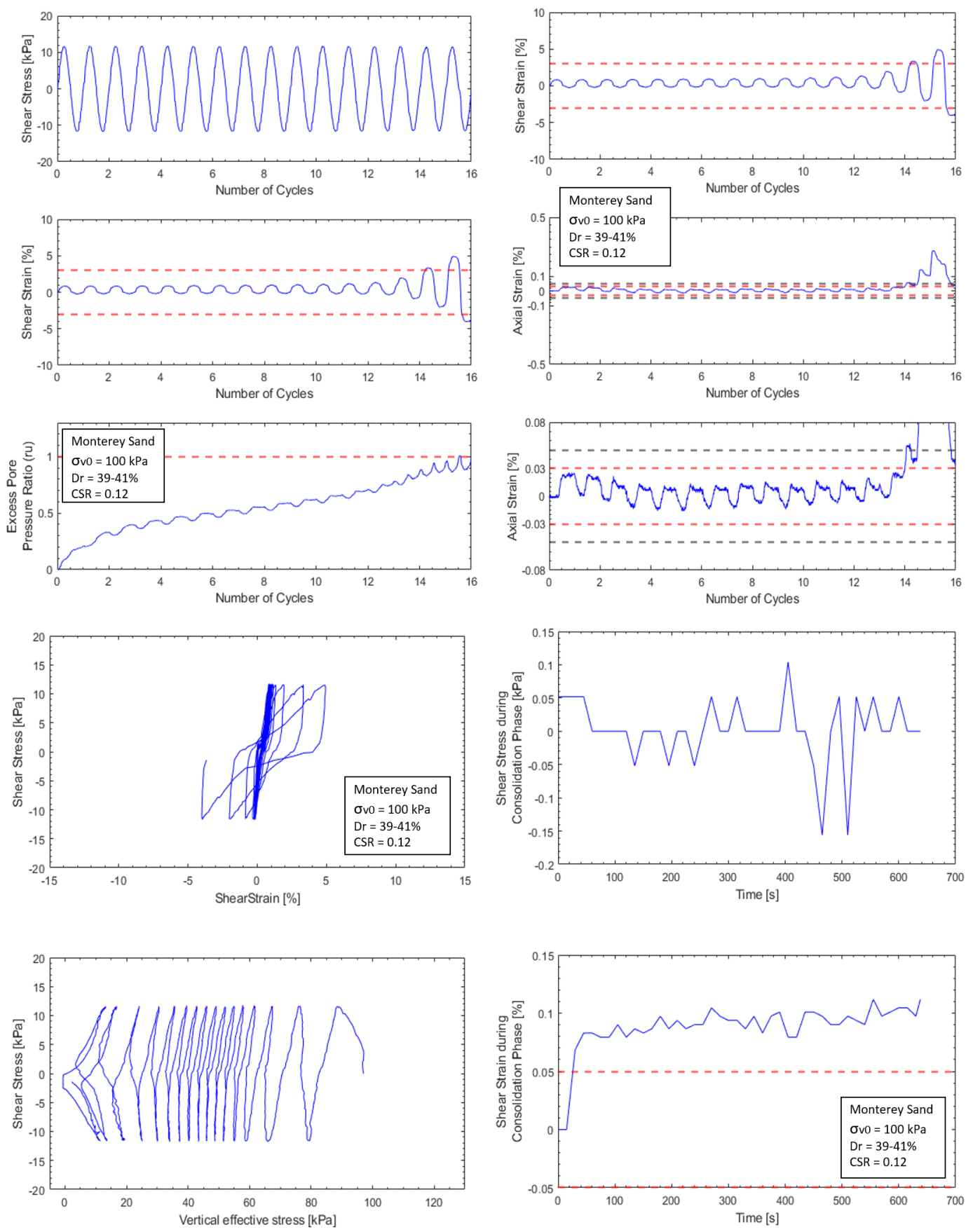

Figure .72. Monterey sand, $\sigma_{v 0}^{\prime}=100 \mathrm{kPa}, \mathrm{Dr}=41 \%, \mathrm{CSR}=0.12$ 
Monterey Sand, Dr $=40 \%, 200 \mathrm{kPa}$
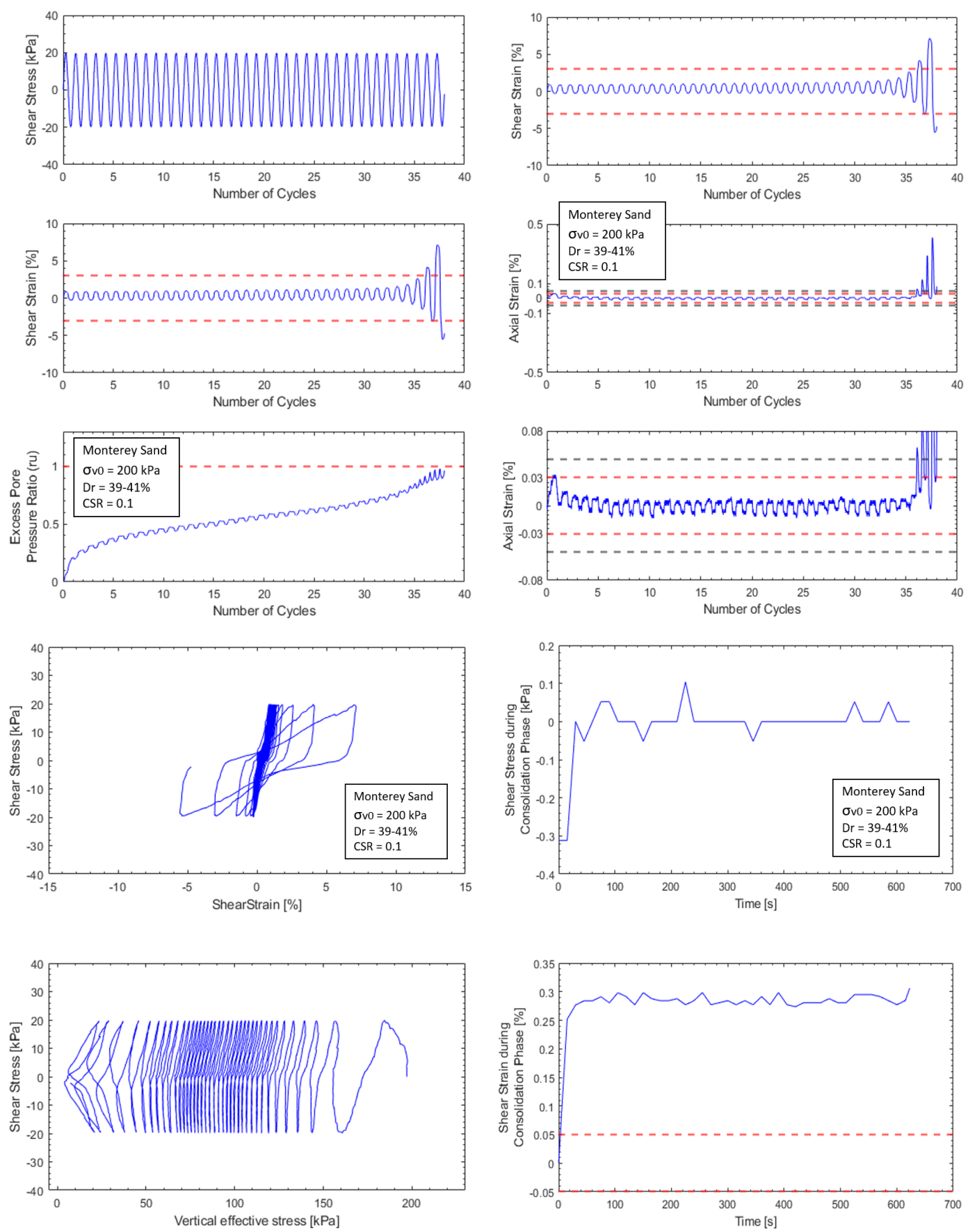

Figure .73. Monterey sand, $\sigma_{v 0}^{\prime}=200 \mathrm{kPa}, \mathrm{Dr}=40 \%, \mathrm{CSR}=0.1$ 

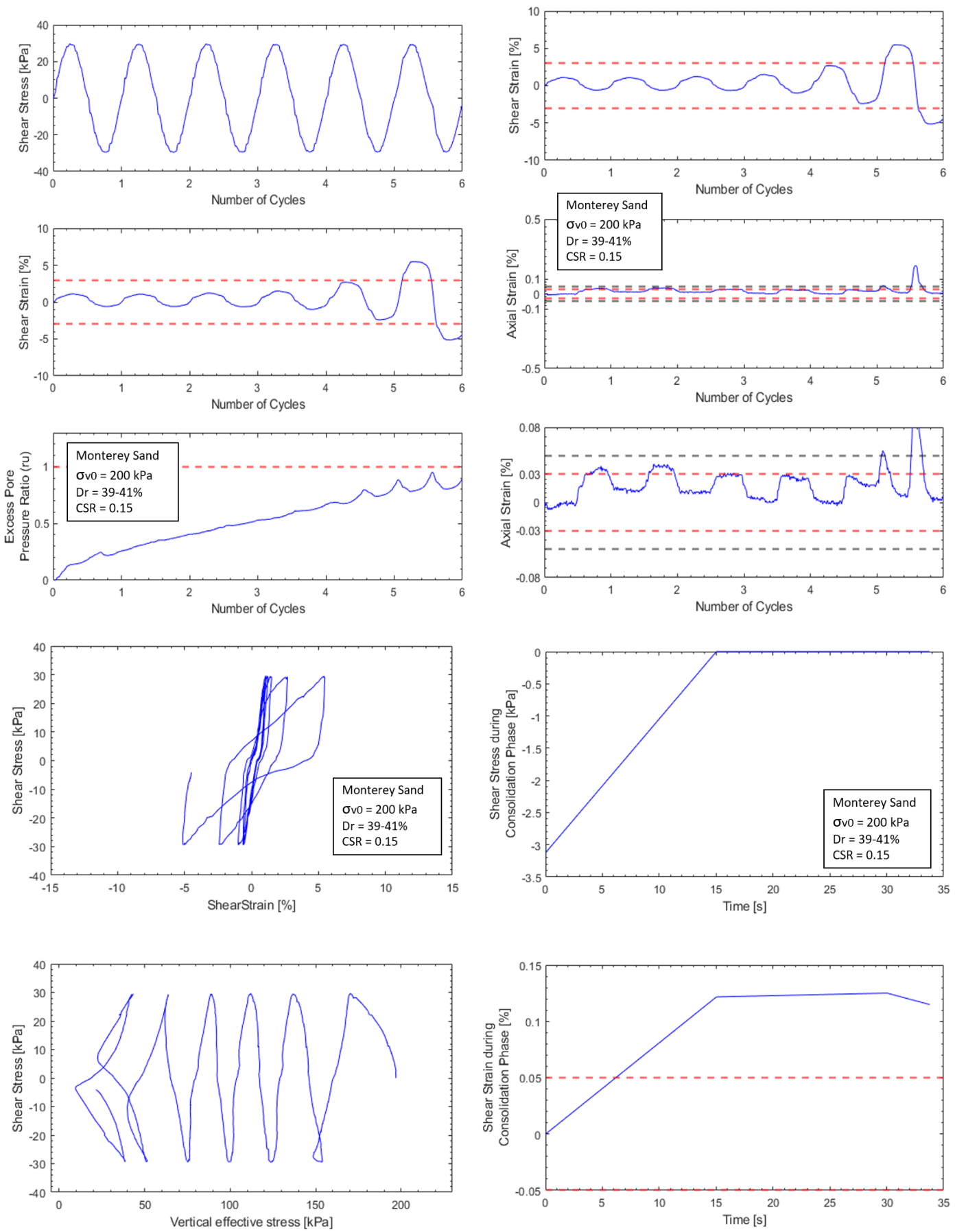

Figure .74. Monterey sand, $\sigma_{v 0}^{\prime}=200 \mathrm{kPa}, \mathrm{Dr}=39 \%, \mathrm{CSR}=0.15$ 

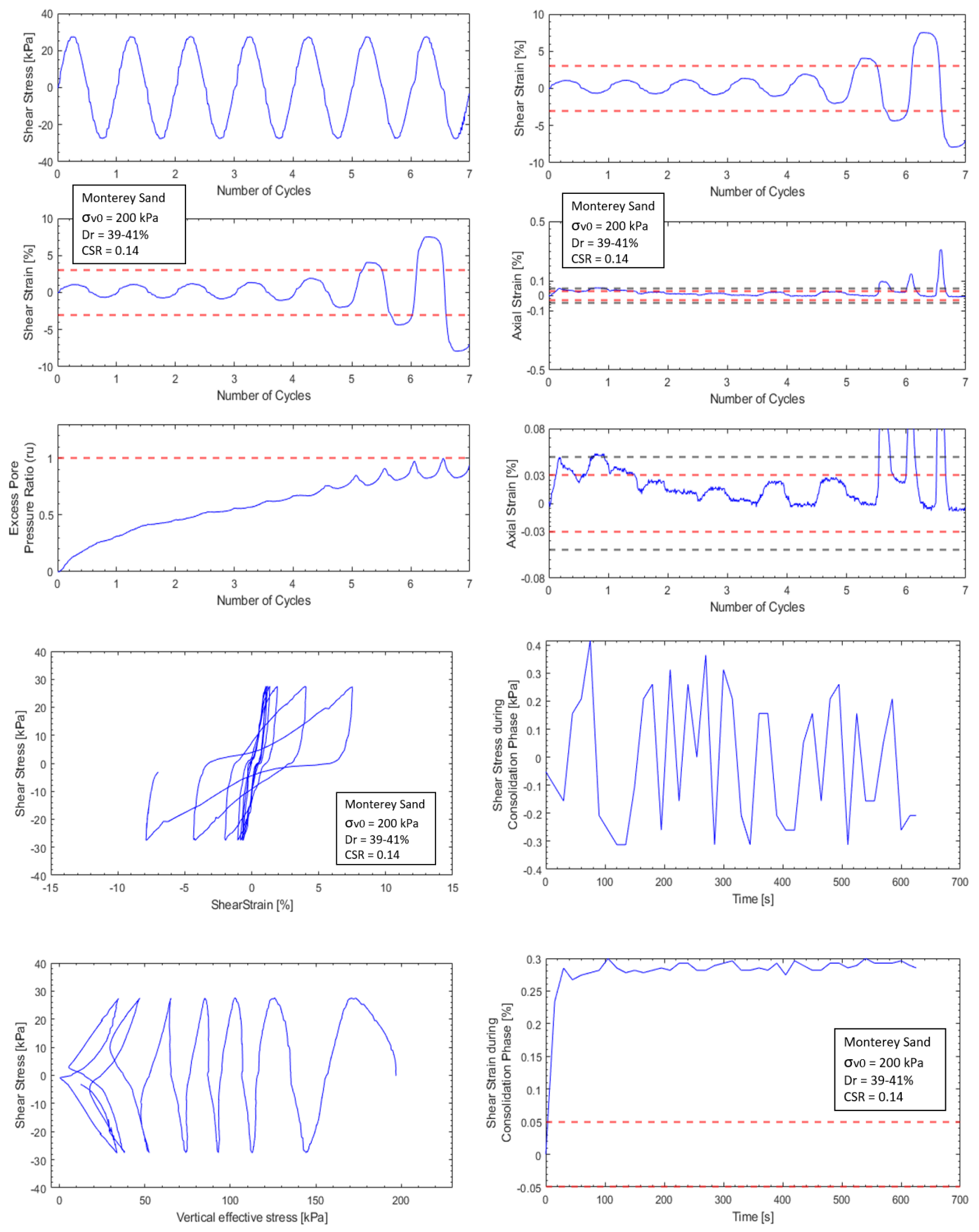

Figure .75. Monterey sand, $\sigma_{v 0}^{\prime}=200 \mathrm{kPa}, \mathrm{Dr}=40 \%, \mathrm{CSR}=0.14$ 

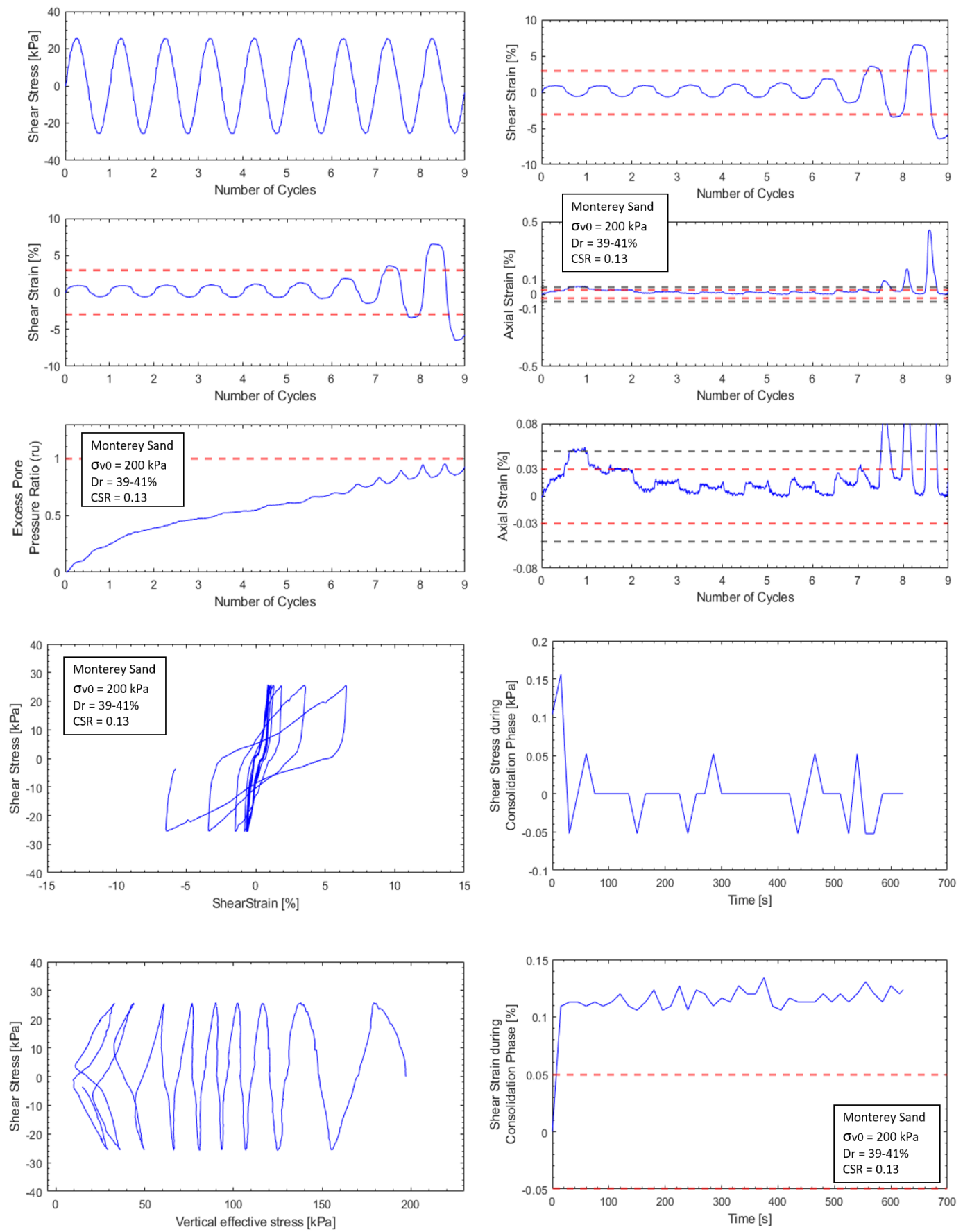

Figure .76. Monterey sand, $\sigma_{v 0}^{\prime}=200 \mathrm{kPa}, \mathrm{Dr}=40 \%, \mathrm{CSR}=0.13$ 

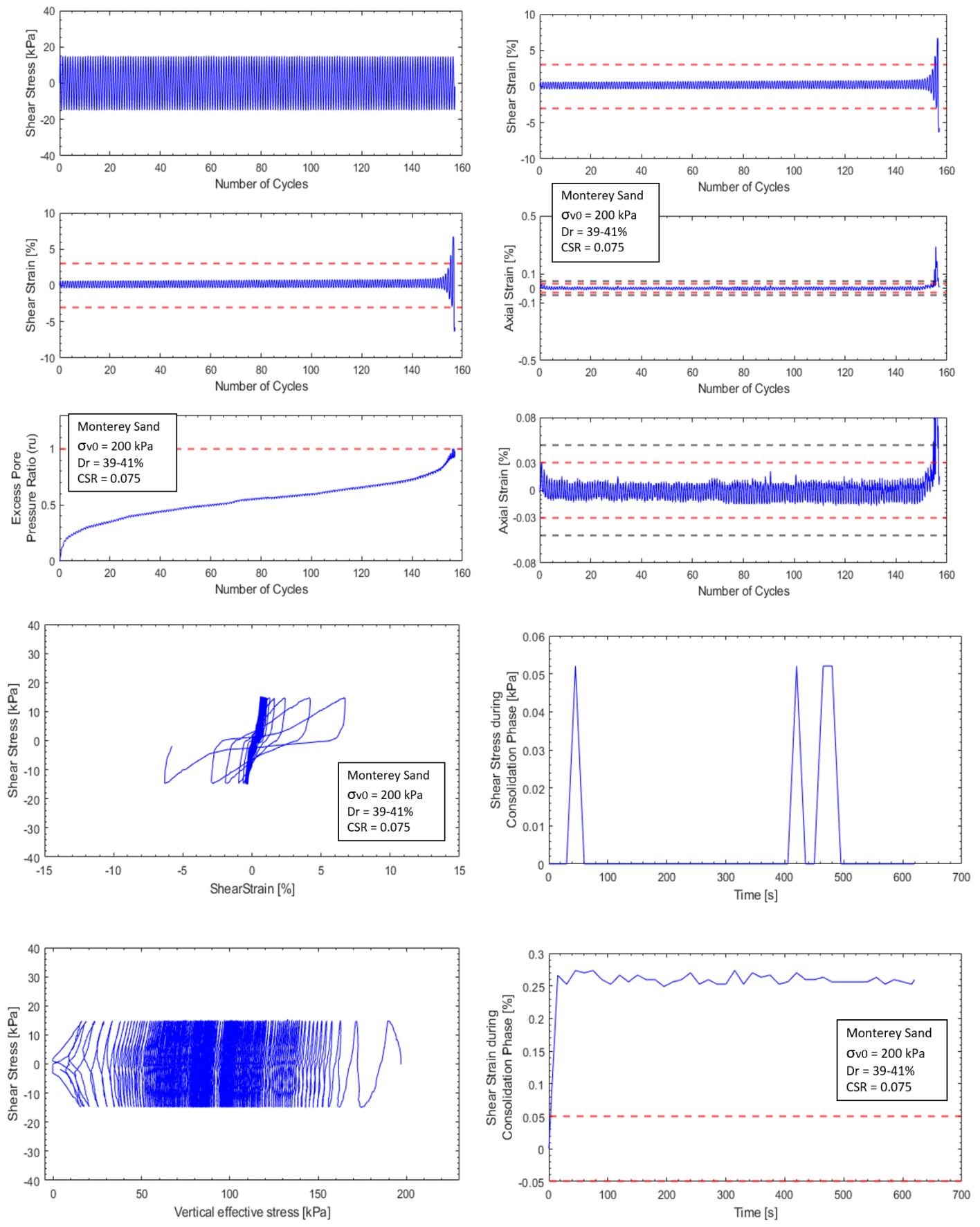

Figure .77. Monterey sand, $\sigma_{v 0}^{\prime}=200 \mathrm{kPa}, \mathrm{Dr}=41 \%, \mathrm{CSR}=0.075$ 

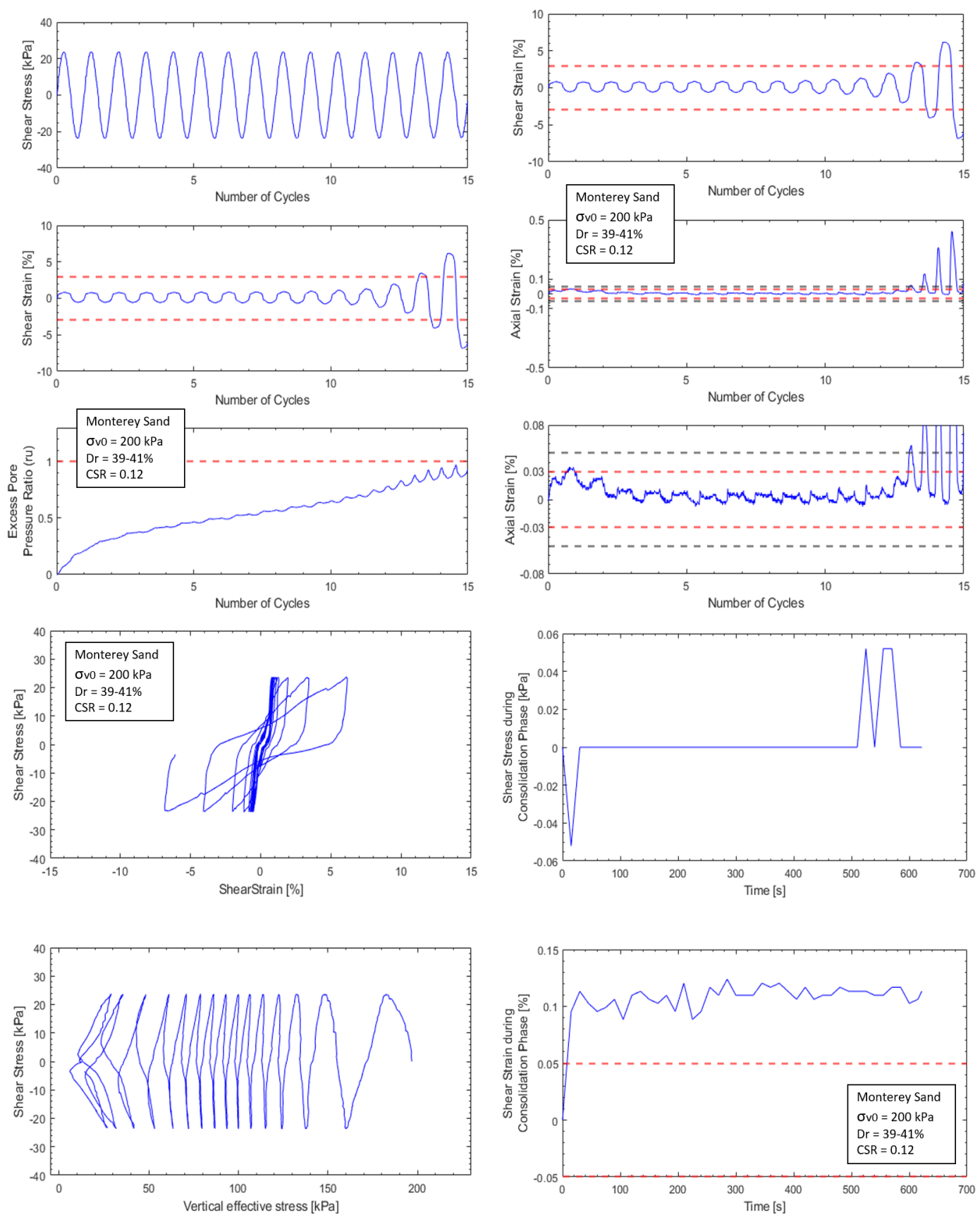

Figure .78. Monterey sand, $\sigma_{v 0}^{\prime}=200 \mathrm{kPa}, \mathrm{Dr}=39 \%, \mathrm{CSR}=0.12$ 

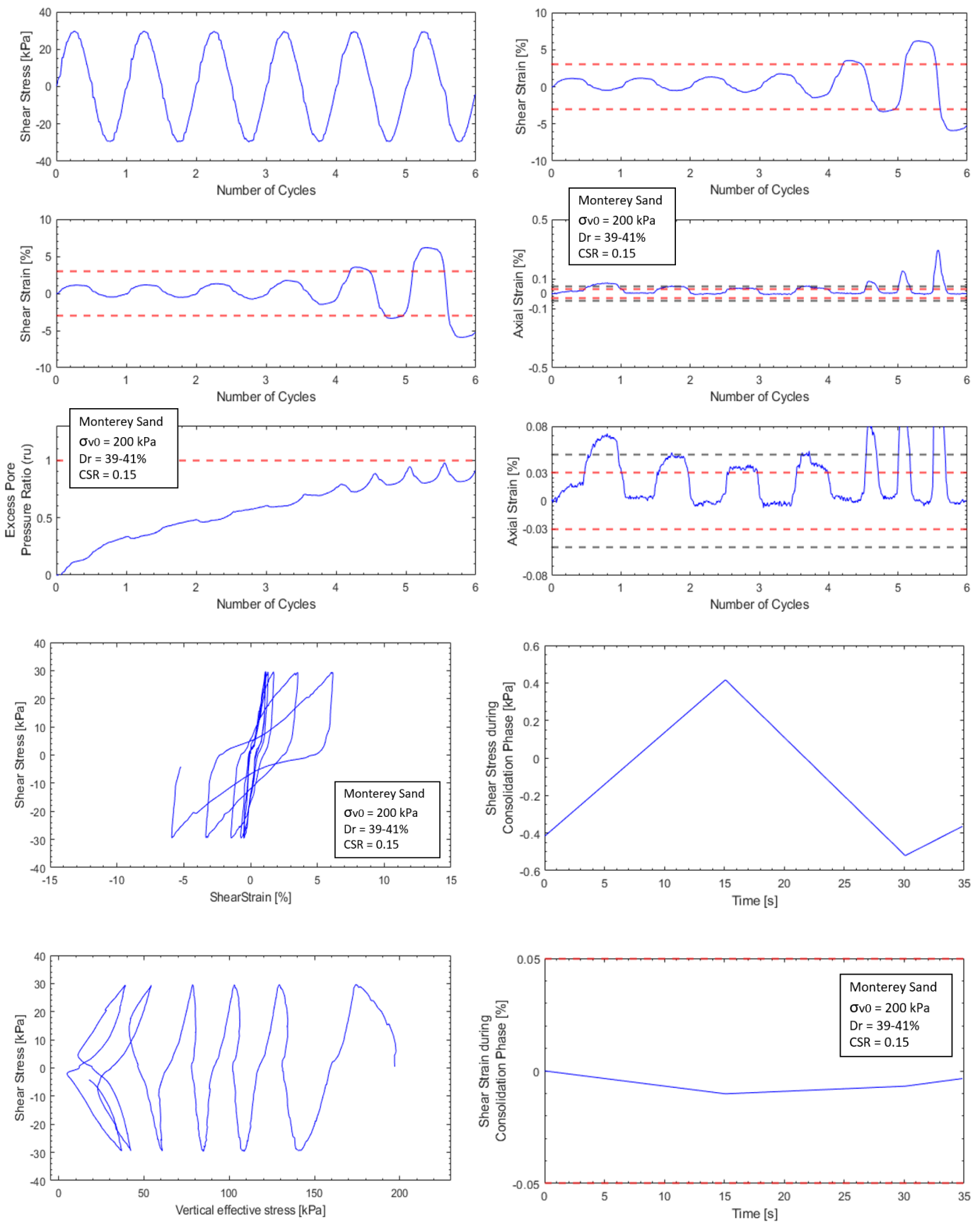

Figure .79. Monterey sand, $\sigma_{v 0}^{\prime}=200 \mathrm{kPa}, \mathrm{Dr}=39 \%, \mathrm{CSR}=0.15$ 
Monterey Sand, $\mathrm{Dr}=40 \%, 300 \mathrm{kPa}$
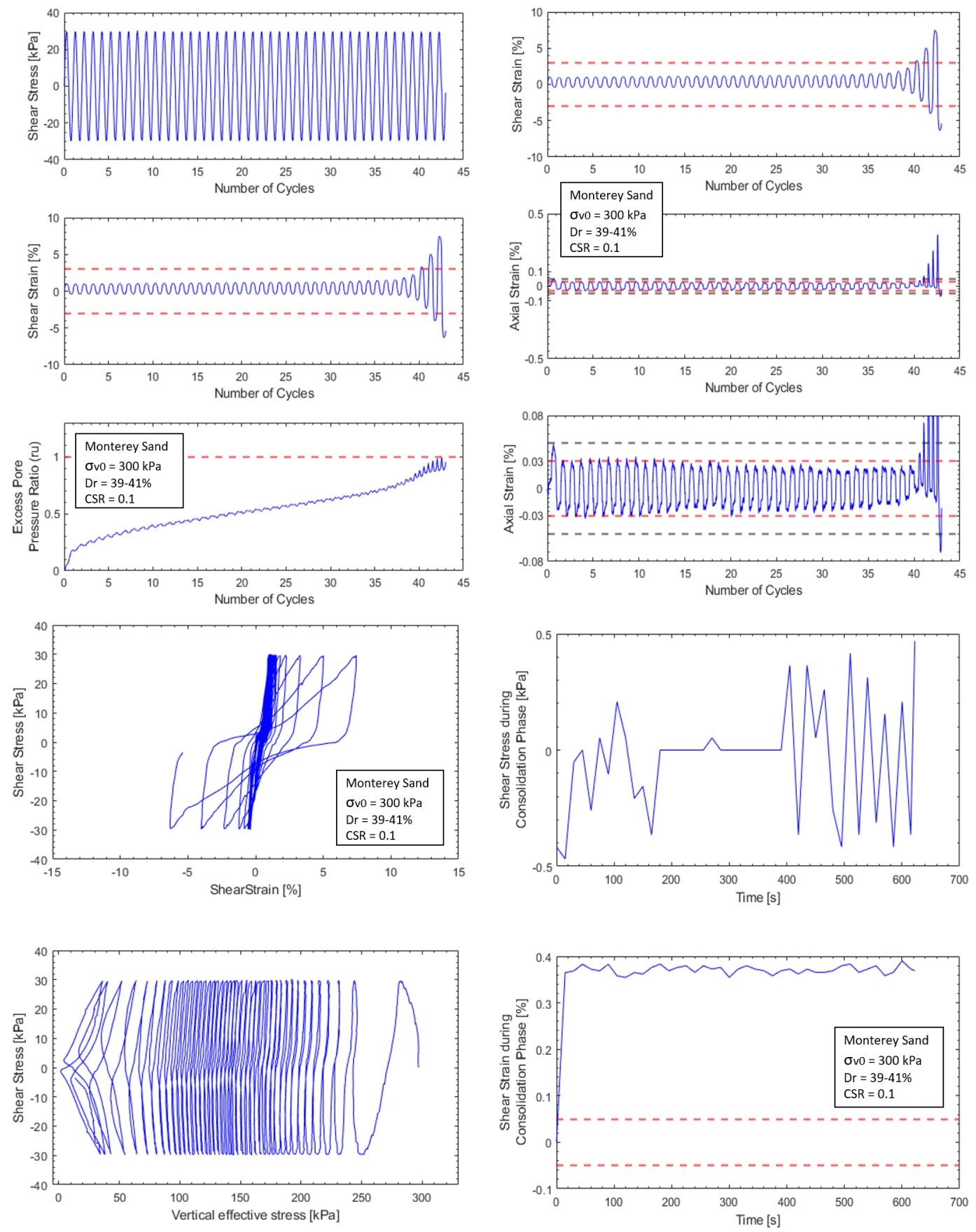

Figure .80 . Monterey sand, $\sigma_{v 0}^{\prime}=300 \mathrm{kPa}, \mathrm{Dr}=41 \%, \mathrm{CSR}=0.1$ 

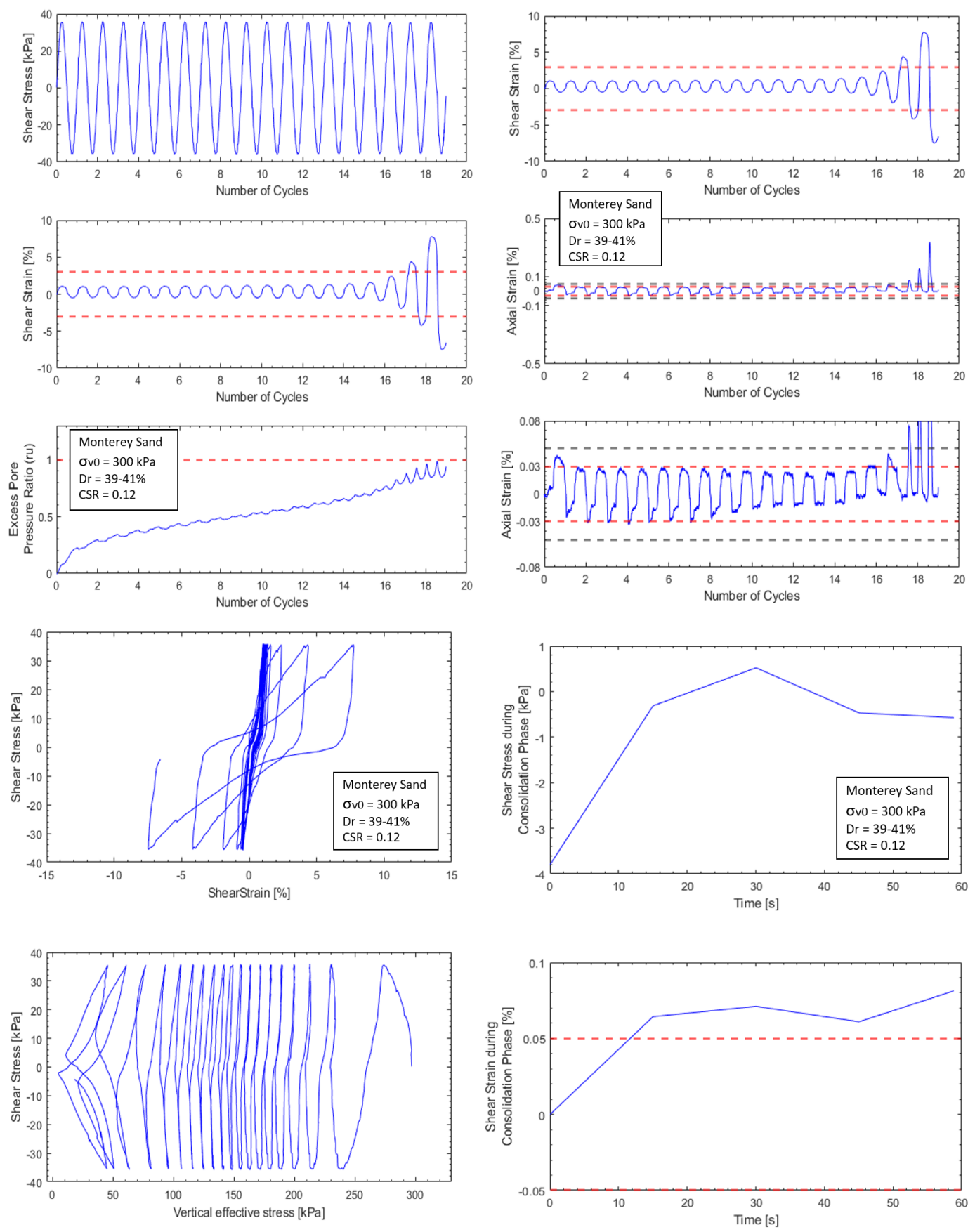

Figure .81 . Monterey sand, $\sigma_{v 0}^{\prime}=300 \mathrm{kPa}, \mathrm{Dr}=41 \%, \mathrm{CSR}=0.12$ 

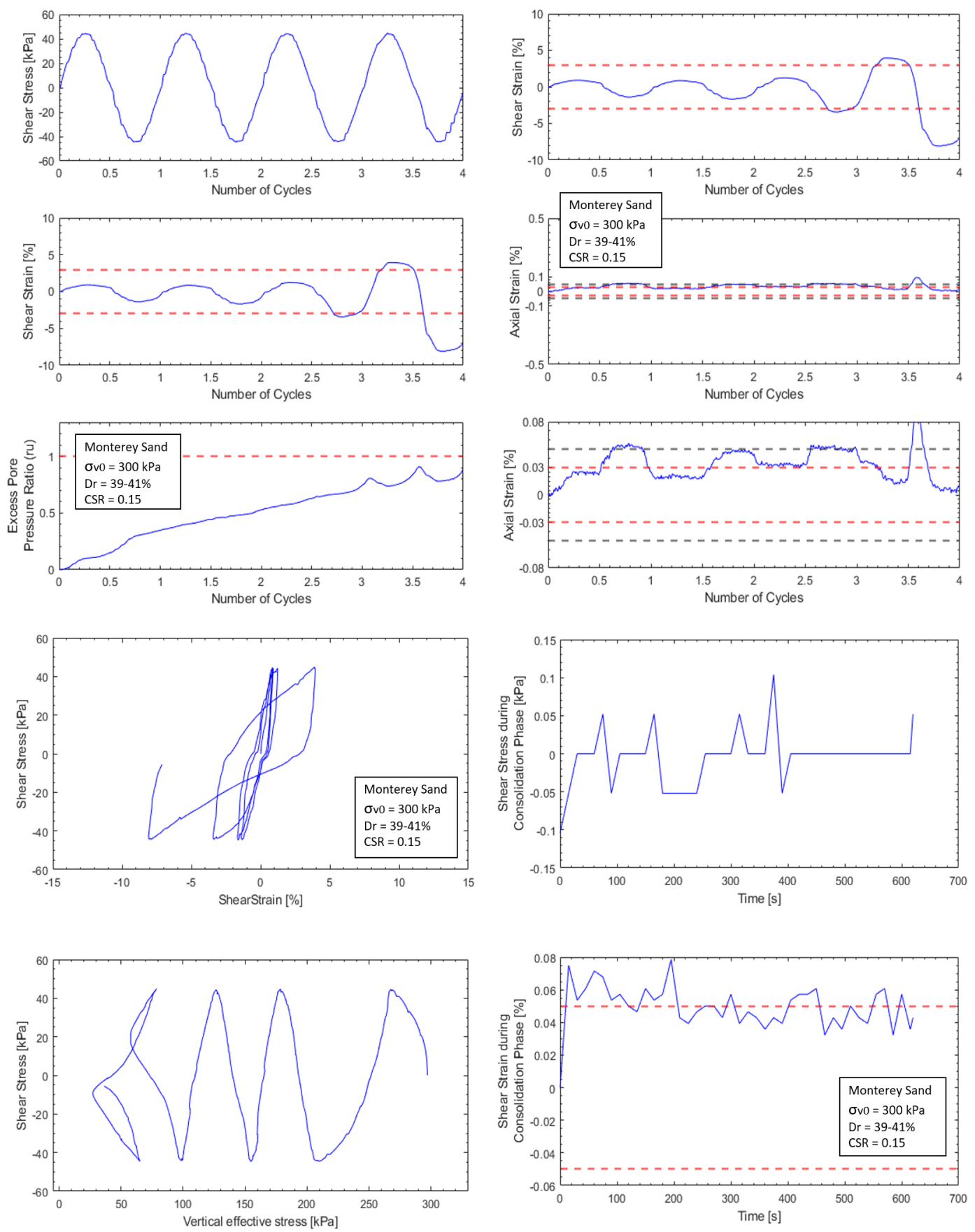

Figure .82. Monterey sand, $\sigma_{v 0}^{\prime}=300 \mathrm{kPa}, \mathrm{Dr}=41 \%, \mathrm{CSR}=0.15$ 

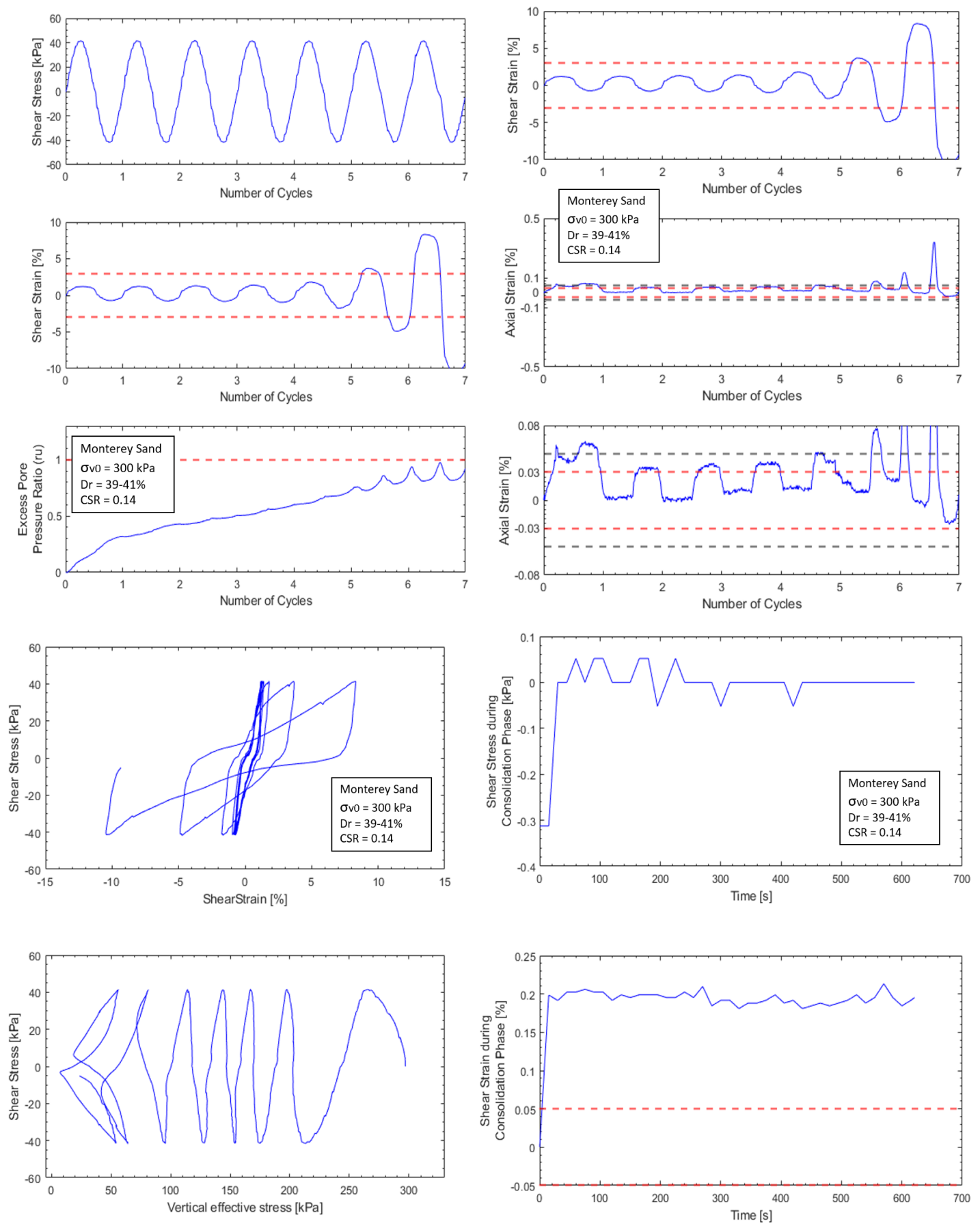

Figure .83. Monterey sand, $\sigma_{v 0}^{\prime}=300 \mathrm{kPa}, \mathrm{Dr}=41 \%, \mathrm{CSR}=0.14$ 

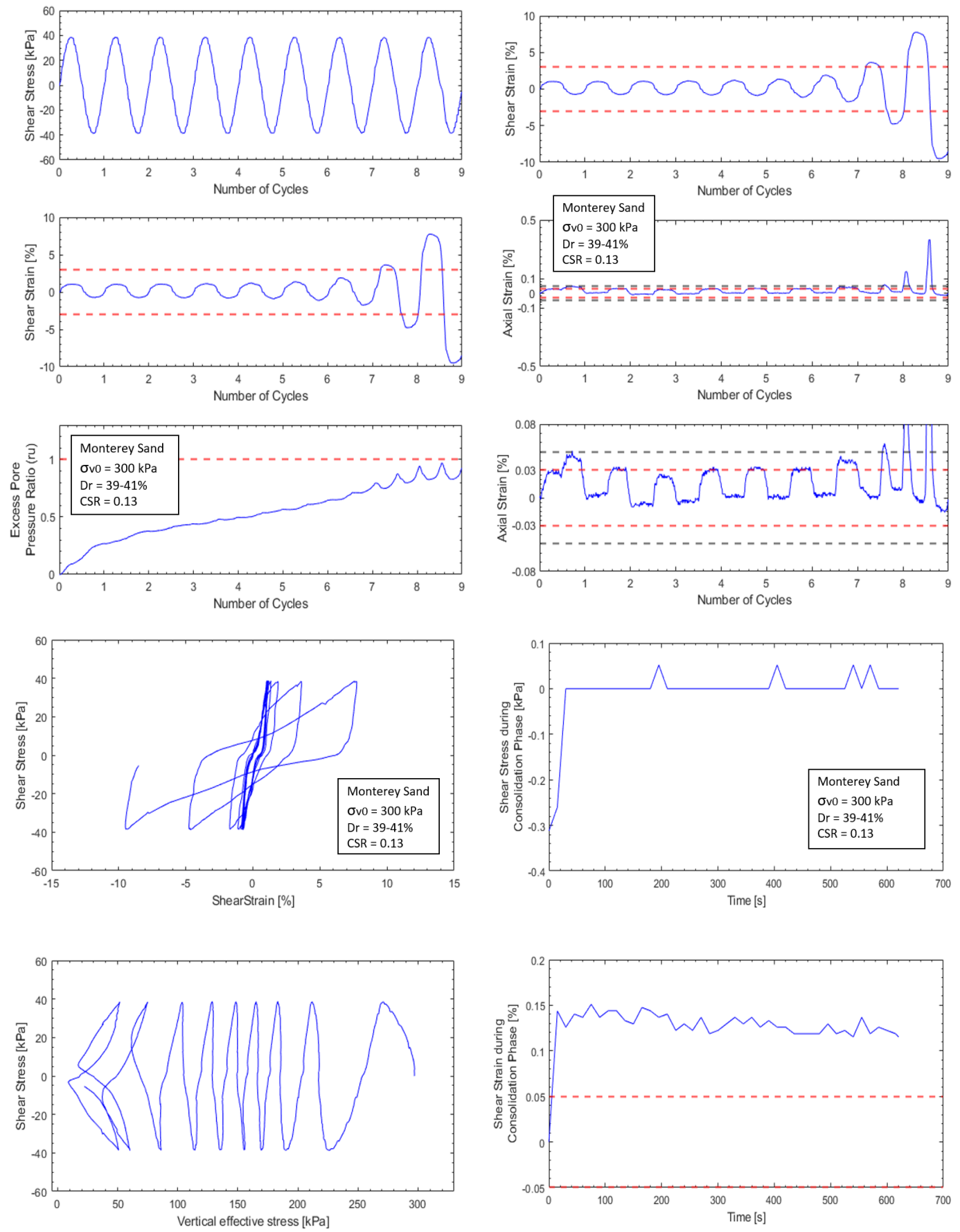

Figure .84. Monterey sand, $\sigma_{v 0}^{\prime}=300 \mathrm{kPa}, \mathrm{Dr}=39 \%, \mathrm{CSR}=0.13$ 


\section{BIBLIOGRAPHY}

ASTM, "Test method for consolidated undrained direct simple shear testing of cohesive soils," West Conshohocken, PA.

Basham, M., Athanasopoulos-Zekkos, A., and Zekkos, D., "The importance of vertical displacement control during constant volume cyclic direct simple shear testing," in 7th International Conference on Earthquake Geotechnical Engineering; Rome, Italy, 2019.

Baxter, C. D. P., Bradshaw, A. S., Ochoa-Lavergne, M., and Hankour, R., "Dss test results using wire-reinforced membranes and stacked rings," Geotechnical Special Puplication, 2010.

Bhatia, S. K., "The verification of relationships for effective stress method to evaluate liquefaction potential of saturated sands," 1982.

Boulanger, R. W., "Liquefaction behavior of saturated coehesionless soils subjected to uni-directional and bi-directional static and cyclic simple shear stresses," Ph.D. dissertation, University of California, 1990.

Camelo, C. S., "Soil dynamics: 4. dynamic soil properties," 2017.

Casagrande, A., "Liquefaction and cyclic deformation of sands - a critical review," Harvard Soil Mechanics Series, vol. 88, 1976.

Dobry, R., Ladd, R. S., Yokel, F. Y., Chung, R. M., and Powell, D., "Prediction of pore water pressure buildup and liquefaction of sands during earthquakes by the cyclic strain method," National Bureau of Standards Buliding Science Series 138, 1982.

Dyvik, R., Berre, T., Lacasse, S., and Raadim, B., "Comparison of truly undrained and constant volume direct simple shear tests," Geotechnique, vol. 37, no. 1, pp. $3-10,1987$.

Dyvik, R. ;Suzuki, Y., "Effect of volume change in undrained direct simple shear tests," Geotechnical Testing Journal, vol. 42, no. 4, pp. 1075-1082, 2019.

Finn, W. D. L., "Aspects of constant volume cyclic simple shear," Advances in the Art of Testing Soils under cyclic Conditions, 1985.

Germaine, J. T. ;Germaine, A. V., Geotechnical Laboratory Measurements for Engineers. John Wiley \& Sons, Inc., 2009. 
Gokyer, S., Zehtab, K., Marr, W. A., Werden, S. K., and Apostolov, A., Eds., Cyclic response of Ottawa sand under different test conditions: cyclic triaxial, unidirectional and bidirectional direct simple shear, 2017.

Green, R. A. ;Gregory, T. A., "Number of equivalent cycles concept for liquefaction evaluation - revisited," Journal of Geotechnical and Geoenvironmental Engineering, 2005.

Idriss, I. M. ;Boulanger, R. W., Soil Liquefaction during Earthquakes. Earthquake Engineering Research Institute, 2008.

Ishihara, K. ;Yamazaki, F., "Cyclic simple shear tests on saturated sand in multidirectional loading," Soils and Foundations, vol. 20, no. 1, pp. 45-59, 1980.

Kammerer, A. M., "Undrained response of monterey 0/30 sand under multidirectional cyclic simple shear loading conditions," Ph.D. dissertation, University of California, 2002.

Kokusho, T., Innovative Earthquake Soil Dynamics, 1st ed. London: Taylor and Francis, 2017. [Online]. Available: https://ebookcentral.proquest.com/ $\mathrm{lib} / \mathrm{gbv} /$ detail.action?docID $=4930804$

Konstadinou, M., Bezuijen, A., Greeuw, G., Zwanenburg, C., Van Essen, H., and Voogt, L., "The influence of apparatus stiffness on the results of cyclic direct simple shear tests on dense sand," Geotechnical Testing Journal, 2020.

Kramer, S. L., Geotechnical Earthquake Engineering. Prentice-Hall, 1996.

Mandokhail, S. J., Rehman, K., Baloch, Z., Sadiq, S., and Kakar, M. G., "Effect of the confining method on the cyclic undrained behaviours of sand," IOP Conference Series: Materials Science and Engineering, no. 414-012036, 2018.

Martin, G. R., Finn, W. D. L., and Seed, H. B., "Fundamentals of liquefaction under cyclic loading," Journal of the Geotechnical Engineering Devision, 1975.

Mc Carron, W. O., Lawrence, J. C., Werner, R. J., Germaine, J. T., and Cauble, D. F., "Cyclic direct simple shear testing of a beaufort sea clay," Canadian Geotechnical Journal, 1995.

Meehan, C. L., Kumar, S., Pando, M. A., and Coe, J. T., Eds., Geo-Congress 2019. Reston, VA: American Society of Civil Engineers, 2019.

Morales-Velez, A. C., "Evaluation of field based liquefaction approaches for calcareous sands using shear wave velocity," Ph.D. dissertation, University of Rhode Island, 2015. 
Mulilis, J. P., Seed, H. B., Chan, C. K., Mitchel, J. K., and Arulanandan, K., "Effects of sample preparation on sand liquefaction," International Journal of Rock Mechanics and Mining Sciences \& Geomechanics Abstracts, vol. 14, no. 3, p. 40, 1977.

Scarioni, J. F., "Cyclic constant normal stiffness tests on sand," Master Thesis, University of Rhode Island, 2019.

Silver, M. L. ;Seed, H. B., "Volume changes in sands during cyclic loading," Journal Soil Mechanics and Foundations Division, vol. 97, no. SM9, p. 1171, 1971.

Ulmer, K. J., "Development of an energy-based liquefaction evaluation procedure," Ph.D. dissertation, Virginia Polytechnic Institute and State University, 2020.

Ulmer, K. J., Green, R. A., Rodriques-Marek, A., and Baxter, C. D. P., "Quality assurance for cyclic direct simple shear tests for evaluating liquefaction triggering characteristics of cohesionless soils: Conference paper," XVII ECSMGE, 2019 .

$\mathrm{Wu}$, J., "Liquefaction triggering and post-liquefaction deformation of monterey 0/30 sand under unidirectional cyclic simple shear loading," Ph.D. dissertation, University of California, 2002.

Zehtab, K., Gokyer, S., Werden, S. K., Marr, W. A., and Apostolov, A., "On the effects of inadequate height control in constant volume monotonic and cyclic direct simple shear tests," 2019.

Zekkos, D., Athanasopoulos-Zekkos, A., Hubler, J., Fei, X., Zehtab, K. H., and Marr, W. A., "Development of a large-size cyclic direct simple shear device for characterization of ground materials with oversized particles," Geotechnical Testing Journal, vol. 41, no. 2, 2018. 